\title{
Pule: Development policy sovereignty in Samoa
}

\author{
Avataeao Junior Ulu
}

2013

A thesis submitted to Victoria University of Wellington in partial fulfilment of the requirements for the degree of Masters in Development Studies

School of Geography, Environment and Earth Sciences 


\section{Table of Contents}

Acknowledgements

Abstract

Glossary

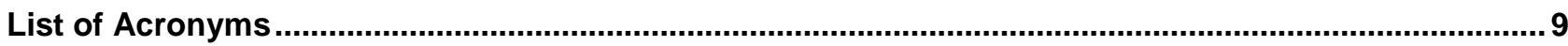

CHAPTER ONE: INTRODUCTION...................................................................... 11

Overall aim:

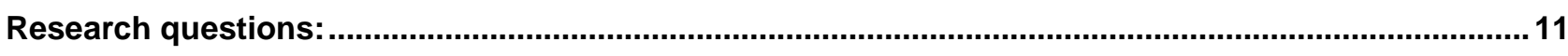

Thesis structure

CHAPTER TWO: AID AND SOVEREIGNTY ..................................................15

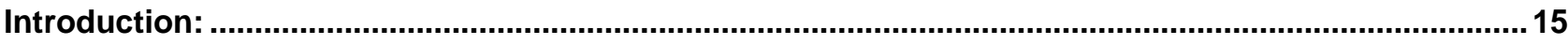

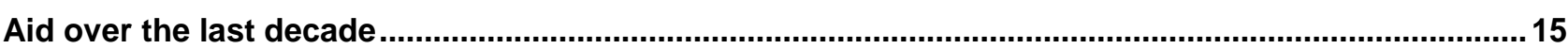

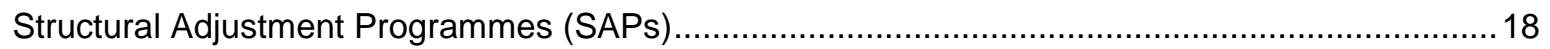

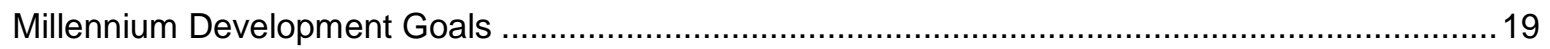

Figure 1: Official development assistance (ODA) 1990 - 2010, billion US dollars .........................20

Figure 2: Official Development assistance (ODA) $1990-2010, \%$ of GNI ....................................21

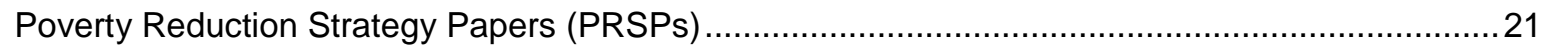

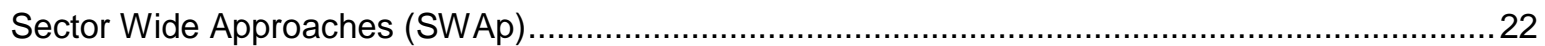

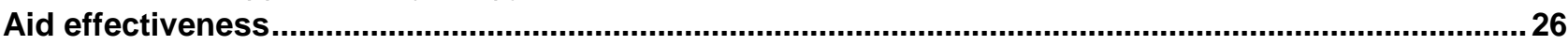

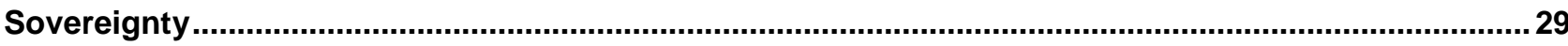

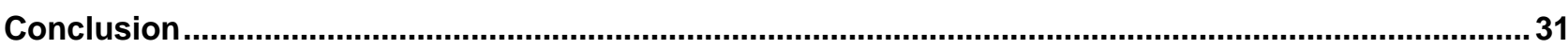

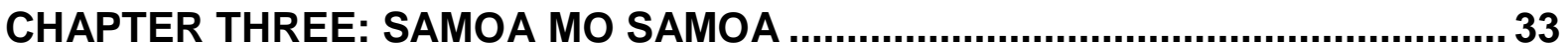

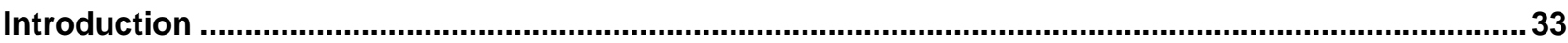

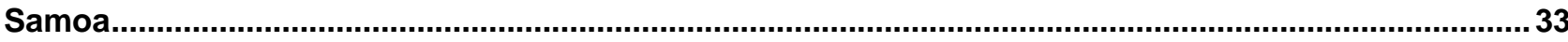

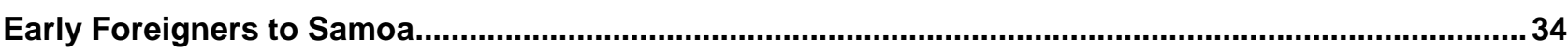

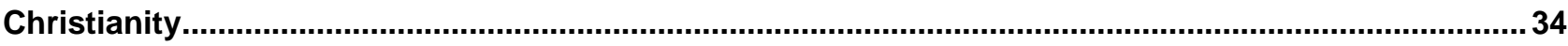

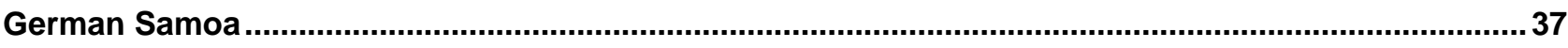

The New Zealand Administration and the rise of the Mau movement ..............................................38

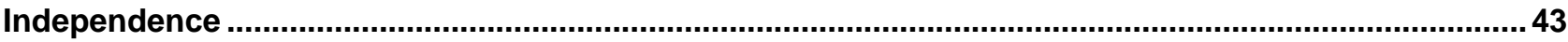

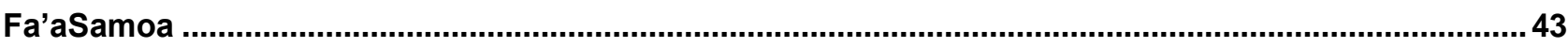

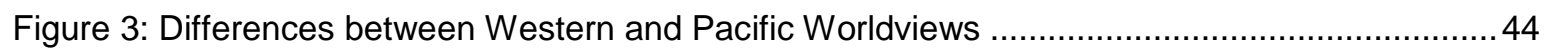

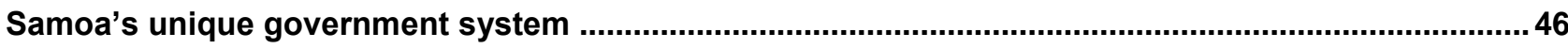

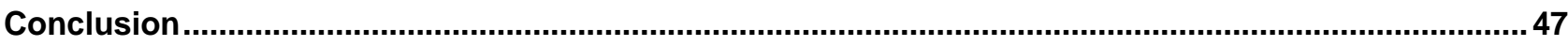

CHAPTER FOUR: METHODOLOGY AND METHODS........................................ 49

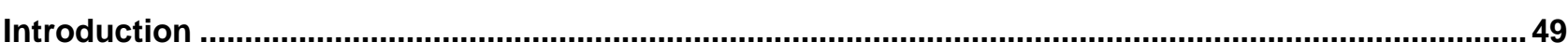

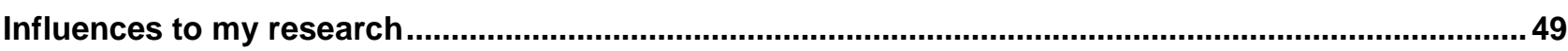




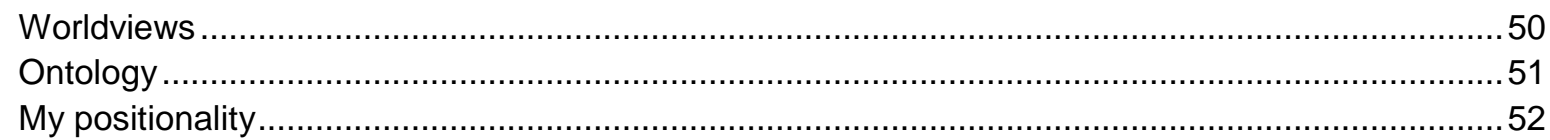

Methodology

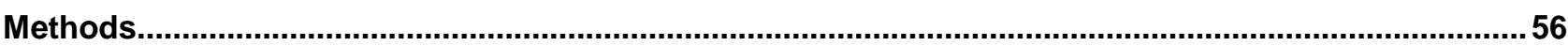

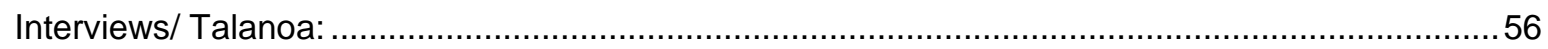

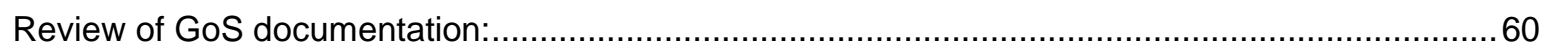

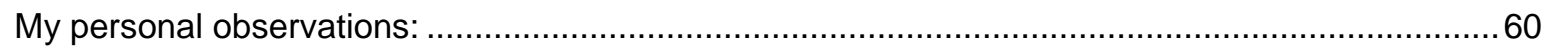

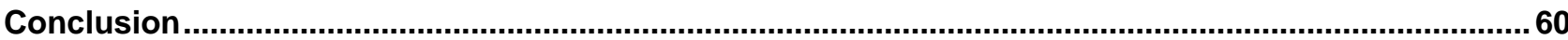

CHAPTER FIVE: THE GOVERNMENT OF SAMOA AND AID $\ldots \ldots \ldots \ldots \ldots \ldots \ldots \ldots \ldots . \ldots . \ldots \ldots$

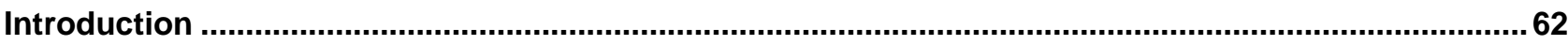

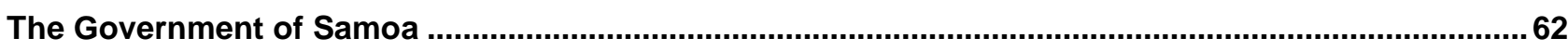

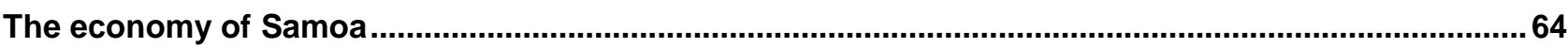

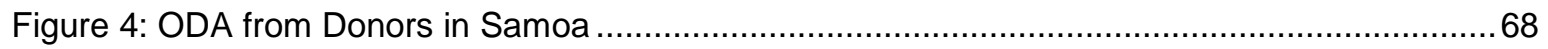

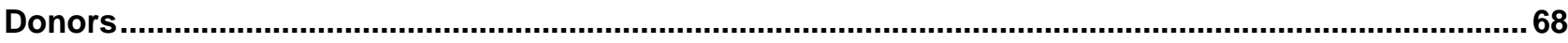

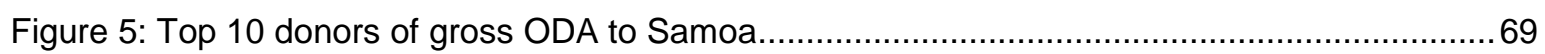

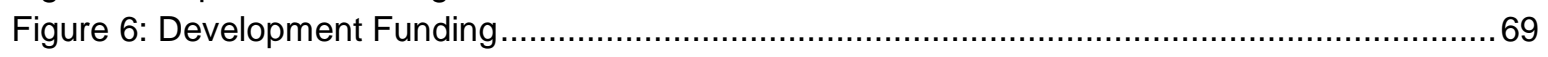

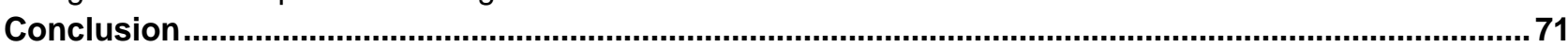

CHAPTER SIX: GOS SOVEREIGNTY THROUGH DEVELOPMENT POLICY.......72

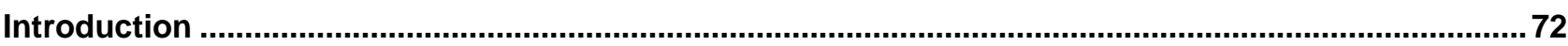

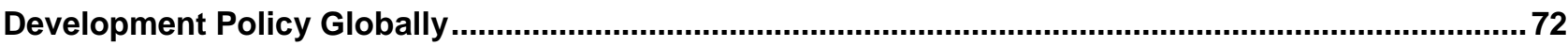

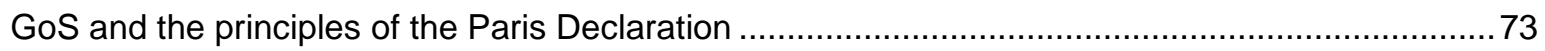

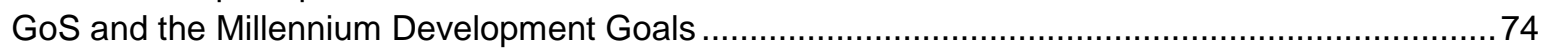

South-South Cooperation and Capacity Development Programme ….......................................... 75

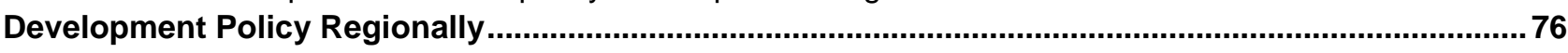

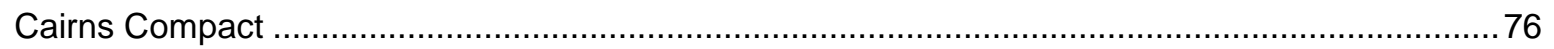

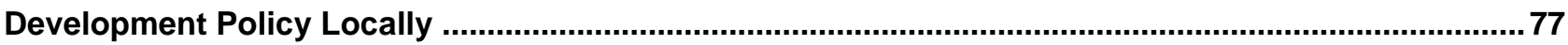

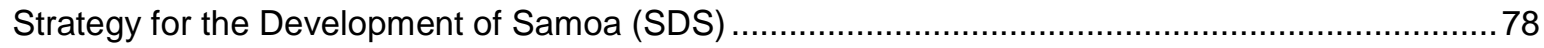

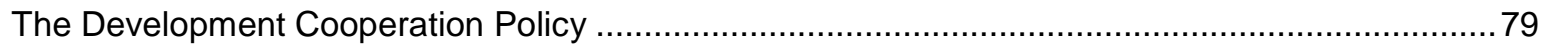

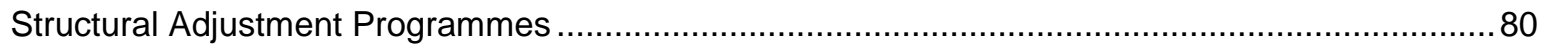

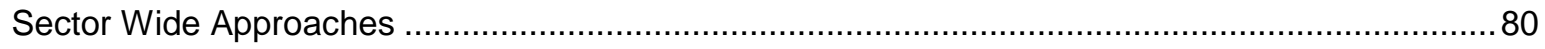

Table 1. Co-operative/ Joint Work between Agencies ............................................................. 81

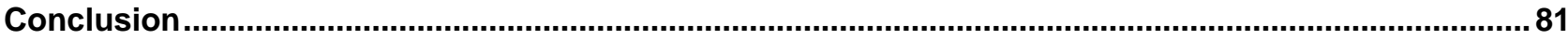

CHAPTER SEVEN: MARKERS OF DEVELOPMENT SOVEREIGNTY.................. 83

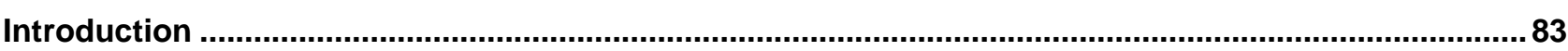

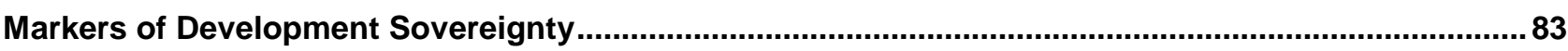

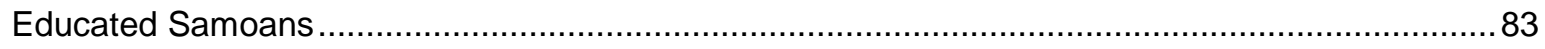

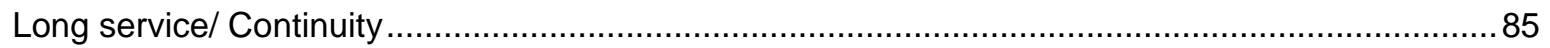

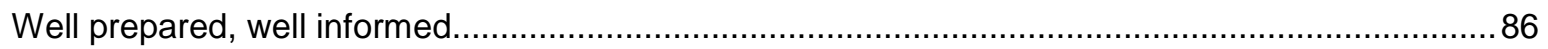

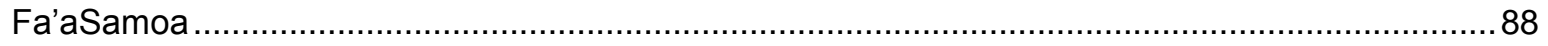

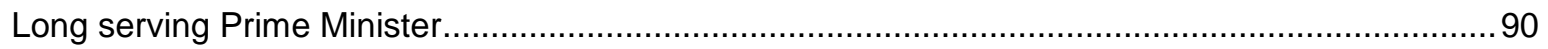

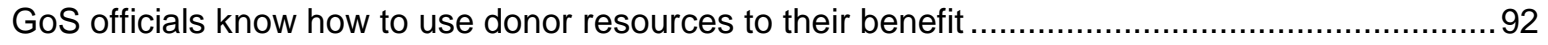

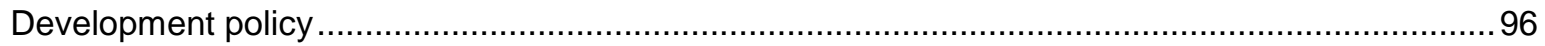


CHAPTER EIGHT: CONCLUSION

REFERENCE LIST

APPENDIX 4: SEMI STRUCTURED INTERVIEW QUESTIONS TO FRAME MY 'TALANOA' INTERVIEWS.

APPENDIX 6: 14 KEY NATIONAL OUTCOMES SET OUT IN THE SAMOA DEVELOPMENT STRATEGY 2012 - 2016. 


\section{Acknowledgements}

I would firstly like to thank all the people who shared their stories with me and whose voices are represented in this thesis. I feel humbled to have been given the privilege to listen, record and document your experiences of aid in Samoa. To Peter Swain for your encouragement to undertake my Masters, John Overton for providing me with the opportunity to embark on this research and your direction throughout, Nicki Wrighton for kick-starting the development policy sovereignty research in Tuvalu, and Adele Broadbent for the hours of proofreading. Alofaaga mo outou e le mavae.

I acknowledge my parents Mano'o and Malae Ulu for your tireless efforts in ensuring that my siblings and I were given the chance of a tertiary education and instilling in us the importance of fa'aSamoa. To my siblings, their partners \& children, (Rev lasepi \& Leone Ulu: Morgan, Eciladen and Graceson; Aloali'i \& Marion Ulu: Grace, Hannah and Eliana; Ma'anaima Ulu; and Vaipousa \& Junior Tui) as well as my parents-in-law (Richard \& Lesley Schofield) for believing in me. To my spiritual parents Bs Brian and Ps Hannah Tamaki, Ps Mike \& Ana Draper and Destiny Church for your aroha and prayers.

To my beautiful wife Pip, I really could not have completed this research without you. You are an amazing woman with a huge capacity to love and support. To Micah and Malachi I feel spoilt to have been given the honour of being your daddy.

Lastly to my Lord and Saviour Jesus Christ who is my source of strength, my provider, my redeemer, my rock and my salvation. You've kept me grounded and focussed to complete this research in a way that is honourable to the people of Samoa. O lou pale lea. 


\section{Abstract}

This study examines how the Government of Samoa (GoS) asserts development policy sovereignty when working with aid donors. Observations from findings of a review of development policy, and the author's work in Samoa since 2002 suggested that GoS does in fact assert development policy sovereignty.

The GoS is engaged with the global aid agenda and this is reflected in their development policy. The GoS is able to hold donors accountable to principles set out in high-level aid effectiveness forums. The outcomes of this research show that the GoS has a high level of ownership of their development programme and this is respected by donors.

Samoa has a long history of independent thought and action. Through resistance groups such as the Mau a pule movement (Opinion of rule), Samoa stood up to the German and New Zealand colonial administrations between 1900 - 1961 and created a unique constitution when they became independent in 1962. Fa'aSamoa (the Samoan way) was central to the constitution and remains a strong part of Samoan culture today. It is suggested that the GoS officials use the Mau movement mindset when dealing with outsiders that come to Samoa. This is seen as a healthy way to act for a recipient country.

Qualitative methodologies were used to keep the GoS at the centre of the research process. Interviews were conducted with representatives of the GoS, the private sector, civil society organisation and donors. All the interviews with Samoans were conducted bilingually.

It was found that the GoS asserts its ownership over its own development through an educated, long serving, well informed and prepared public service. Due to a high calibre public service, officials know how to use donor resources to their advantage through the GoS development policy. Furthermore GoS officials are not intimidated by donors and are therefore not afraid to hold donors accountable to outcomes of high level aid effectiveness talks. The GoS follows the principles of the current global aid agenda in the contest for aid sovereignty - pule. 


\section{Glossary}

\begin{tabular}{|c|c|}
\hline Aiga & Family \\
\hline Ali'i Sili & High Chief \\
\hline Alofa & Love \\
\hline Fa'aaloalo & Respect \\
\hline Fa'alavelave & A disruption but also refers to a cultural exchange \\
\hline Fa’alupega & Constitution \\
\hline Fa'aSamoa & The Samoan way \\
\hline Fa'avae i le Atua Samoa & Samoa is founded on God \\
\hline Fiapoto & $\begin{array}{l}\text { Someone who thinks they know what they are talking but } \\
\text { in actual fact do not Mau a pule 'Opinion of Rule' (A } \\
\text { resistance group also referred to as Mau movement) }\end{array}$ \\
\hline Fono a le nu'u & Village Council \\
\hline Gagana & Language \\
\hline Galue fa'atasi & Work together \\
\hline Matai & Chief \\
\hline Moa & Centre \\
\hline Momoli or o'o & Ceremony to confirm a new status or position \\
\hline Nu'u & Village \\
\hline Pakeha & European \\
\hline Palagi & European \\
\hline Sa & Sacred \\
\hline Tafa'ifa & Holder of four paramount chiefly titles \\
\hline Talanoa & Talk \\
\hline Tama’aiga & Paramount Chief of which there are four in Samoa \\
\hline Taonga & All things precious \\
\hline
\end{tabular}


Tapua'i

Tauivi

Tautua

Tino Rangatiratanga

Tumua ma Pule

Umu

'u’u mau lau aganu'u'
Support

Never give up

Service

Sovereignty

The two islands of Upolu and Savai'i

Ground oven

'Hold on tight to your culture' 


\section{List of Acronyms}

ACC Aid Coordination Committee

ACEO Assistant Chief Executive Officer

ACP African, Caribbean and Pacific

ADB Asian Development Bank

AIDS Acquired Immune Deficiency Syndrome

AusAID Australian Agency for International Development

CDC Cabinet Development Committee

DAC Development Assistance Committee

LMS London Missionary Society

CCCS Congregational Christian Church of Samoa

CSO Civil Society Organisations

DHPG Deutsche Handels and Plantagen Geselischaft

EC European Commission

EU European Union

GoS Government of Samoa

GNI Gross National Income

HRPP Human Rights Protection Party

IMF International Monetary Fund

ISP Institutional Strengthening Project

JICA Japanese International Cooperation Agency

LDC Least Developed Country

MDGs Millennium Development Goals

MIRAB Migration, Remittances, Aid and Bureaucracy

MoE Ministry of Education 
MoF Ministry of Finance

MTEF Medium-term Expenditure Framework

NGO Non-Government Organisations

NORAD Norwegian Agency for Development Cooperation

ODA Overseas Development Assistance

OECD Organisation for Economic Co-operation and Development

PEFA Public Expenditure and Financial Accountability

PEF Public Expenditure Review

PFM Public Financial Management

PIFS Pacific Island Forum Secretariat

PRSPs Poverty Reduction Strategy Papers

SAPs $\quad$ Structural Adjustment Programmes

SDS Samoa Development Strategy

SPREP Secretariat of the Pacific Regional Environment Programme

SROS Scientific Research Organisation of Samoa

SWAp Sector Wide Approach

UN United Nations

UNDP United Nations Development Program

USP University of the South Pacific

VSA Volunteer Service Abroad

WB World Bank

WHO World Health Organisation

WWI World War I 


\section{CHAPTER ONE: Introduction}

Since the turn of the millennium the global aid agenda has placed emphasis on aid recipients attaining aid sovereignty. This is achieved by recipients and donors adhering to high-level aid effectiveness principles that encourage ownership, alignment, harmonisation, and mutual accountability. Since 2011 researchers from Victoria University of Wellington, Massey University, the University of the South Pacific and the University of New Caledonia have been investigating "the impact of changing aid modalities on development policy sovereignty in the Pacific" (Overton, et al, 2012, p. 25). This research contributes to this investigation, specifically looking at the Government of Samoa (GoS) ${ }^{1}$.

The initial question of this research was to find out whether the GoS has development policy sovereignty. It soon became apparent that the answer could be a simple 'yes' so the aim changed to the following:

\section{Overall aim:}

To examine how the Government of Samoa (GoS) asserts its development policy sovereignty when working with donors.

This overall aim raised some more specific questions:

\section{Research questions:}

1. What are the key elements of the global aid effectiveness agenda?

2. How does the GoS assert development policy sovereignty?

3. How has the GoS used the initiatives of the global aid effectiveness agenda in their development policy and government processes?

4. How has the history of Samoa influenced the GoS and their dealings with donors?

5. How does the GoS 'development policy' translate in daily practice?

6. What are the markers of development policy sovereignty from both the perspective of the GoS and the donors?

\footnotetext{
${ }^{1}$ The term Government of Samoa is interchangeable between Government and the public service that carries out the government's wishes as the politics has been stable in Samoa for so long.
} 
To establish how the GoS has development sovereignty a review was completed of the GoS development policy at the start of this research. The review suggested that the GoS has a strong degree of sovereignty and launched me into the body of this thesis and the teasing out of the research questions.

I lived in Samoa from February 2002 to May 2003 while working for the New Zealand High Commission and I have managed the Volunteer Service Abroad (VSA) Samoa Programme since 2003, During this time I have developed many relationships and networks that have given me an inside look at the delivery of aid in Samoa. I came to this research being able to look through multiple lenses as an employee in the donor world, as an employee of a non government organisation and as a Samoan. This has led me to believe Samoa may be unique in the world of development. It is a country where officials have no problem in disagreeing with donors if they feel Samoa's best interests are not at the forefront of donor programmes. Working as a development practitioner since 2002 I have witnessed how donors can dominate development work simply because they control funding. It is clear many aid programmes fail and the blame can be placed in both the donors' and recipients' camps.

The Organisation for Economic Co-operation and Development (OECD) has been working since 2000 to hold donors more accountable on effective ways to deliver aid. The main theme of the OECD's aid effectiveness approach is that recipient countries should be at the centre of aid programmes with donors at the periphery as providing guidance if and where neccesary. The ideal position for any aid recipient is to have general budget support. This is where donors provide money with few conditions leaving it up to the aid recipient to decide where the money is spent. Then it delivers a report to the donor at the end of the financial year using its own financial systems. There is still a long way to go before aid recipients can reach this goal and understandably donors need to be convinced that donor money is not going to be misspent.

Samoa gained independence in 1962. This study highlights an example of a country that can maintain pule - sovereignty over their own development as an aid recipient. I have deliberately chosen 'Pule' as the title of this thesis as it reflects to me that the 
GoS controls the donor/recipient relationship. The GoS shows a level of independence when working alongside donors that donors also respect. Through the building of lasting relationships between the GoS and donors, both parties seem to work collaboratively and agree on ways aid is delivered. This is not to say that all aid programmes in Samoa are perfect but it does confirm that the GoS is at the centre of their aid and development and the likelyhood of aid programmes succeeding is increasing.

When discussing development sovereignty it is difficult not to question whether the GoS can be sovereign in their development when Overseas Development Assistance (ODA) makes up close to $30 \%$ of their annual budget. Poirine (1995) highlights that Pacific Island countries receive more aid per capita than anywhere else in the world. From these statistics it is easy to reach the conclusion that the GoS cannot have development sovereignty as they would not function without aid. This also reinforces Bertram and Watters' (1985) Migration, Remittances, Aid and Bureaucracy (MIRAB) model and their suggestion that "remittances and foreign aid are the main economic resources of the local economy" (Poirine, 1998, p. 65). To an extent this is true: without the huge amount of aid being poured into Samoa from donors perhaps they would not be as well off as they are today.

Epeli Hau'ofa (1993) in his article entitled 'Our Sea of Islands' challenges the perception of the Pacific as "too small, too poorly endowed with resources, and too isolated from the centres of economic growth for their inhabitants ever to be able to rise above their present condition of dependence on the largesse of wealthy nations" (Hau'ofa, 1993, p. 4). He says these views are based on economic and geographical points of view. His idea that Pacific Islanders instead display considerable resourcefulness and autonomy will be used as an on-going theme throughout this thesis.

\section{Thesis structure}

Setting the scene for this research we take a chronological journey through the story of how aid has evolved from its inception to the current global aid agenda. This thesis looks at the implications of aid on recipient countries, particularly with reference to 
the way aid has been delivered. It also looks at sovereignty and what this means in the context of this research.

To place this research firmly in Samoa, chapter two looks at the history of this country with specific attention to the legacy of the colonial powers. The way Samoa has dealt to foreign powers in the past reflects the way the GoS works alongside donors today. Samoa's colonial history, although significant and quite destructive, was very short with a resistance group forming to defend the people of Samoa from foreign rule. There are lines that can be drawn from this and how Samoa has dealt with donors, adding to the picture of development policy sovereignty in Samoa.

Chapter three looks at the methods and methodology I used to undertake this research. It also highlights learnings that took place and subsequent changes that were made throughout the research.

The final part of this study looks more in depth on how aid is managed and delivered in Samoa. It takes a close look at development policies in the context of Samoa and draws on the views and experiences of officials and others. Finally the thesis addresses the core of this research: markers of development sovereignty.

It then concludes by summarising the learnings to answer the initial question: "how does the GoS assert its development sovereignty when working with donors?'. 


\section{CHAPTER TWO: Aid and Sovereignty}

\section{Introduction:}

Aid and sovereignty are the two concepts that establish the foundation for this research. By providing a background on aid we will be able to see how the GoS has used aid, in its numerous delivery iterations since inception, to hold donors accountable to current high level aid effectiveness principles. This helps to understand how the GoS gains sovereignty in the delivery of aid within a Samoan setting. Defining aid is not an easy task but this chapter will look at the increase of aid over the past decade, the motivations for aid and the current aid effectiveness agenda. The last part of this chapter looks at sovereignty and what this term means in the context of this research.

\section{Aid over the last decade}

Aid (also known by the Organisation for Economic Co-operation and Development (OECD) as Official Development Assistance or ODA) is a multimillion dollar industry (Warah, 2011) and has over decades remained a permanent fixture of international foreign relations (Wood, 1986). Aid does not necessarily imply a uniform group of funds or practices (Bermeo, 2009) nor does it imply that developed and developing countries have a shared understanding on how aid is delivered (Mertens, 2004). There are many forms of aid and, depending on the parties involved in the aid relationship, the spectrum of interpretation and method of delivery is wide.

The origin of aid is a contestable topic (Hjertholm \& White, 2000; Tarp, 2000). Tchuigoua (2009) argues that 'aid' was inspired by the experiences of the Russian Revolution.

The Communist Party brought together the former colonies of the Russian empire as independent states in a Union of Soviet Socialist Republics. In these new republics, Bolshevism destroyed the exploitative primordial relations and deposed the ruling classes who had links to the Tsarist system. This is where the notion of development aid was conceived with the aim of establishing equality between the member states of the union (Tchuigoua, 2009, p. 15). 
More commonly referred to as the genesis of aid is the Marshall Plan 1947-1952 (Brownlie, 2008). Following World War II, the United States of America put in place a humanitarian economic programme that would assist Europe to recover from wartime destruction of industry (Gimbel, 1976; Hogan, 2002; Agnew \& Entrikin, 2004). The intention of the Marshall Plan was to help developing countries with economic, political and social reconstruction. The benefits for the U.S were that the money would be used to buy their goods therefore allowing them to retain and expand their super power status (Gimbel, 1976; Brownlie, 2008). The Marshall Plan is often referred to as the first real aid programme. I have focussed this research around this latter origin of aid.

Synonymously 'aid' and 'development' can often be lumped together by practitioners. I will focus specifically on aid in this chapter, although it is important to note that it is difficult not to mention development when discussing aid. Indeed 'aid' in this thesis implies 'development aid', namely assistance with improving overall well-being.

There is still no universally accepted definition of aid (Lancaster, 2007; Hunter, 1984; Goldthorpe, 1975; Tchuigoua, 2009). To form a foundation for this research I have chosen Lancaster's (2007) definition of aid as a starting point: "an effort to use public concessional resources from one country to bring about sustained, beneficial change in another" (Lancaster, 2007, p. 3).

To expand on this Hunter (1984) aptly highlights a comment made by a practitioner that "aid is very much 'what people say is aid', a situation that derives partly from the fact that there are two parties to any aid relationship, with often totally different perceptions of what constitutes aid" (Hunter, 1984, p. 158). Throughout this research, the two parties referred to by Hunter (1984) will be known as 'donor' (the giver of aid) and 'recipient' (the receiver of aid).

Like the origins of aid, development theories came into practice after World War II and at the time of decolonisation (Coxen \& Tolley, 2005). An important landmark was President Harry S. Truman's inaugural speech of 1949. Truman effectively defined the world into two clear areas: the 'developed' and the 'underdeveloped'. Truman stated the main aim for the developed world: 
...should be to help the free peoples of the world, through their own efforts, to produce more food, more clothing, more materials for housing, and more mechanical power to lighten their burdens. The old imperialism - exploitation for foreign profit - has no place in our plans. What we envisage is a program of development based on the concepts of democratic fair-dealing (Brownlie, 2008, p. 11).

What followed over the next four decades was a series of theories that proposed ways to narrow the gap between the developed and underdeveloped, the rich and the poor (McMichael, 2004). During that time development was established, adapted, and transformed. I favour Brownlie's (2008) definition of development as this best captures not only the economic aspects of development but also the human development aspects:

[d]evelopment is a process of change and growth. It usually involves an improvement in people's lives, so that they become better, happier, and freer... ....it should also include social and human development, as well as issues such as respect for the environment, democracy, and human rights. (Brownlie, 2008, p. 11).

Over the past 60 years shifts in the delivery and receipt of aid have impacted both policy and practice. Up until the late 1970s donors were interested in building the capacity of the state and trusted that aid delivered directly to recipient countries was the best policy mechanism for their development. The Cook Islands for example received general budget support in effect from the New Zealand government when it was annexed in 1901 until 1965. It then became self-governing in free association with New Zealand following an act of self-determination under the United Nations (Bertram \& Watters, 1984).

Emerging from Rostow's five stages of growth and to assist a country to 'take off' was the assumption that aid should be invested in tangible activities such as large scale infrastructure projects. Easterly (2001) refers to this as filling the 'finance gap'. By the 1980s international development agencies such as the World Bank became increasingly concerned about the capacity of recipient countries to manage aid given directly to them from donors. There seemed to be little accountability and transparency around how aid was being spent and this old model provided opportunities for corruption to take place. 


\section{Structural Adjustment Programmes (SAPs)}

In the 1980s and 1990s neoliberalism guided development policy. Neoliberalism looked at shifting away from budget support and large scale infrastructure projects, moving towards Structural Adjustment Programmes (SAPs). In 1981 the Reagan administration of the U.S. and the Thatcher government in the United Kingdom, along with their allies, were determined to see a shift of power from the state to the market. The Washington Consensus describes ten policy prescriptions used as a baseline of directions for recipient countries from entities such as the two Bretton Woods Institutions - the World Bank (WB) and the International Monetary Fund (IMF) - as well as the US Treasury (Stiglitz, 2003; Stiglitz, 1998). It was an agreement that encouraged radical reform and enforced restructuring so the market would determine development with less involvement from the state. Neoliberalism put development in the hands of markets and entrepreneurs but not political processes that were suggested as inefficient and open to corruption (Overton \& Murray, 2011). Neoliberalism was further reinforced by Adam Smith's concept of 'invisible hand' that argues the market drives the economy for positive outcomes for developing countries (Rothschild, 1994).

The IMF and WB were able to exercise such power and spread the neoliberal agenda because of stabilising plans imposed by the IMF on recipient countries who had mounting debt problems and faced rises in interest rates and falling commodity prices. As a result developing countries were in major debt and unable to service let alone repay their loans. Peabody (1996) highlights an example of this in Latin America, "hyperinflation occurred at rates over $300 \%$, limiting the effectiveness of investment and taxation... the deteriorating terms of trade led to shortages of foreign exchange, production bottlenecks, and negative economic growth" (Peabody, 1996, p. 824)

The IMF and WB were in a position of power to bail out recipient countries by rescheduling their debts through concessional loans but under the 'condition' that the recipient country underwent economic reform (Beneria, 1999; Peabody, 1996). It was believed by the Washington Consensus that collective economic growth be promoted internationally eventually filtering down to the developing countries (Overton \& Murray, 2011). Once SAPs were approved for a recipient country by the 
IMF, conditionalities were placed on the loans or grants that were specific to their fiscal situation (McCann \& McCloskey, 2003).

With SAPs there was a belief that wealth would trickle down to poorer countries to assist them to become better off. SAPs however lacked a poverty focus and in fact increased poverty for developing countries (Thomas, Humphreys, \& Carr, 2001). The legacy that SAPs did leave was increased poverty through unemployment, the loss of welfare services and weakened state capacity. Developing countries found it difficult to work their way out of poverty. Furthermore states were cut out of the neoliberal agenda and were therefore less able to perform their core functions. Privatisation of government owned industries impacted how the state ran its government. The market in fact was not able to function as originally hoped. As a result states began to fail as their core was weakened with overworked staff and fewer resources. The problem with SAPs was that it gave increasing power to large donors therefore weakening the power of recipients and civil society organisations. Conditionalities were used to manipulate the state to force reform (McCann \& McCloskey, 2003).

\section{Millennium Development Goals}

In 2000, 189 nations met at the United Nations headquarters in New York for the Millennium summit. At the summit national leaders recognised that it was their collective responsibilities to developing countries to not only reaffirm the principles of the United Nations but to also acknowledge the goal of human dignity and equity at the global level (United Nations, 2000). As a result the Millennium Development Goals (MDGs) were launched. These are a series of eight time-bound development goals that were agreed upon by United Nations General Assembly to be achieved by the year 2015 (Gajida, LLiyasu, \& Kemevou-Asima, 2010). The goals are to: eradicate extreme poverty and hunger; achieve universal primary education; promote gender equality and empower women; reduce child mortality; improve maternal health; combat AIDS, malaria and other diseases; ensure environmental sustainability; and promote a global partnership for development (UNDP, 2010). The MDGs provide a framework for donors to work together towards a common end in order to make sure that human development reaches everyone. It was believed at the summit that if these eight goals are achieved, world poverty will be cut by half 
(United Nations, 2000). The United Nations Development Programme (UNDP) produces the annual Human Development Report that focusses on poverty reduction through strategies of capacity building, empowerment, paticipation by civil society, good governance and environmental sustainability. The MDGs became the cornerstone of the New Poverty Agenda (Storey, Bulloch, \& Overton, 2005). The MDGs became the foundation of putting poverty reduction as the centre of focus for donor countries (Poku \& Whitman, 2011; Overton \& Murray, 2011b).

From 1960 to 1990 aid from OECD countries to developing countries rose steadily (OECD, 2011). Particularly after the creation of the MDGs, donor countries were determined to tackle the issue of poverty so the formula 'doubling aid to reduce the poverty by half' was adopted by donors (Guillaumont, 2009). Over the last decade, there has been a huge increase in aid as measured in Figure 1 (Fisher, 2011) by the Development Assistance Committee (DAC) of the OECD. In 2002, at the Monterrey Conference on Financing for Development, donor countries renewed their pledge to increase development assistance to $0.7 \%$ of national income, on the condition that recipient countries took necessary measures to improve governance and adopt sound policies for growth (ODI, 2005).

Figure 1: Official development assistance (ODA) 1990 - 2010, billion US dollars

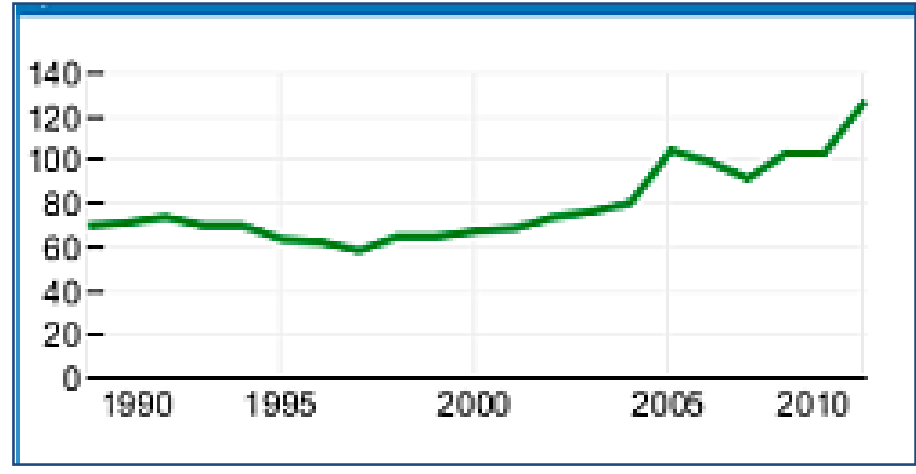

(Fisher, 2011)

Donor governments pledged at the 2005 Gleneagles (G8) Summit that they would make a commitment to increase their ODA. What the pledges implied was raising ODA from about USD80 billion to nearly USD130 billion (Lesage, Van de Graaf, \& Westphal, 2009). 
From 2008 there was a dip in aid received from donor countries due to the economic recession that hit the international market. Yet despite the financial recession aid has continued to increase and in 2010 donor countries' aid totalled to USD129 billion, an historical high. The United States of America, United Kingdom, France, Germany and Japan were the highest contributors of aid in 2010. The combined share of aid in the gross national income (GNI) of DAC member countries for 2010 was $0.32 \%$ as shown in Figure 2 (Fisher, 2011).

Figure 2: Official Development assistance (ODA) 1990 - 2010, \% of GNI

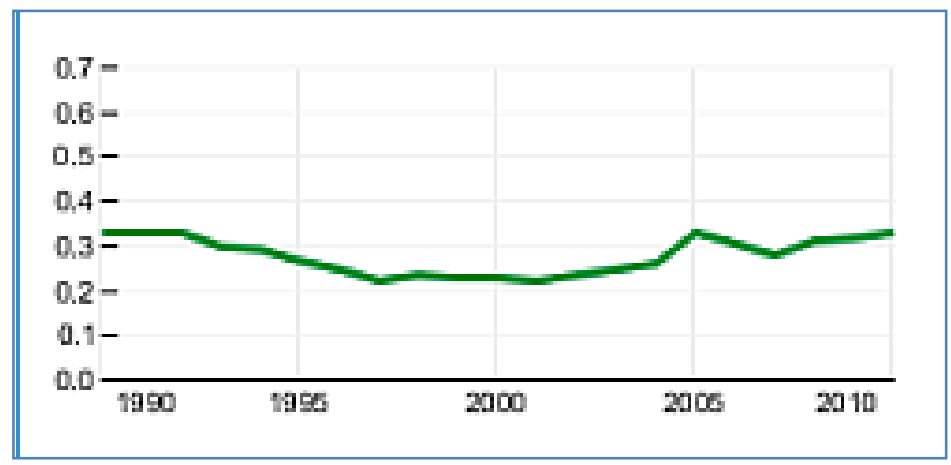

(Fisher, 2011)

\section{Poverty Reduction Strategy Papers (PRSPs)}

As a response to the criticisms of SAPs, in 1999 the IMF and the WB initiated Poverty Reduction Strategy Papers (PRSPs) (Marcus, Wilkinson, \& Marshall, 2002). Countries were encouraged to show a commitment to reducing poverty and achieving the MDGs by producing 'nationally-owned' PRSPs through broad participation processes (Komives \& Dijkstra, 2011). Since the adoption of the eight MDGs in 2000 by the United Nations World leaders, donor and recipient countries have been able to provide benchmarks to track extreme poverty in its many dimensions (Clemens, Kenny, \& Moss, 2007).

In order for PRSPs to be successful it required a big shift in theory, policy and practice. Unlike SAPs, PRSPs required not only the state but relevant stakeholders to participate in the design of PRSPs. In order for PRSPs to be successful it required a participatory approach and terms like 'empowerment', 'ownership', 'consultative', and 'results orientated' came to the fore (Folke, 2004). Donors realised that 
involvement by the state and stakeholders was key to the elimination of poverty which was at the core of the PRSPs (Gould, 2005).

Recipient countries were asked to prepare PRSPs based on their assessments of their needs after consultation with government departments, and civil society as well as donors. The idea was that the recipient country would drive the PRSPs and write the papers themselves so they had a feeling of ownership. Unlike SAPs and earlier forms of aid, PRSPs pushed the message of equality in an aid programme. The catch was although the recipient country wrote their own PRSPs, the template, language and objectives were set by the donor. There were a number of conditionalities that were set that recipient countries had to adhere to. Recipient governments were to tie their budgets to a Medium-term Expenditure Framework (MTEF) set by IMF; under the Public Expenditure Review (PER) donors were able to routinely check recipient public accounts; and lastly poverty reduction had to be the focal point for budget expenditures as defined by the WB and IMF (Gould, 2005). Including all stakeholders in the consultation process was crucial for the recipient country. Any agency that had some involvement in a PRSP had to be acknowledged. This gave the illusion of broad participation. The papers had to show that there were clear actions and targets (medium and long term) that could be measured to alleviate poverty. Once the PRSPs were completed to the format set by donors, the recipient countries could present this to the donors and it became a way recipient countries could secure donor funding.

\section{Sector Wide Approaches (SWAp)}

Following on from the PRSPs the second half of the 1990s saw the emergence of the Sector Wide Approach (SWAp) as an aid modality. SWAps presented a process that donor partners could use to gain greater consistency in their appoaches to providing development assistance (Riddell, 2007). The SWAps differed in approach to earlier development policy in that they gave developing countries the opportunity to design programmes to address their development needs in a particular sector (typically education and health), as opposed to their needs being identified by donor partners (Riddell, 2007), and these sector wide programmes were to be funded by donors over a resonable span of time. 
Riddell (2007) notes that one of the main factors behind the creation of SWAps was to facilitate greater developing 'country ownership' of the process. The reality is some recipient countries have tarnished their reputation with donors over mismanaged aid programmes in the past and like any relationship, trust takes time to develop. Hyden (2008) questions whether mutual trust and accountability are attainable at all. He refers to country ownership as a goal that is striven for and not an established fact. Buiter (2008) argues the term 'country ownership' has been abused to such an extent that it is at best unhelpful and at worst destructive, "a term whose time has gone" (Buiter, 2007, pp 647).

In the design process of a SWAp, both the Paris Declaration and the Accra Agenda for Action recommend that in a spirit of consultation, the different public and private stakeholders come together to negotiate the indicators for a SWAp. However while it is a consultative process in theory, the practical application does not always match intended reality.

The Norwegian Agency for Development Cooperation (NORAD) produced a series of reports in 2004 on SWAps and civil society. In Report 1 (NORAD, 2004a) it highlights examples where consultation in the design process was skewed for various reasons. In Uganda, consultation was by invitation only and often smaller Non-Government Organisations (NGOs) were overlooked. In Malawi although a range of NGOs were invited to consultative workshops very few took part due to lack of understanding of the process. In the case of Mozambique the involvement of CSOs was largely dependent on the government and their support of CSOs. This support was often very small. It is evident in the reports that very few local CSOs were aware of their role in the design process. The reports also noted the lack of synthesis between stakeholders. There were obvious communication barriers between groups and little chance to interact due to the way information filters from the top to the bottom. In Zambia, the quality of the consultative process was challenged in an education SWAp where documents were released so late that all decisions had been made prior to the dissemination of the information. This effectively ignored the comments from the CSOs and assumed they did not carry any significance (NORAD, 2004b). The design process in these examples was disempowering for CSOs and NGOs. 
It is difficult to identify if real 'consultation' has taken place. Mitlan (2001), highlights that higher income groups tend to take on leadership positions to the exclusion of other groups in the community. There is often little real consultation of the 'ordinary' citizenship, especially women. And if there are benefits that are secured from a consultation process, in general many of these appear to only personally benefit the elite community leaders. In addition, Mitlan (2001) says that how the views and voices of such a range of people are composed into country ownership remains a mystery. Development negotiations, to arrive at agreed indicators, require the representatives of each group to have a strong voice to ensure they are not drowned out by more dominant members. Therefore, although participation may be increased through the SWAp process, this participation does not always lead to wide representation.

There is an existing dichotomy regarding the role that CSOs should play in a SWAp. Riddel (2007) states even where traditions of consultation exist, the involvement of a CSO runs the risk of being token or, otherwise known as the 'tick box venture' (Ishkanian, 2006) to appease donor requirements in a SWAp process. Theoretically, in countries where CSOs are strong, they will have a more direct influence on how much civil society is included in the SWAp process and their ability to affect policy more substantially. However, Uganda has a history of strong CSOs and is upheld as an example of best practice for the development sector. Yet independent research has shown that this is not necessarily the case. While participation in negotiations has increased, the evidence of CSO representation and influence on subsequent policy has not been as clear. The Uganda case also highlighted the issue of the method of inclusion and exclusion of different organisations (Lister \& Nyamugasira, 2003).

A major concern in the SWAp process is capacity building. In the case of the education SWAp carried out in Burkina Faso (NORAD, 2004b), while national ownership had improved considerably to past project implementation there remained two major hurdles in the establishment of national ownership. Firstly too little leadership from the Ministry of Education and secondly too much pressure from donors highlights capacity issues. The donors in the Burkina Faso case actively 
focussed on strengthening capacity in planning, finance and administration, and human resources of the Ministry of Education. Unfortunately the donors were not confident that local capacity was strong enough to manage a SWAp. This was largely because of limited external support for capacity building, and because ministries gave little priority to developing local capacity to implement the SWAp indicators.

Killick (2005) discusses, in his policy brief on the SWAp in Ghana, that the budgetary process is so weak it is essentially a 'ritualised facade' and has little relation to the reality of actual state spending. Killick's policy brief highlights evidence of large leakages in allocated funds between central government and local service delivery of up to $51 \%$ leakage in non-salaried expenditure in education and $7 \%$ leakage in nonsalaried expenditure in health clinics. Failings can be attributed to the lack of transparency in the budget process, wider public and interested non-state parties being excluded from budgetary discussions and the Government of Ghana's lack of time and resources to provide any real scrutiny that is not "hurried, superficial and partisan" in nature (Killick, 2005, p.2).

The expectations put on all levels to implement the indicators in a SWAp can result in major gaps in the delivery on the ground. Reflections on policy, partnership, strategy and implementation of the Education reform in Uganda (Ward, Penny, \& Read, 2004) identified a gap in curriculum development and the implementation stage. The curriculum was launched into schools with no overall plan, no budget and no department nor individual with line management responsibility for its launch. The result was catastrophic with the late delivery of the curriculum to schools, with textbooks and teachers' guides arriving up to three years late. At the grassroots level, no policies were in place for the recruitment and career development of teachers. There was no clear career and professional route for those who wanted to pursue a career in teaching. Few teachers had recent and relevant primary school teaching experience. In the Uganda case skills and capacity were scarce and unevenly distributed. Most levels lacked a technical grasp of issues, and a proper understanding of government procedures (Ward, Penny, \& Read, 2004). 
One of the main intentions of a SWAp is country ownership. Developing countries are encouraged to own the development process, to be a part of the consultations, to actively contribute towards policy formulation, and be actively involved in the SWAP implementation. However, if the agreed policy designed by the developing country does not match that of donors, it will be altered accordingly. The reality of the SWAp may be compared to buying a house with a bank loan. You as the owner own the house, however the bank sets the specifications such as the price, condition and, sometimes, even location of the house. The bank has the authority to change floating interest rates without your approval and if you forfeit on payments long enough you will lose the house in a mortgagee sale. At the end of the day the bank walks away with more money and you may be left homeless.

It has been demonstrated that SWAps place a huge amount of pressure on developing countries with unrealistic expectations of local staff who do not always have the capacity to carry out guidelines that are still implemented from above.

\section{Aid effectiveness}

Running parralel and also influencing aid policy and practice is the dialogue on aid effectiveness. There has been much speculation around the effectiveness of aid delivery (Booth, 2011; Glennie, 2011; Gulrajani, 2011; Bird \& Glennie, 2011; Busse; Buss, 2007; Hansen \& Tarp, 2000; Beneria, 1999; Cassen, 1994; Hayter, 1971). Since the adoption of the MDGs donor countries have been in ongoing dialogue on ways these goals will be achieved by 2015 . One positive outcome of the discussions on aid effectiveness is that donor countries have identified that some of their practices have proven to be problematic for recipient countries. Donors have acknowledged that the lack of working together, overzealous targets, unrealistic timeframes and budget constraints have worked against the very goal of poverty elimination (OECD, 2010).

A series of high level forums to discuss aid effectiveness have taken place since 2000. The purpose of the forums have been primarily to 'make the right to development a reality for everyone' (OECD, 2010). A set of principles on aid effectiveness was agreed to by over 200 countries as the template for meeting the targets set by the MDGs. 
Rome hosted the first high level forum on aid effectiveness - the Rome Declaration on Harmonisation 2002. The Rome Declaration listed the following priority actions:

- that development assistance be delivered based on the priorities and timing of the countries receiving it,

- that donor efforts concentrate on delegating co-operation and increasing the flexibility of staff on country programmes and projects,

- and that good practice be encouraged and monitored, backed by analytic work to help strengthen the leadership that recipient countries can take in determining their development path.

The second high level forum, the Paris Declaration on Aid Effectiveness (OECD, 2005), proposed a shift towards country ownership for developing countries through harmonising and the use of differing aid modalities. The Paris Declaration aimed to learn from mistakes made from programme and project aid approaches (Hyden, 2008). "The Paris Declaration on Aid is a landmark international agreement and programme of reform - the culmination of several decades of attempts to improve the quality of aid and its impacts on development" (Wood, et al., 2011, p. xii). It was brokered by the DAC and was the first time that both donors and recipients agreed to joint commitments and to hold each other accountable. "The Paris Declaration marked a significant and potentially revolutionary change in the way aid was conceived and delivered and it represented a remarkable consensus amongst most of the aid community" (Overton et al, 2012, p. 26)

The Paris Declaration principles are a key influence on the global aid effectiveness agenda. Both donors and recipients use the Paris Declaration to influence development policy and daily operations.

The Paris Declaration followed five key principles:

1. Ownership: Partner countries exercise effective leadership over their development policies, and strategies and co-ordinate development actions.

2. Alignment: Donors base their overall support on partner countries' national 
development strategies, institutions and procedures'

3. Harmonisation: Donors' actions are more harmonised, transparent and collectively effective

4. Managing for Results: Managing resources and improving decision-making for results

5. Mutual accountability: Donors and partners are accountable for development results

The first principle of 'ownership' is crucial to this research. Ownership encouraged recipeint countries to develop their own strategic plans to address development issues. Donors would align their assistance with these plans and work more closely with other donors to encourage 'harmonisation' (the second principle of the Paris Declaration) therefore creating more sustainable development programmes for the recipient country (Eyben, 2007). Ownership also recognised the recipient country's own institutions and systems. If a recipient country could prove to donors they had robust financial systems then donors would use a recipient country's financial systems rather than recipient countries having to account for donor funds through a myriad of different financial systems which had been common practice in the past (OECD, 2005). There are always human resource issues for recipient governments, and finding time to report to donors using their respective financial reporting systems is challenging, so having one system to report on is a better use of time (Wrighton, 2010).

The Paris Declaration also moved away from individual aid projects that were led by donors, towards programmes that used recipient country reporting systems and gave the recipient country a license to lead their development work not only in 'policy' but, more importantly, in 'practice' (Overton et al, 2012).

The Paris Declaration principles were not without their faults. Consequently the $4^{\text {th }}$ of September 2008 marked the third high level forum on aid effectivness held in Accra, Ghana, to develop the Accra Agenda for Action (OECD, 2008). The Accra Agenda reviewed the progress and shortcomings of the Paris Declaration and proposed a way forward for its member countries. Accra specifically targeted the principles of 
strengthening country ownership over development, building more effective and inclusive partnerships for development, and delivering and accounting for development results (OECD, 2008). Its intention was to emphasise the implementation of the goals set in the Paris Declaration on aid effectiveness in 2005. Unfortunately policy does not always reflect reality. One critic, Kharas (2008), titles his article on the aid effectiveness meeting in Accra as 'Old Promises, Different City'. The most recent and fourth high level forum was hosted by Busan, South Korea in November 2011. The focus at Busan was whether progress in the aid effectiveness agenda is enough to overcome even greater global challenges.

\section{Sovereignty}

The aid effectiveness agenda of the 2000s was a deliberate move away from a topdown neoliberal approach that saw the donors at the helm of aid (OECD, 2008). The move was essential in order for aid to be effective. Under the new aid modality, recipient countries are encouraged to be drivers of their own development and therefore having sovereignty is crucial. In the context of this research 'sovereignty' refers to the level of self-determination the GoS has when dealing with donors.

The Paris Declaration on Aid Effectiveness' principle of ownership focuses on state to state transfers (Overton et al, 2012). Wiessner (2007) refers to the origins of sovereignty as a Western concept that replaced a feudal system with that of a nation-state. Sovereignty underpins every legal system (Wiessner, 2007) and the state refers to Western-styled democratic states that are,

politically independent entities, exercising various practices of sovereignty including upholding fixed geographic borders and determining who can reside within them, governing citizens via domestically approved policies, enforcing law and order via domestically controlled public forces, controlling a national currency or proxy thereof, and cooperating with other nation states through, for example, pursuing international treaties and bodies (Overton et al, 2012, p. 33).

The definition of a 'state' in a Pacific Island context poses challenges. As identified by Overton et al (2012) on one hand there are states such as Papua New Guinea, Vanuatu, Samoa who are considered fully sovereign states but who are also dependent on donors so the level of sovereignty varies from country to country. On 
the other hand there are countries like the Cook Islands and Niue who are selfgoverning territories in free association with New Zealand whereby New Zealand can choose to take on some sovereign obligations. Sovereignty is therefore not simple to define.

Looking at New Zealand, for generations there has been contention over the term sovereignty under the Treaty of Waitangi signed between the British Crown and various Maori leaders. Article Two of the Treaty of Waitangi assured Maori they would retain their sovereignty (tino rangatiratanga) over lands, villages and all things precious (Orange, 2004). Unfortunately for Maori the Crown did not honour the treaty and proceeded to strip Maori of their taonga. In the past 30 years Maori have begun to assert their sovereignty, holding the Crown accountable for all they have lost (Moon, 2000). Sovereignty, or tino rangatiratanga, for Maori in the 21st century is controversial for some New Zealanders. The idea of Maori having control over their own development could be seen as threatening to those comfortable with the Western nation-state that has governed New Zealand since colonisation. What the tino rangatiratanga view of sovereignty does is shift focus away from statehood to look at daily practices and institutions that can be used by people to promote control over their own resources and lives.

As addressed in the introduction of this research, using the Western definition of sovereignty, and bearing in mind the challenges of this definition in a Pacific context, is it possible for the GoS to have sovereignty as self-determination?

Epeli Hau'ofa (a lecturer at the University of the South Pacific at the time) was challenged by his Pacific students' reactions to being taught that their future was one of dependency and not soverignty due to the size of their nations. Hau'ofo states "[o]n the contrary ... the world of Oceania is not small; it is huge and growing bigger every day" (Hau'ofa, 1993, p. 6). Hau'ofa (1993) pushes the blame of the perception of small mindedness on 19th century colonisation that placed boundaries on Pacific nations that were once boundless. But this has changed with increasingly more Pacific people travelling far and wide expanding boundaries to all parts of the world.

When those who hail from continents, or islands adjacent to continents - and the vast majority of human beings live in these regions - when they see a Polynesian or 
Micronesian island they naturally pronounce it small or tiny. Their calculation is based entirely on the extent of the land surfaces that they see (Hau'ofa, 1993, pp. 6-7).

At the opening of the 43rd Pacific Island Forum in October 2012 by the Prime Minister of the Cook Islands, Hon. Henry Puna (2012), he acknowledged that Pacific Island countries are small, but the collective territories places the Pacific three times the size of China, Canada and USA. Puna (2012) suggests that the Pacific people rethink their sense of identity and the Cook Islands has more recently being referring to the Pacific as a grouping of Large Ocean States as opposed to Small Island States (Puna, 2012).

Hau'ofa and Puna challenge the Western perception of sovereignty. As reflected so far "sovereignty is neither simple nor absolute" (Overton et al, p. 35). Although it is important for a recipient country to have development policy aligned to the global aid agenda, what is more pertinent is discovering whether policy reflects practice.

Sovereignty therefore is "flexible and malleable and it is continually contested and negotiated at a local scale through everyday interactions that contain both overt and subtle performances of power" (Overton et al, 2012, p. 35). Nation-states have processes and procedures in place to develop their own development programmes and therefore demonstrate to donors it is possible for them to have sovereignty. In the case of Samoa to find out the extent to which the GoS has development policy sovereignty in its day-to-day interactions when working alongside donors would be a good indicator of the level of sovereignty it holds.

\section{Conclusion}

Aid is a contestable topic. Like development some have argued that aid encourages statism (Liuvaie, 2009) and others have argued that aid has contributed positively to the development of Least Developed Countries (LCDs) (McGillivray, Feeny, Hermes, \& Lensink, 2006). This chapter has looked at the many changes in the delivery of aid from its inception to the current global aid effectiveness dabate. Motivations for donors providing aid varies from the traditional altruistic assistance to improve economic growth and reduce poverty, including the poverty of opportunities (Addison, Mavrotas, \& MCGilivray, 2005) to the more sinister as outlined by Boone 
(1996) that delivering aid is about driving the political motivations of donors. Whatever the reason aid is going to be delivered to recipient countries. In order for recipient coutries to have sovereignty is not only dependent on aid policies they have in place but is also on day-to-day operations with donors. 


\section{CHAPTER THREE: Samoa mo Samoa}

\section{Introduction}

There is a common Samoan saying: u'u mau lau aganu'u or 'hold on tight to your culture'. Although I was born and raised in New Zealand my Samoan heritage has always been important to me. I worked hard to speak Samoan fluently and practiced writing in Samoan since I was at primary school. Despite there being extensive research on the loss of language and culture by the Samoan diaspora in New Zealand (Anae, 1998; Macpherson, 2008), at the core of many Samoans is a drive to not be second to anyone. Since undertaking this research and conducting interviews with Samoans I have often found myself asking where this pride derives from.

The GoS's assertiveness when working alongside donors is not new. Samoa has had a long history of assertiveness, self-confidence, and the ability to deal with the outside world. There have been unique situations where Samoa has used external concepts and adapted these to fa'aSamoa (the Samoan way) therefore making them their own. This starts by tracing the history of Samoa's interaction with foreigners; the impact of Christianity on fa'aSamoa and fa'aSamoa on Christianity; German and New Zealand administration and the rise of the Mau movement and finally the impact of the matai (chiefly) system on the Samoan political system.

\section{Samoa}

Oral traditions link the origins of Samoan people to the Sa (sacred) moa (centre) almost two to three thousand years ago. Samoans established a way of life that suited their cultural context, subsistence living, social structures and a spirituality linking them back to their land and sea (Swain, 1999).

Historically Samoa was referred to in two parts: Eastern Samoa made up of Tutuila; Aunu'u; Ta'u; Olosega; and Ofu; and Western Samoa made up of Upolu; Savai'i; Apolima; Manono; Fanuatapu; Namu'a; Nu'utele; Nu'ulua and Nu'usafe'e. The Americans annexed Eastern Samoa in 1900 to take advantage of the deep water port for coaling and it became known as American Samoa (Swain, 1999). 
Samoa ${ }^{2}$ has a total land area of $2,820 \mathrm{~km} 2$ with a population of 186,340 people (2011 Census) that speak one indigenous language and has a shared cultural tradition that is fairly consistent throughout the country. Seventy six percent of the population resides on Upolu and the remainder on the other islands (Government of Samoa, 2012). Around $40 \%$ of the population are under 15 and $97 \%$ of the population are Samoan (Government of Samoa, 2010b).

\section{Early Foreigners to Samoa}

Like many countries in the Pacific, Samoa's history is complicated by the interference of foreign powers in an already complex social system. Unlike Cook's description of Tonga, dubbed 'the friendly islands' (Veys, 2009), early explorers to Samoa such as Roggenwien (1722) and Bougainville (1768) did not recommend Samoa as a priority destination (Richards, 1994). Explorer La Perouse who arrived in Samoa in 1787 lost 12 men killed by Samoans during his expedition. As a direct result Samoa gained a treacherous reputation that limited the number of foreigners during the late 1700 s.

The number of foreign visitors and settlers in Samoa began to increase from the 1800s with varying motivations (Davidson, 1967). Foreigners arrived mostly to spread Christianity and to trade and develop economic development opportunities for their own personal benefits (Kramer, 1994a; Meleisea, 1987a).

\section{Christianity}

Missionaries were amongst the early settlers to Samoa arriving to convert local people to Christianity. John Williams from the London Missionary Society (LMS) arrived at Sapapali'i in 1830 with eight Tahitian and Rorotongan teachers (Gilson, 1970). Following the period of Tongan domination of Samoa there were a series of civil wars to identify a king. Whoever was chosen would hold the four tama'aiga (paramount) titles (Tuia'ana, Tu'iatua, Gatoaitele, and Tamasoali'i) of the country and be referred to as Tafa'ifa (literally four sided) (Meleisea, 2012). Malietoa Vainu'upo, the Tafai'ifa and the highest ranking chief in Samoa, welcomed Williams and therefore made it easier for Christianity to be spread throughout the country.

\footnotetext{
2 'Samoa' here and throughout this thesis refers to the former Western Samoa
} 
Hymn books, prayer books and the Bible were translated into Samoa within the first 20 years of Vainu'upo accepting Christianity to the Islands (Meleisea, 1987; Kramer, 1994b).

Christianity did spread wide and fast (Richards, 1994). Traders and whalers were also landing on the shores of Samoa and from a Samoan perspective it would have been difficult to differentiate between the groups as they brought a wealth not available on the island. Richards (1994) quotes Williams from his book Narrative of Missionary Enterprise in the South Seas:

Williams also quoted at length a "venerable chief' who listed enviously the clothes, axes, knives, and other material wealth of the foreigners and concluded, "the God who has given his white worshippers these valuable things must be wiser than our gods, for they have not given the like to us (Richards, 1994, p. 30)

It is evident that there were locals who would have accepted Christianity as an exchange. The act of reciprocity lies at the heart of the Samoan culture. Reciprocity is in reference to the giving and receiving of gifts. In the Western world saving for retirement is factored in a weekly or fortnightly payment towards a superannuation plan. In the world of a Samoan your wealth is shared throughout your life contributing to different fa'alavelave ${ }^{3}$ (cultural exchange) (Mageo, 1991; Levine, 2003) but being repaid for your generosity by being supported by your extended family in your old age. If the principle of reciprocity is practised there will be a continued preservation of material wealth for a Samoan. Reciprocity also extends to relationships - sharing regardless of your status (Sauni, 2011). By Samoans accepting Christianity, in return they would not only receive material wealth but also spiritual wealth.

Some could argue that Christianity in Samoa can be seen as the imposition of an external ideology on their culture, however Samoans have adapted Christianity to suit their culture and heritage and, as a result, Christianity is ingrained in almost all aspects of fa'aSamoa. When Samoa became independent the motto chosen for the

\footnotetext{
${ }^{3}$ The word fa'alavelave literally means a problem, interruption, obstacle, or to bother. Fa'alavelave is also referred to as a cultural exchange. Should a member of your community hold a wedding, funeral, birthday, church opening, fundraiser then it is expected that you would contribute financially or materially. However in return if you were to have a fa'alavelave then others would be expected to contribute financially or materially to you therefore completing the circle.
} 
country was fa'avae i le Atua Samoa, Samoa is founded on God. At independence Samoa had been Christian for around 130 years (Vaai, 2012).

My family have been Christians for five generations so I have always known Christianity as a major part of fa'aSamoa. Although Samoa did have a spirituality prior to Christianity (Turner, 1884) it was frowned upon by missionaries and so to by my forefathers. Samoans themselves were very proactive to ensure Christianity became a part of their culture. Keesing (1934) states "instead of accepting Christianity and allowing it to remould their lives to its form, the Samoans have taken the religious practices taught to them and fitted them inside Samoan custom, making them a part of native culture" (Keesing, 1934, p. 14).

Samoans spare no expense when it comes to church structures and there is never a shortage of churches on the island. In the villages the church structures are the most visible and the church manse is often the most elaborate of houses. Some villages hold a sa (sacred) and it is a time usually between 6:00-6:30pm, that is blocked out where families in the villages are to hold their family devotions. The young men in the village guard the streets in uniform and no people are allowed to walk the streets, shops must close and no cars are allowed to leave or enter premises during this time. If these rules are broken there can be severe penalties issued by the village council.

The three main denominations in Samoa are the Congregational Christian Church of Samoa (CCCS) with $33.8 \%$ of the population; Catholic (19.6\%) and Methodist (14.3\%) (Vaai, 2012). The rest of the population attend a range of denominations in Samoa. By 1962 the CCCS church became independent from the LMS, the Methodist church became autonomous from its New South Wales headquarters in Australia in 1964 and the Vatican allowed vernacular languages to be used instead of Latin in the church liturgy in the mid-1960s. Other religious groups in Samoa are the Seventh Day Adventists, Latter Day Saints, and the more recent Pentecostal movement that has gained a lot of interest. 


\section{German Samoa}

Economically, perhaps the most influential group of foreigners in the mid-1800s were the Germans who dominated the trade and plantation industry in this part of the Pacific. All foreigners lived under the authority of the matai who were the highest authority in Samoa. However as time progressed, although the foreigners were small in number, they were strong in material wealth and they slowly began to possess the land. As they grew in strength, to protect their new wealth, foreigners opposed the control of the matai system and demanded a Western-style central government (Meleisea, 2012).

As Germany gained economic dominance in Samoa it annexed Samoa in 1900 motivated by Deutsche Handels and Plantagen Geselischaft (DHPG) formerly known as Godeffroy and Sohn who were leaders in trade and plantations, growing coconuts, cacao, and hevea rubber cultivation. The first German Governor to Samoa Wilhelm Solf could see the long term economic benefits of DHPG for both Samoa and the German Administration (Meleisea, 1987a). Germany took control of Samoa following a period of civil war. Solf's main aim was to maintain peace in Samoa and to settle any question of kinship. Solf elected a paramount chief, Mata'afa losefa, the eldest of the tama a aiga titles. Solf agreed with Mata'afa to keep Samoans exempt from being forced to work on DHPG plantations. DHPG brought labour to work on the plantations from New Guinea, western Solomon Islands, Bougainville and China. Mata'afa was also interested in protecting the land from being purchased by Europeans. Aside from Apia most land was protected for Samoans, and today $81 \%$ of the land is still customary land. In return Mata'afa would assist Solf to keep Samoa a quiet and calm colony. At first Samoa were receptive to Solf's thinking that Germany had established a protectorate that still permitted internal self-government. Sadly, contrary to Solf's maiden speech that he would govern in accordance with fa'aSamoa, Samoans soon learnt that this would only occur if it was in accordance with the Governors' plans (Meleisea, 1987a).

Meleisea \& Schoeffel (1987) highlight a story that reflects just how unreasonable Solf was in the way that he governed Samoa. A ceremony in fa'aSamoa to confirm a new status or position is a momoli or o'o. The ceremony takes the form of the distribution 
of fine mats, food and money presented to the village, group, organisation, church etc. accepting the person with the new status or position. Mata'afa and his family had prepared a momoli or o'o for the different villages to acknowledge his newly found title as Ali'i sili. When Solf received news of the plans he instructed Mata'afa to hold the ceremony at the seat of the government in Mulinu'u rather than Amaile the seat of the Mata'afa title and gave strict instructions that no food be distributed and once each village received their gifts they were to leave immediately so that other groups were unaware of each other's gifts. Mata'afa also made a speech at this momoli that his title as Ali'i Sili (highest ranking chief) came from the German Emperor. Samoans took issue with the ceremony: firstly that any paramount title was only ever created and bestowed by Samoans and secondly that a momoli would be held in such a manner going against Samoan traditions. Solf became unpopular with many other decisions he made that failed to acknowledge fa'aSamoa accurately. Solf became arrogant and indicated that he alone had final authority in any matter that he chose to be involved (Meleisea, 1987a)

Solf also wanted to do away with the institution of Tumua and Pule that recognises the leading districts Tumua of Upolu and Pule of Savai'i by undermining paramount rank (Meleisea,1995) as reflected in Mata'afa's momoli. There were a number of examples of resentment towards the German administration, none more prominent that the formation of the Mau a Pule - the firm opinion of sovereignty - in 1905 (Meleisea, 2012). Their motto Samoa mo Samoa - Samoa for Samoa - implied that outside influence was not required or welcome. The Mau a Pule was led by Lauaki Namulau'ulu Mamoe, a leading orator from Safotulafai in Savai'i who wanted to protect and restore the national fa'alupega (constitution). Lauaki planned to present a petition to Solf at Mulinu'u with a large group of supporters outlining the desired reforms of the Mau a Pule for the German administration. Unfortunately Solf travelled the country to turn the people away from Lauaki and eventually Lauaki and his family were exiled to the Marshall Islands (Meleisea, 1987b) for their conspiracy against the German Administration. Germany continued to govern Samoa until 1914.

\section{The New Zealand Administration and the rise of the Mau movement}

New Zealand has a special relationship with Samoa. According to the $2006 \mathrm{New}$ Zealand census there are 265,974 Pacific people living in New Zealand making up 
$6.5 \%$ of the New Zealand population with almost $50 \%$ represented by Samoans alone (Kailahi, 2007). Over the last 50 years New Zealand has had a huge impact on the Samoan economy and assisted in many development programmes to improve health and education. Many Samoans who live and work in New Zealand have reached high levels in all sectors. New Zealand has a very positive reputation with Samoa and its people. However, Samoa's relationship with New Zealand did not start out positively. At the outbreak of WWI in 1914 New Zealand under Colonel Robert Logan who became governor, were mandated to invade and take control of Samoa for Great Britain (Meti, 2002).

Unlike the Germans, New Zealand did not have any significant economic interests in Samoa and their motivation was supposedly a civilising mission (Meleisea, 2012). Like Solf, Logan imposed unrealistic rules that clashed with fa'aSamoa. Logan enforced curfews where Samoans were banned from travelling village to village between 10pm and 6am the next day, there were liquor bans for Samoans but much less for Europeans and the main method of travel by boat or canoe was also banned (Smith, 1924). Interestingly matai were so dissatisfied with Logan and his administration that Hempenstall (1978) records a telegram sent by matai to Solf requesting his return.

Two significant events contributed towards tensions mounting against the New Zealand administration. The first was the influenza epidemic of 1918. Towards the end of World War I influenza was a worldwide epidemic, the virus killing more people around the world than the war itself (loane, 1992). The ship Talune departed Auckland in 1918 with reported cases of influenza on board and arrived in Samoa on 7 November the same year. The Talune stopped in Fiji on route to Samoa and was quarantined, however it was not quarantined in Samoa nor were officials informed that passengers on board the ship carrying the influenza (Rowe, 1930). Before long locals picked up the sickness and lives were lost daily. It was reported that nearly every family in Samoa lost someone to influenza. My paternal grandfather was the sole survivor of his family and at a young age was taken away from his birth place and raised by a family miles from home. New Zealand initially did not take responsibility for the catastrophe which claimed $22 \%$ of Samoa's population (Field, 1984). Furthermore Keesing and Keesing (1956) note that the Fono a Faipule 
(Council of Chiefs) made up of 31 members lost 24 experienced matai and orators taking with them valued knowledge of Samoan customs and beliefs.

Logan was blamed by the Samoans for not having the Talune quarantined but he dismissed the claims stating that Samoans were careless in their interaction with those infected therefore contributing to the high death rate (Meleisea, 1987b). Logan's unapologetic response led to the matai drawing up a petition requesting Samoa be transferred from New Zealand to the United States Government (Meleisea, 1987a). Logan left Samoa in 1919 and was replaced by Colonel Robert Ward Tate (Meleisea, 1987b).

The non-violent Mau movement was again reborn as a direct result of disgruntled matai and Samoan leader's attitude towards the New Zealand administration. The measures stipulated by the New Zealand administration were unrealistic and unfair. By the 1920s, with more and more foreigners living in Samoa, there were a lot of interracial marriages. The Mau movement was therefore not only made up of influential Samoan matai such as Tupua Tamasese Lealofi III, but also wealthy partSamoan businessmen such as Olaf Nelson who was also one of the three elected 'European' members on the Legislative Council and a key figure in the Mau movement. Nelson was seen as a huge threat to the New Zealand administration (Meleisea, 1987a). The main motivation of the Mau was self-government as was reflected by their motto 'Samoa mo Samoa' Samoa for Samoa (Field, 1984).

Unlike Lauaki's attempt to unify Samoans when the Mau movement was first introduced under the German Administration, the rebirth of the Mau saw around $90 \%$ of Samoans (Pedersen, 2012) stand together and actively challenge the New Zealand administration, holding it accountable for its actions. This was helped by propaganda networks paid for by Nelson. The Mau had their own newspaper the Samoan Guardian, a uniform that was distributed widely, and their own police force. They also began boycotting certain white businesses and government services (Pedersen, 2012).

George Spafford Richardson, who replaced Tate as Administrator in 1923, did not respond well to the resistance group. He found it difficult to control the growing 
numbers of Mau followers (Pedersen 2012). He would go on to deport key leaders, those he believed to be the backbone to the movement and the troublemakers, to New Zealand. Both Olaf Nelson and Tupua Tamasese Lealofi III were thus deported (Field, 1984).

With tensions rising under New Zealand administration, Pedersen (2012) highlights a petition to the League of Nations lodged on 9 March 1928 by,

7982 Samoan taxpayers (out of a total native tax-paying population estimated at 8500 adult men) appealed to the League either to transfer the administration of Western Samoa from New Zealand to England or to grant the small territory self-government (Pedersen, 2012, p. 231).

Inhabitants of any territory governed under a mandated authority could petiton to the League of Nations if they felt their rights were being violated:

The current administration was autocratic, costly and unjust, with the Samoans 'treated as a subjugated race' and all power and positions concentrated in the New Zealand administrator's hands. Ancient customs were being trampled: the administrator had appropriated the right to appoint hitherto elected members of the Samoans' representative body; he had abolished chiefly titles; he was individualising collectively owned land; he had perverted the rarely used custom of banishment into a tool with which to punish political dissenters. Nor would he listen to their grievances, instead attributing their protests entirely to European instigation. This claim was "an insult to your Petitioners' and to their 'justifiable and creditable national aspirations (Pedersen, 2012, p. 232).

The petition was formal in its language and ornately lettered but unfortunately never made it beyond the British Colonial Office (Pedersen, 2012). New Zealand was arrogant in its management of Samoa. For years when New Zealand High Commissioners to London gave reports to the League of Nations regarding their mandating of Samoa the League were led to believe that Samoa was a model mandated territory. It wasn't until 1927 that the first intimation that things were not going well between Samoa and New Zealand actually materialised when a former official in the Samoan administration made charges against former employers (Pedersen, 2012). The League of Nations was angered that it was not informed by New Zealand of what was really going on in Samoa. Richardson left Samoa in 1928 
losing the support of both Samoa and New Zealand and he was replaced by Stephen Shepherd Allen.

By the time Allen arrived in Samoa New Zealand had well and truly lost their credibility. Tupua Tamasese Lealofi III returned from deportation in 1929 to take part in his last protest with the Mau marking the second event that reinforced the resistance of Samoans. Black Saturday, 28 December 1929, saw that Mau take a peaceful procession through Apia led by the three paramount chiefs Tamasese, Tuimaleali'ifano and Faumuina. When the New Zealand police attempted to arrest a Mau member a scuffle broke out and the New Zealand police opened fire on the unarmed procession, killing the Mau leader Tupua Tamasese Lealofi III. A total of nine died that day with 50 people wounded (Field, 1984). Following the death of Tupua Tamasese Lealofi III a number of ineffective New Zealand administrators were placed in Samoa. Some attempted to map out Samoa's future with no consultation with the people and this annoyed the matai and leaders of the country. The Mau started to lose hope for self-government, but were encouraged by Nelson to forge on, Nelson returned to Samoa only to be deported again because of the possibility of the Mau reappearing.

Pedersen (2012) states that Samoa went on to lodge many more petitions to the League of Nations, therefore helping to sustain a Samoan national movement. Taking heed of the resistance from the Mau movement by the 1950s, and in line with decolonisation pressures worldwide, New Zealand allowed Samoans to have more participation in their government. Sir Guy Richardson Powles spent 11 years in Samoa and worked together with the Samoa and the New Zealand governments to establish Samoa autonomy, something the Mau had fought for years to achieve (Field, 1984).

Samoa became the first country in the Pacific to gain independence on the $1^{\text {st }}$ January 1962. Seven months after becoming independent, New Zealand recognised its special relationship with Samoa. The Treaty of Friendship was signed on the $1^{\text {st }}$ August 1962 by the New Zealand High Commissioner John Bird Wright, who replaced Powles in 1960, and the Samoa Prime Minister Fiame Mataafa Faumuina. The treaty was not to provide protection from a powerful nation over a weak inferior 
nation but rather it was an agreement recognising the strengths of two South Pacific states uniting Samoa and New Zealand as mutual partners. The Treaty also acted as a way of righting the wrongs of New Zealand's past in Samoa.

\section{Independence}

When Samoa became independent its constitution was unique in that it hoped to combine two very different sets of principles, a Western parliamentary democracy with fa'aSamoa (the Samoan way) (Huffer \& So'o, 2003; lati, 2005; Sapolu, Suaali'iSauni et al 2012). The principle of fa'aSamoa was based on a matai (chiefly) system where titleholders represented their aiga (family), whilst the Western parliamentary democracy was based on a very different set of values such as individual rights, religious freedom and equality under law (Meleisea, 2000).

In 1962 these differences did not pose too many problems as the majority of the people lived in the villages in a semi-subsistence eonomy (Meleisea, 2000). However with huge migration that saw about one-third of the population moving overseas during the 1970s and 1980s (Meleisea M, 2000) the constitution began to change. Both sets of principles have evolved significantly since 1962.

Samoans were included in the dialogue in establishing a constitution for the country. The first Constitution Convention was held between 10 November - 22 December 1954. There were 170 members representing different constituencies to ensure a broad range of people were considered during the dialogues. It was said that there were some very heated debates during the convention as Samoan representatives were keen not to lose their notions of hierarchy and social control (Sapolu et al, 2012). The Convention included the four tama'aiga title holders Tupua Tamasese Mea'ole, Malietoa Tanumafili II, (joint holders of the Head of State position at independence); Mata'afa Faumuina Mulinu'u II, the first Samoan Prime Minister; and Tuimaleali'ifano Suatipatipa held the office of deputy Head of State.

\section{Fa'aSamoa}

It is important to gain an understanding and appreciation of the significance of fa'aSamoa on this research as it impacts on the interaction between the recipients and the donors. 
It is commonly understood that there are differences between Western and Pacific worldviews (Peet R, 1999; Shiva, 1989; Crewe \& Harrison, 1998; Bodley, 1999; Huntington, 1996; Haverkort, van 't Hooft, \& Hiemstra, 2003, Deruyttere, 1997). Figure 3 below (Swain, 1999, p. 226) illustrates some of these differences. This figure was used in consumer education workshops in the Pacific to illustrate the clash of values when the marketplace confronts Pacific Islanders and Pacific Islanders confront the marketplace.

\section{Figure 3: Differences between Western and Pacific Worldviews}

\section{The Pacific Way}

Communal

(Extended family, clan, village)

Consensual

(Participation and shared decision-making)

Cooperative

(Seeking positive outcomes for all)

Reciprocal

(Sharing creates obligations to each other)

Spiritual

(Sacredness of food and products made by people)
The Way of the marketplace

Individual

(Individual, nuclear family)

Confrontational

(Take it or leave it)

Competitive

(Winners and losers)

Profit seeking

(Only obligation is money)

Secular

(Only the dollar is sacred)

Different cultures operate under different worldviews. Figure 3 illustrates the fundamental differences between the Pacific culture and the Western culture.

Fa'aSamoa has many intricacies that are deeply woven into the fabric of Samoan culture. Although I grew up in New Zealand fa'aSamoa was instilled in my siblings and me from a very young age. The principles of tautua (service); fa'aaloalo (respect); tapua'i (support); galue fa'atasi (work together); alofa (love); tauivi (never give up), (Huffer \& So'o, 2003) have become a part of who I am and how I think. Fa'aSamoa is very structured, ordered and hierarchal; roles are therefore not only gendered but also age specific. Mulitalo-Lauta (2000) states that fa'aSamoa influences individual's values and belief systems and becomes the basis for decision making on the well-being of the collective. 
The aiga or family forms the foundation of fa'aSamoa (Lilomaiava-Doktor, 2004). My mother often told me that the aiga for a palagi is essentially their immediate family which consists of father, mother and their children. In contrast for a Samoan, aiga extends to aunts, uncles and cousins who are often three to four times removed. As aptly put by Meleisea (1987), "[a]n aiga can be any family group from a married couple to a large clan comprising all the descendants of a common ancestor either male or female" (Meleisea, 1987b, p. 6). Each aiga is led by a matai (chief), a long standing governance system whereby individuals are chosen by the aiga to carry a chiefly title and act as their representative, voice and leader. According to Meleisea (1987) matai is derived from 'mata $i$ ai' which connotates being set apart or consecrated. There are two types of matai: ali'i, which implies the title was founded by an ancestor who had sacred origins (Tcherkezoff, 2000); and a tulāfale those that speak on behalf of the Alii.

Acquiring a matai title is not based on genealogical links alone. Although it is important to be connected to the title either by birth or marriage the most important aspect is service to the aiga (lati, 2000; Macpherson \& Macpherson, 2000). Certainly the Samoan proverb 'O le ala i le pule o le tautua' the road to leadership is through service' (Ulu Kini, 2000) best demonstrates that service is indeed a prerequisite for even being considered a matai title. In March 2012 the Land and Titles Amendment Act 2012 was passed by parliament. It was believed that matai titles were losing their credibility particularly when youth were given titles but did not understand their significance, or serious criminal offenders holding titles brought shame on the aiga. The Act prohibits anyone under the age of 25 from becoming a matai (Sapolu et al, 2012).

The nu'u or village is made up of different aiga. Each nu'u is governed by a fa'alupega, a set of ceremonial greetings (Meleisea, 1995; Huffer \& So'o, 2003; Ye, 2010) which acts as the charter or constitution for the nu'u. As noted by lati (2005 the $n u^{\prime} u$ (village/polity) (Meleisea,1987) is organised by the fono a le nu'u (village council) who are made up of matai within the nu'u who hold different rankings within the nu'u hierarchy. At the fono level matai possess a substantial amount of power and are expected to understand their rank, village protocols, land issues, religion and social control and collectively decide on what is best for the village (Lockwood, 
1971). The Village fono manage the affairs of the village such as food production, health and sanitation, social control and relationships with other villages (Sapolu et al 2012). The Village fono also have the power to strip other matai of titles if they have brought shame on the family, deciding on banishments, burning of properties if families are seen to challenge the village structures as well as acknowledging the positive aspects of the village (Va'a, 2000).

The nu'u also has its own hierarchy of matai and depending on the nu'u both an Ali'i or a Tulafale can hold paramount titles, it is therefore important to note that each title can only be understood in the context of the respective nu'u. For example, in my father's paternal village of Toamua, there are two paramount chiefly titles 'Ulu' and 'Ale'. Both titles are interchangeable and can be both ali'i and tulafale. There are other matai alii and tulafale that support the paramount titles but when the district meet these other titles have no voice only Ulu and Ale. When the different nu'u combines an itumalo or district is formed.

\section{Samoa's unique government system}

The Western parliamentary system of the Samoan government is based on the Westminster model with a unicameral legislative assembly (Government of Samoa, 2012). Samoa has a head of state whose function is to assent bills before they become law (So'o, 2012). There are 49 members of whom 47 are matai representing the 41 territorial constituencies (six have two representatives each due to the size of the constituency) (So'o, 2009) and the remaining two seats are for individual voters (So'o, 2012).

At the first Constitution Convention in 1954 there were concerns over the extent that all Samoans would be represented by their matai and it was agreed that Samoans would be represented by matai suffrage therefore only allowing matai to stand for election and of course to vote and Europeans would be elected through universal suffrage. (Sapolu et al, 2012). As a result of an evolving constitution the matai suffrage was challenged and considered discriminatory, particularly prohibiting the individual's right to vote. Universal suffrage was introduced in 1991 allowing any citizens 21 years and over to vote. Prior to this only matai could vote (Macpherson, 1997). 
Another unique arranged marriage between the Western culture and fa'aSamoa was the formation of the Samoa Land and Titles Court alongside the District Court, Supreme Court and Court of Appeal. Samoa's Chief Justice Patu Falefatu Sapolu again highlights the contradictions between the two different worldviews stating that the most frequent area of tension in law and justice in Samoa is between communal philosophy and individual rights as reflected in Figure 1 (Sapolu et al, 2012).

To differentiate the two court systems any offences "including the non-payment of debts, illegal weapons ownership, sexual offence, theft, trespassing driving offence and assault were considered offences under both Samoan customary law and Western law" (Sapolu et al, 2012, p. 25) are handled by the Western legal system. "Samoan disputes over customary lands and titles were mainly dealt with in the Land and Titles Court by Samoan judges, known as fa'amasino Samoa to differentiate them from judges of the Supreme and Magistrate Courts" (Sapolu et al, 2012, p. 25).

To formalise an already existing tier in the law and order hierarchy, the Village Fono Act 1990 gave formal recognition of the Village fono of matai and their authority in the village. If there were cases over customary lands and titles they were either handled by the Lands and Titles Court or the Village Fono.

The origins of politics in Samoa saw the tama'aiga title holders in the key positions in Government. It was agreed in the 1960s that in order to maintain unity Samoa did not need political parties. However over time when lower class title holders were passed over for senior positions to those that held the tama'aiga titles things started to change.

\section{Conclusion}

Assertiveness and self-confidence in dealing with external forces have been traits of the people of Samoa since contact with Europeans through Christianity and colonisation. Samoa's history is littered with examples of foreign interference that have helped to mould Samoa into what it is today. Christianity, although an adopted faith, has been turned around to suit the Samoan people and aspects of fa'aSamoa are reflected in many denominations today. The two key administrations that governed Samoa from 1900 - 1961 really did challenge Samoa with their unrealistic arrogant demands. However Samoans need to be thankful to the Mau movement 
and the demands it made to resist these foreign powers. The Mau movement worked hard to maintain and strengthen fa'aSamoa and therefore was able to establish sovereignty over the land and political system. As abhorrent as the history of Samoa is, the people have come through relatively unscathed in comparison to other countries in the Pacific. They were not enslaved to work in the DHPG plantations, and in fact people were brought in from other countries to do this work. Samoans were eventually listened to by the New Zealand administration and the current government system reflects both aspects of fa'aSamoa and Western politics. Possibly the New Zealand administration released its grip on Samoa because the Samoans were clearly capable, intelligent, hardworking people who were not going to be bullied by external powers on their own land. This assertiveness and selfconfidence has carried through to today and is reflected in the way the government of Samoa works with donor countries. 


\section{CHAPTER FOUR: Methodology and Methods}

\section{Introduction}

Dr Konai Helu Thaman (2003) presented a paper at the 2003 Decolonizing Pacific Studies Conference hosted by the University of Hawai'i. In her presentation she addresses how the course - Pacific Studies - has been strongly influenced by Western, scientific and liberal thinking. The course after all sits in a Western academic structure of a university. What she suggested in her presentation was that although Pacific Studies is being taught in a Western setting, there is nothing wrong with teaching it with a Pacific flavour. What was notable about Thaman's presentation was her art of combining academia with anecdotal material, synonymous with the oral cultures of the Pacific that brings to life her topic in a way that reflects the Pacific. I have used this approach in my research. This chapter outlines what influenced my research and my methodology, and how I carried out my research - my methods.

\section{Influences to my research}

There are a number of research methodologies that have influenced this thesis. This next part will outline these influences and provide a synopsis of areas that I was able to draw on throughout my research.

I was mindful before I started this research that a methodology appropriate to Samoa and its context must be taken into consideration. I made careful decisions based on my upbringing and understanding of fa'aSamoa to ensure that my research was ethical and in no way discredited the Government of Samoa (GoS). Linda Tuhiwai Smith (1999), urges researchers in 'Decolonizing Methodologies' to use culturally appropriate practices and the conscious development of indigenous peoples as researchers. Smith (1999) strongly opposes researchers and intellectuals that

extract and claim ownership of our ways of knowing, our imagery, the things we create and produce and then simultaneously reject the people who created and developed those ideas and seek to deny them further opportunities to be creators of their own culture and own nations (Tuhiwai-Smith, 1999, p. 1). 
For many years the books produced in the Pacific were written by Western researchers who wrote from very Eurocentric perspectives that silenced, misrepresented and belittled the perspectives of the very people they studied. Examples of these are littered throughout most areas of research such as Pacific mental health (Tamasese, Peteru, Waldegrave, \& Bush, 2005), education (Taufeulungaki, Benson et al, 2004) and the development sector (Gegeo, 1998) (Gegeo \& Watson-Gegeo, 2002). In Thaman's (2003) early years as a lecturer she was told that an article she had written for a book was deemed unfit for publication because "there was too much of me in it; it was too different, too personal, and too Tongan" (Thaman, 2003, p.10).

Although I totally agree with my fellow Pacific researchers, I feel we must also be careful that as Pacific researchers we do not become elitist around who can and cannot research the Pacific based solely on skin colour and ethnicity. I feel that I can write with confidence about my topic not because I am Samoan (although beneficial) but because I place the perspectives of Samoans at the centre of this research.

\section{Worldviews}

"All things are subject to interpretation; whichever interpretation prevails at a given time is a function of power and not truth" (Nietzche cited in Cornwall, 2007, p. 471). To illustrate 'worldviews' I will use a personal example. Being married to a palagi woman and understanding each others' cultural norms has its challenges. We discovered this recently when my wife's aunt died. In my culture we would give money to assist with funeral expenses but when I suggested this to my wife she laughed and replied 'my aunt has way more money than us'. It was obvious to my wife that her aunt would have had an insurance policy and a funeral plan to cover the funeral expenses. In my culture the extended family is your insurance policy and funeral plan based on reciprocity. And even if the deceased did have an insurance policy or funeral plan in place (which is becoming increasingly more popular), the mere act of giving is about acknowledgement of lineage.

In order for me to accept my wife's view I had to look at the event through a Western lens which I found amusing. We turned up on the day of the funeral, gave a card to the husband of the deceased (with no money in it as I was told that if we did give 
money in the card they may have taken offence as it would appear to be a "handout'); in lieu of flowers we could make a donation to a chosen charity; attended a short service where there were only two speakers; followed by sandwiches and sausage rolls in the church hall as only immediate family were invited to the private cremation. This whole concept was foreign to me. For a Samoan funeral we spend every night together with the family of the deceased until the day of the burial; we contribute financially to the funeral expenses as well as buying flowers; we sit through hours of testimonies about the deceased from every member of the family the night before the burial during a family service and repeat everything again at the actual funeral service the next day; every man and his dog attends the burial followed by a lavish meal where there is always way too much food. When we look at this example, both my wife and I viewed the same event with very different lenses based on our respective cultures and upbringings. Here is an example of two people, similar generation and both raised in New Zealand but with very different 'worldviews'.

In O'Leary's (2004) 'The Essential Guide to Doing Research' she states "[w]e make sense of the world through the rules we are given to interpret it. But because we are immersed in these rules and surrounded by them, they can be very hard to see" (O'Leary, 2004, p. 46). Understanding worldviews therefore helps researchers to avoid the trap of judging others reality in relation to their own reality (O'Leary, 2004, p. 47).

\section{Ontology}

To understand worldviews it is important to unravel why humans react so differently to similar topics. Mathez-Stiefel et al (2006) state that human actions are an expression of "culturally constructed nature-society relationships that result from a set of symbolic representations, value systems, tacit and explicit forms of knowledge and practice." (Mathez-Stiefel et al, 2006, p.70). This can be referred to as ontology, a branch of philosophy that explains what exists or the state of 'being' (Uphoff, 2005). When my wife's family visit us, our four-year-old twins are at the centre of lounge and we sit and watch how they play, interact, dance and sing to each other and to us. When our twins are with my family my parents are at the centre of the 
lounge and the children are at the periphery. No one way is correct as both have their positives and negatives depending on which lens you are looking through.

\section{Epistemology}

Seemingly more interest and work has been put into understanding epistemologies by Gegeo (1998); Batibasaqa et al (1999); and Gegeo \& Watson-Gegeo, (2002). Often ontology and epistemologies are lumped together but epistemology is how knowledge is created and reproduced. Indigenous epistemologies proposed by Gegeo (1998) are essentially a cultural group's way of thinking and of creating and reformulating knowledge using traditional discourses and media of communication and anchoring the truth of the discourse in culture. Indigenous epistemology assists practitioners to fundamentally change the understanding of strategies for development. Indigenous research ideologies such as Kaupapa Maori, as stated by Tuhiwai-Smith (1997) encourage researchers engaging with indigenous people to ask the following questions: "Whose research is it? Who owns it? Whose interests does it serve? Who will benefit from it? Who has designed its questions and framed its scope? Who will carry it out? Who will write it up? How will its results be disseminated?" These questions will form the basis of my talanoa.

\section{My positionality}

I will use the concept of 'positionalities' to assist in interpreting my frame of reference and beliefs. Knowing my birth place, education, gender, personal beliefs, employment, culture, political following, and religion will provide a framework for my research, for the purpose of this research "it is important to leave no stone unturned" (Hutchings, 2010, lecture).

I am a first generation New Zealand-born Samoan raised in the suburb of Te Atatu South in West Auckland. My mother is the educated daughter of Rev Aloali'i and Sa'ilele Fuimaono who were Methodist church ministers in Samoa. My mother is a registered midwife and a trained teacher who taught for most of my life until her retirement. My mother is from Salani in Falealili, the fa'alupega (constitution) for Salani is:

Afio le Gafatasi

Le Fetalaiga ia Tofua'iofoia 


\section{Le mamalu ia Sata'eleaga}

Fa'apea fo'i Salani ma Alofisula ${ }^{4}$

My father is from Toamua in Faleata and the fa'alupega for Toamua is:

\section{Tulou le paia aua Ulu ma Ale}

Leitulua o Sa Tunumafono

Le Gafa o A'atoe

Ma le Fetalaiga i le Va'aulu ${ }^{5}$

My father is the son of an orator Ulu Kini and Ta'atele Ulu who served their families through cultural duties within the extended family. Although my father does not have any formal qualifications he was labelled by a family friend as 'street-wise' and is a very gifted orator. My parents returned to Samoa to retire in 2004.

I am the middle child of four boys and one girl. The older three boys are close in age with a seven year gap between my younger brother and me leaving my sister as the baby. As my mother was an educator there was no choice for us but to attend university after secondary school. She even went as far as choosing careers for the three older children; my eldest brother would be a church minister, my second brother a lawyer and me a teacher. We fulfilled her wishes just as she planned. My younger brother is also a university graduate.

Like a lot of first generation New Zealand-born Samoan children, although we grew up in New Zealand speaking English and attending a Western school, when we arrived home everything was Samoan. For Samoans living in New Zealand church was more than religion, the Pacific Island Presbyterian Church in Glen Eden became our surrogate village and essentially our community. For years I thought I was related by blood to the families at church because we attended each other's birthdays, weddings, funerals and my parents also contributed financially to these events. I was immersed in the Samoan culture from a young age, learning how to dialogue in gagana (language) Samoa, read the Samoan Bible, understand my place

\footnotetext{
${ }^{4}$ This constitution pays homage to the high ranking titles of the village of Salani.

${ }^{5}$ This constitution pays homage to the high ranking titles of the village of Toamua.
} 
as a son and respect cultural values. I lived and breathed being Samoan and frequently visited the islands as a child.

After secondary school I studied for my undergraduate degree at Victoria University of Wellington and completed a Bachelor of Arts in History followed by a Diploma in Secondary Teaching from the Auckland College of Education. After teaching I moved to Samoa and lived and worked in Samoa. It was during my time in Samoa that I was fortunate to develop networks with the Samoan government officials that I interviewed for this research. I returned to New Zealand after a year and a half in Samoa to start a job with Volunteer Service aboard (VSA) where I currently work as the Programme Manager (Polynesia). I have worked at VSA for nine years and I travel to Samoa frequently for work and pleasure. I am married to a palagi woman and together we have fraternal boy/ girl twins. We have been members of Destiny Church for the past nine years.

\section{Methodology}

I am constantly reminded as a development practitioner never to operate in a deficit model. Words like sustainability, capacity building, skills exchange imply that the donor is in the position of power when in fact in a local setting recipient countries already have a wealth of experience and knowledge. As outlined by Gegeo and Watson Gegeo (2001): "Around the world today indigenous ethnic groups are asserting the validity of their own ways of knowing and being, in resistance to the intensifying hegemony of mainstream epistemology from the metropolitan powers" (Gegeo \& Watson Gegeo, 2001, p.55).

Research methodologies are forever evolving (Tamasese et al, 2005, Smith, 1999); Pacific people in New Zealand have become part of the professional, educated, middle-class as well as leaders within politics, education, sports, church, university, law, medicine and the arts. It is because of these individuals, who have paved the way for researchers like me, I have a buffet of methodological options to choose from to answer my research question. I have selected a series of methodologies from both Western and Pacific researchers to form the basis of my methodology. 
My research sits in a qualitative research paradigm (Tuafuti, 2011). Qualitative research has progressed over time. Traditional academic research was dominated by scientific methods (Lichtman, 2006) but researchers such as Lincoln and Guba (1985) suggested that research be carried out in natural settings rather than in laboratories.

Quantitative studies were traditionally heralded as the preferred methodology in academic settings. I am not discrediting this methodology but as we know in development 'one size does not fit all', and thankfully qualitative research is considered just as legitimate. Qualitative research is described by Lichtman, (2006) as 'fluid and ever-changing'.

I have taken two of the three common characteristics about qualitative research from Tuafuti (2011) to cement my reasons for choosing this research paradigm. First is 'naturalistic inquiry': "behaviour and the sharing of real-life experiences are best understood when they occur in natural settings, as the interpretation and meanings of shared experiences rely heavily on contexts" (Tuafuti, 2011, p. 35). My interviews took place in both Samoa and New Zealand with Samoans and donor representatives. Being in Samoa positions the interviewees in a familiar setting and provides context to the local situation.

Secondly 'collaborative inquiry' is adopted: the view that all those involved in the research are co-researchers and everybody is included with genuine collaboration. Collaborative inquiry does not only include those that are being interviewed but also fellow researchers. My research will contribute to a larger body of research (Overton et al, 2012). Wrighton (2010) carried out a similar research on Tuvalu and I have collaborated quite closely with Wrighton (2010) on what worked and did not work for her research. This advice has been invaluable to answer my research question.

My methodology is also influenced by Anae et al, (2010) on the Samoan cultural concept of teu le va which is being used by the Ministry of Education to address the low attrition rate of Pacific children in New Zealand. Teu le va places emphasis on working together and sharing power. It makes a conscious effort to move away from underachievement but focuses on everyone "taking responsibility for optimising 
education outcomes for and with Pasifika learners." (Anae et al, 2010, p. 5). Teu le va in fa'aSamoa is about respect and knowing your place. Samoa is very hierarchical and in every family there are duties that are carried out by parents, sons and daughters. When we grew up we knew our place. If there was a lunch after church we knew the routine. The parents always ate first. When they finished, a bowl of soapy water was brought to them to wash their hands and their plates were cleared away. It was not until the last adult was full that we were allowed to eat. Even after I returned with a university degree and I was teaching I was still considered a young person. Teu le va is essential when interviewing Government of Samoa officials for my research. These are people that are considered very senior in their roles and if I am not respectful in my approach interviews will be cut short with no room for redemption. Samoans do not like it when people ask questions with ulterior motivations. This is deemed as being fiapoto (someone who thinks they know what they are talking about but in actual fact do not). I am also mindful of respectful ways of addressing my interviewees and, as I speak fluent Samoan, I conducted the interviews bilingually.

I acknowledge that the outcomes of this research strongly favour the GoS officials as having development policy sovereignty when working with donors. My own cultural background may suggest that I show a bias to Samoa. I do not deny that I am proud of my heritage and my positionality has clearly influenced my methodology. However my findings are a direct reflection of GoS officials and donor interviews that conclude the GoS has development policy sovereignty.

\section{Methods}

The methods that I used for this research were semi structured interviews influenced by talanoa; a review of the GoS development policy, and my own observations I have made as a researcher.

\section{Interviews/ Talanoa:}

To explore how the GoS has asserted development sovereignty when dealing with donors I chose semi structured interviews. I have blended the established Western method of interviewing with talanoa. There is not a lot of literature documented about talanoa - which literally means 'talk' (Otsuka, 2005). Gegeo (1998) says that talanoa 
could mean different things to different societies. There are therefore no hard and fast rules established around how talanoa is conducted as a research method.

Talanoa means 'talk' or 'discussion' (Robinson \& Robinson, 2005). Vaioleti (2006) summarises talanoa as speaking broadly in both a formal and informal manner but without a rigid framework. This does not suggest that the content of the conversation is not important, in fact I found that when my interviews were not rigid that the participants were more willing to share anecdotal information that supported my thesis. This is where Vaioleti (2006) suggests that talanoa offers discussions that are multilayered and critical to the research.

Relationships are important in talanoa. Otsuka (2006) encourages researchers to have good interpersonal relationships with the researched. Otsuka (2006) proposes to researchers that through talanoa it moves away from a surface interview process but encourages the interviewer to engage emotionally with the interviewee.

I conducted 17 interviews: eight were GoS officials, four from the private sector; one from civil society, three from the donor community and one an independent researcher. Two of my interviews were conducted in New Zealand and 15 were conducted in Samoa.

As a frequent visitor to Samoa and having lived and worked there for one and a half years my research in Samoa took place over two weeks. Having a full-time job with a busy travel schedule as well as a young family I was only able to afford a two week window to undertake my field research.

I was fortunate that I had worked, studied or am related to most of my participants so it made it easier for me to connect with people. I had organised all of my interviews in Samoa prior to my departure. With good telecommunications in Samoa I was able to ring all my participants and follow up with an email confirmation of a time, venue, as well as attaching a brief about my topic and consent form (see Appendix 1 and 2). I took extra printed copies with me as I know that people are always busy and may not have had the chance to read my email prior to my arrival for the interview. 
From experience if you are not a high level diplomat or a Prime Minister it is advisable to organise an interview schedule for countries in the Pacific a week or two out from departure. This can be challenging as it poses the risk of no one being available for your interviews. However I have learned from wasting countless hours and sitting in waiting rooms around the Pacific after having organised a meeting schedule a month out from arrival. People are busy in all countries and as I am not a VIP the reality is I may not feature on people's priority list no matter how much I rate myself. Booking interviews a week or two from your arrival in-country means that you are fresh on the calendar or minds of the participants. To combat the risk of participants forgetting their interview times and schedule, I asked for up to date mobile numbers to reconfirm appointments once in Samoa. The Digicel mobile network is cheap and reliable so most Samoans have a mobile phone. Armed with my interview schedule and mobile phone upon arrival in Samoa I called each participant the day before their appointments with a friendly reminder. If people were not available I simply changed the schedule to suit them.

For Samoans, gatherings are centred on food; I wanted my participants to feel relaxed so that I could get some good examples of development sovereignty. Where possible I wanted to conduct interviews away from their normal places of work, but not all were able to do this so I held meetings at their office space. I conducted the majority of my interviews over breakfast, lunch or dinner at either restaurants in town or at my parents' home in Toamua which was vacant at the time. The interviews were low key and I wanted to create a comfortable atmosphere for people to relax. If I was unknown to the interviewee I was first asked about my parents and their villages. Before long both parties were able to establish lineage and connections no one else understands. As I knew most of my participants we mixed the interviews with general catch-ups. For those that I did not know so well I was keen to establish a relationship. A huge part of the interviews was getting to know each other's background. I did not want to 'use' the participant for my benefit but I wanted them to know that I valued their time and stories. I did not place a time limit on the interviews.

One of my main interviews started at $2 \mathrm{pm}$ and finished at $11 \mathrm{pm}$ over dinner. I could have carried on all night but I was mindful it was a work night for the participant who had an extremely busy schedule. I conducted no more than three interviews a day 
and some interviews were by accident. Whilst catching up with some family and friends over meals and being asked about my research topic, stories of development sovereignty started to emerge so the catch up ended up becoming an interview with participants signing consent forms. This occurred with two different participants, one from the private sector and one from the GoS.

As Samoa is a small country I was keen to protect the identity of the participants. Each participant was the given the option to remain anonymous. Some chose to for the protection of their respective organisations, mainly the donors, while others in more senior roles of the GoS were happy to release details of their identity. I decided for the sake of each individual, as well to ensure I would not harm existing relationships in Samoa, I would keep all identities of my participants anonymous. Each participant will be referred to as either GoS (Government of Samoa); PS (Private Sector); CSO (Civil Society Organisation); D (Donor) or I (Independent) and a number reflecting the order of each interview (Appendix 3). I left out details that would identify the person or their organisation, particularly the CSO and donors as it would not be difficult to identify who they are being that there is only one CSO participant and three donor participants. There were some examples from my findings that referred to other countries in the Pacific region, I have been careful not to reveal the identity of these countries as it could harm the GoS's relationships.

All the participants were senior staff within their respective organisations. I had prepared a list of questions (see Appendix 4) to guide my interviews and in all cases I was flexible in its use. I found that some answers led to other interesting lines of enquiry so I pursued a different tangent. All the participants had different experiences so I wanted to make sure that I captured this and was not bound by my prepared questions. I had become familiar with my line of questioning and by the third interview I did not even refer to the questions page. For some interviews I did not use the questions at all, particular for the two interviews that were unplanned and evolved out of conversations.

It is natural, particularly for educated Samoans and some Samoans that have grown up outside of Samoa (if they have learned their mother tongue), to speak in both English and Samoan. My interviews with the Samoans participants were therefore 
conducted bilingually. I have been travelling over the last nine years in the Pacific as part of my role at VSA and developed volunteer assignments with partner organisations through meetings and taking notes. I therefore decided not to record any my interviews but I took notes throughout the interviews being sure to ask the participant to repeat lines if I felt I had missed something. As a result I was still able to use direct quotes from my participants.

\section{Review of GoS documentation:}

I looked at a number of the GoS's documents that are reflected in chapter six. The documents were either found on the official Government of Samoa website (Government of Samoa, 2012a) or provided to me by GoS officials. These documents include: Development Cooperation Policy Partners in Development: Promoting Aid Effectiveness; Evaluation of the Paris Declaration on Aid Effectiveness and the Accra Agenda for Action; the Millennium Development Goals: Second Progress Report. Prepared by the National Task Force with support of the UN System; Strategy for the Development of Samoa 2012 - 2016; and two Tsunami 2009 reports. I also reviewed documents from major donors in Samoa such as the New Zealand Aid Programmes Joint Commitments for Development with the GoS. A review of the documentation is reflected in chapter six.

\section{My personal observations:}

As a New Zealand born Samoan I have had a long-standing involvement in the Pacific community in New Zealand and the Pacific. In social research terms, I could be considered as both an insider and an outsider, exercising objectivity and subjectivity. I have intimate knowledge of Samoa which is balanced with an evidence-based approach to the research utilising the methods listed above to identify my findings. A rigorous process of debate and discussion was part of the research process with my supervisor 'interrogating' my results to ensure rigour in my observations.

\section{Conclusion}

A number of methodological research approaches have influenced my thesis. I was keen to ensure that the Government of Samoa were at the centre of this research. Having being been influenced by worldviews, ontology, epistomology and positionality I was able to identify a methodology appropriate to my context but also 
being able to present a credible piece of research. A qualitative methodology was most appropriate and understanding the Samoan culture and language played a big part in choosing this methodology. The methods chosen were semi-structured interviews through talanoa of representatives of the GoS, private sector, CSO, donors and independent researchers; reviewing of GoS documentation and my own observations as a development practitioner. Through these methods I was able to acquire the relevant information in the following chapters to answer the aim of this research. 


\section{CHAPTER FIVE: The Government of Samoa and Aid}

\section{Introduction}

My field research highlighted some very interesting examples of the way the Government of Samoa (GoS) asserts their development sovereignty when working with donors. To provide contextual background to the findings this chapter will look specifically at an overview of the current status of the GoS with specific reference to how aid is delivered and managed for Samoa. I will then look at the Samoan economy and discuss donor contributions to further build the picture of development sovereignty.

\section{The Government of Samoa}

Samoa is currently governed by the Human Rights Protection Party (HRPP) who has been in power since 1982 aside from a brief period between 1986 - 1987 when internal differences forced them into a coalition (So'o, 2005). HRPP was set up by Vaai Kolone (Samoa's Prime Minister 1981, 1986-87) in 1979 and was the first political party established post-independence (So'o, 2012). There have been several different political parties that have been established and have since collapsed. Following the 2011 elections, HRPP currently holds 36 seats and the Tautua Party 13 seats (So'o, 2012).

The current Prime Minister since 1998 and leader of HRPP is Tuila'epa Sailele Malielegaoi, the longest serving Prime Minister in both Samoa and the Pacific region. Malielegaoi grew up in the village of Lepa (a village on the South Coast that was severely affected by the 2009 tsunami). Malielegaoi has a Bachelor of Commerce and Master of Commerce from Auckland University. Before Malielegaoi entered parliament he was posted to Brussels and worked as a treasury department official for the African Caribbean and Pacific (ACP). He has also held a position at the World Bank gaining familiarity with their financial systems. Malielegaoi's economics background has been reflected in his government portfolios: Minister of Finance, Minister of Foreign Affairs and Trade, and Minister of Tourism.

Samoa has thirteen government ministries (see appendix 5). Each ministry has a Minister elected from Cabinet, a Chief Executive Officer and depending on the size 
of each Ministry there may be a tier of Deputy Chief Executive Officers. Every Ministry has a tier of Assistant Chief Executive Officers, Principal Officers, Senior Officers and Officers, the entry level position for recent graduates, as well as administration and service staff. All government departments are guided by the Strategy for the Development of Samoa.

Any form of Overseas Development Assistance with donors, line ministries, government corporations and CSOs in Samoa is coordinated through two mechanisms - the Cabinet Development Committee (CDC - revitalised in 1988) and the Aid Coordination Committee (ACC) with its operating arm, the Aid \& Debt Coordination Division of the Ministry of Finance (Government of Samoa, 2010c).

The CDC has a membership of 72 comprising Ministers of Cabinet, Associate Ministers, Chief Executive Officers of all government ministries and corporations, and a representative of the CSOs. The CDC is chaired by the Prime Minister and the Economic Planning and Policy Division of the Ministry of Finance is the secretariat. The Cabinet Development Committee appraises all new proposals, approves policy frameworks and monitors progress of implementation (Government of Samoa, 2010b).

The ACC has a membership of seven, is chaired by the Prime Minister and the Aid Coordination/Debt Management Division of the Ministry of Finance is its secretariat. Its key role is the coordination of all development cooperation in particular the allocation of resources should external funding be required (Government of Samoa, 2010b).

To ensure that aid reaches all sectors in Samoa, the private sector is represented by the Chamber of Commerce: "[i]ts main role is to interact with the government on key policies affecting the private sector and provide feedback on key strategic areas that need development interventions" (Government of Samoa, 2010a, p. 34). The Samoa umbrella for NGOs (SUNGO) officially represents CSOs and channels information between CSOs and the GoS. 
The main functions of the Ministry of Finance are to provide policy and strategic advice as well as financial services to support the Strategy for the Development of Samoa 2012 - 2016. The Ministry of Finance is divided into three different departments and the Aid and Debt Coordination Division sits in the Policy Management Department. There is a team of seven staff members managed by a very experienced and long serving Assistant CEO. It was felt the Economic Aid Division, which sat within the Ministry of Foreign Affairs in the mid-1980s, was not very effective. It was moved to the Ministry of Finance in 2003 as part of a restructure and renamed the Aid Coordination and Debt Management Division. The Debt Management Unit was established in 2010 as a result of a Medium Term Debt Management Strategy. Initially positions for the unit were to be filled externally by a contracted position, however the tenders were too expensive and the Ministry of Finance realised it had the experience to "develop in house capacity to monitor the overall level of Government debt including, domestic and external debt ... for which Government is responsible, and to undertake debt sustainability and risk analysis" (Government of Samoa, 2011a).

\section{The economy of Samoa}

Samoa's economy is based on subsistence living with trade based on a system of reciprocity that includes all levels of the Samoan social hierarchy (Claessen \& van de Velde, 1991). This is supplemented and interconnected with a long established and expanding market economy.

Western influences have impacted the Samoa economy in a major way. Capitalism, colonialism and the world market system were introduced alongside the advent of new diseases, alcohol, firearms, the coconut oil and copra trade, the labour trade, the introduction of wage employment, and the establishment of colonial administrations. The result has been a modern economic sector dominated by Europeans and monopolised by immigrant Asians. In many ways Samoa was fortunate in that it lacked mineral resources, had limited land, very small markets, and was protected by missionaries and administrations. These conditions coupled with a strong social structure that has been reasonably unchanged meant they were relatively left alone by foreign interests (Watters, 2008). The strength of fa'aSamoa that clashed with Western economic systems acted as a protector of the Samoa 
economy. "The narrow scope for individual enterprise in a Samoan-type society has been criticised by economists and geographers who note that the matai system inhibitied social deviancy, discouraging innovation or the accumulation of individual savings" (Watters, 2008, p. 62).

Since independence the Samoan economy has been fairly dependent on aid, reinforcing Bertram and Watters (1985) MIRAB theory that claims "remittances and foreign aid are the main economic resources of the local economy" (Poirine, 1998, p. 65). When Samoa became independent many Samoans took advantage of employment opportunites in New Zealand, helping the New Zealand economy with its labour shortage and assisting families back in Samoa with the "desired cash income because of their increasingly cash-based economy" (Va'a et al, 2012, p. 107).

My father and his three brothers moved to New Zealand during the 1960's. My father repeatedly told us of the story of keeping a third of his weekly pay to live on and sending the rest to his father in Samoa to clothe and feed the aiga. I believe his intention for telling the story was for us to do the same once we started working. It became the desired option for most Samoans to move to New Zealand for a better life.

The GoS since independence has striven to manage the impact of Western influences on their comparitively small community (OECD, 2011). Samoa has had a series of Five Year Development Plans dating as far back as 1966. The earlier plans 1966-1970 and 1971-1975 focussed on the building of Apia town and its supporting infrastructure including the wharf, airport, telecommunications services, electicity and water supply (Va'a et al, 2012). It is estimated that $52 \%$ of the current population live in the Apia town area today (2006 Census). Agricultural development was the backbone of the Samoa economy as reflected by the German DHPG plantations in the late 1800s. The now University of the South Pacific (USP) Alafua campus specialising on agricultural development was set up in 1966 to "accelerate the training of agricultural specialists" (Va'a et al, 2012, p. 97).

In 1971 Samoa was classified by the UN as a 'Least Developed Country" (LDC)' but is expected to graduate to 'Developing Country' status by 2014 (Community Scoop, 
2012). As part of the LDC classification Samoa welcomed a large number of donors to its shores including multilateral institutions such UNDP and the Asian Development Bank (ADB). These donors provided significant funds to the Samoa economy, assisting to end a "25-year period of little economic change" (Va'a et al, 2012, p. 108).

From 1976 to 1980 the focus of the development plans was agricultural export production and tourism to encourage foreign exchange which enabled the importation of consumer goods. Tourism was inspired by the 1983 South Pacific Games with more infrastructure development (Va'a, Va'a, Fuata'i, Chan Mow, \& Amosa, 2012).

The International Monetary Fund (IMF) entered the scene in the early 1980s when Samoa's economy was looking grim with the prices of its major export crops (copra and cocoa) being unstable in the world markets and impacting on exports (World Bank, 1991). The Samoan economy was not in a good way failing reviews from the World Bank due to significant economic mismanagement of funds by public servants (World Bank, 1991). As a result "[f]rom 1989, Samoa embarked on a number of reforms to encourage growth of the private sector and foreign investment. The programme of privatisation and corporatisation concentrated on a few operations with investor potential, most notably the telecommunications sector" (Va'a et al, 2012, p. 109). As part of privatisation Yazaki EDS Samoa (a wiring harness manufacturing plant) was set up in 1991, employing up to 1000 Samoans and turning over approximately 110 million Samoan tala per annum, therefore providing considerable net income to the Samoan economy (Yazaki, 2010; Pacific Islands Trade and Invest, 2009)

The cyclones in 1990 (Ofa) and 1991 (Val) and the 1993 collapse of Samoa's leading export crop (taro) due to an introduced leaf blight have had severe economic impacts on Samoa with a decline of approximately $50 \%$ of Samoa's GDP between 1989-1991 (World Bank, 1991). Aid coordination and aid effectiveness terms were used with even more donors assisting with disaster relief and continued development work. In the 1990s the GoS put in place economic reforms "including the liberalisation of exchange controls and the institutionalisation of strategic 
planning" (Va'a et al, 2012, p. 110). The European Union became a player in Samoa's economy during the 1990s.

A major earthquake in 2009 measuring 8.5 on the Richter scale precipitated the tsunami that followed, claiming the lives of 143 people. This cost the country over $20 \%$ of GDP recovering infrastructure, resettling communities and re-establishing services to the affected areas. It was reported that 850 households spread over 51 villages were affected by the tsunami (Government of Samoa, 2010c). Tourism was directly impacted by the tsunami which damaged $25 \%$ of Samoa's tourist accommodation.

Samoa's current economy is dependent on tourism, agriculture, fisheries, remittances and external development assistance (Government of Samoa, 2010b). Between 2000 and 2011 remittances averaged about $23.6 \%$ of the Gross Domestic Product (GDP) amounting to SAT\$348.4 million (Government of Samoa, 2012). Tourism made SAT\$297.4 million which was $20.1 \%$ of GDP. By comparison external development assistance and concessionary lending in the 2010/2011 financial year made up $37 \%$ of the Government of Samoa budget (NZ Ministry of Foreign Affairs and Trade, 2012).

Samoa's major exports are fresh fish, coconut oil and cream, copra and nonu juice which amount to approximately SAT\$30.4 million per annum (Government of Samoa, 2011). Samoa imports a large amount of food items, petrol and manufactured goods (Government of Samoa, 2010b). Economic growth is a priority area for the Strategy for the Development of Samoa (SDS) (2012) that is driven by commerce, transport, communications and construction (Government of Samoa, 2010b).

Samoa's GDP in 2011 was US $\$ 505.8$ million with a composition of $10 \%$ primary sector, $22 \%$ secondary and $68 \%$ tertiary. GDP per capita in 2009 was US $\$ 3,121$. Samoa ranks $99^{\text {th }}$ of 187 in the Medium Human Development Index in 2011 up five places since 2010. Figure 4 below reflects the amount of funding per donor, showcasing the huge contribution of aid to Samoa. "This increase reflects Samoa's increased capacity to effectively utilise ODA, increased confidence by donors in 
Samoa's political, economic and social stability, as well as donor responses to disasters such as the 2009 tsunami" (Government of Samoa, 2010, p. 31).

Figure 4: ODA from Donors in Samoa

\begin{tabular}{|l|l|l|l|}
\hline SAMOA & $\mathbf{2 0 0 8}$ & $\mathbf{2 0 0 9}$ & $\mathbf{2 0 1 0}$ \\
\hline Receipts & 40 & 77 & 147 \\
\hline Net ODA (USD Million) & $59 \%$ & $56 \%$ & $58 \%$ \\
\hline Bilateral share (gross ODA) & $7.2 \%$ & $16.1 \%$ & $27.1 \%$ \\
\hline Net ODA/ GNI & 38 & 12 & 22 \\
\hline Net Private flows (USD million) & & \\
\hline
\end{tabular}

\begin{tabular}{|l|l|l|l|}
\hline For reference & 2008 & 2009 & 2010 \\
\hline Population (million) & 0.2 & 0.2 & 0.2 \\
\hline GNI per capita (Atlas USD) & 2880 & 270 & 2860 \\
\hline
\end{tabular}

Source: (OECD, 2011)

\section{Donors}

Samoa receives aid from around 23 donors in the form cash grants, soft term loans, in-kind grants, and technical support from volunteer sending agencies such as Volunteer Service Abroad and the US Peace Corps (Government of Samoa, 2011a). Aid effectiveness and the principles of the Paris Declaration (2005) guide Samoa's interactions with donors.

Since independence New Zealand has been a major bilateral ${ }^{6}$ donor to Samoa, along with Australia, Japan, and China. All four bilateral donors have offices in Samoa. There are six key multilateral ${ }^{7}$ donors operating in Samoa, the World Bank administered from Australia, Asian Development Bank - administered from Fiji and Australia, the United Nations Development Program, World Health Organisation (WHO) (which both have offices in Samoa), the European Commission (EC), and Organization of the Petroleum Exporting Countries (OPEC) who Samoa has recently re-engaged with. The International Monetary Fund has been involved in Samoa since the early 1980s (Government of Samoa, 2010a).

Figure 5 below shows the top ten donors in Samoa and their contribution to the Samoa budget between 2009-2010.

\footnotetext{
${ }^{6}$ Bilateral refers to aid given from one country to another country.

${ }^{7}$ Multilateral refers to aid given from two or more countries.
} 
Figure 5: Top 10 donors of gross ODA to Samoa

\begin{tabular}{|l|l|l|}
\hline & $2009-10$ average & USD m \\
\hline 1 & Australia & 30 \\
\hline 2 & Japan & 21 \\
\hline 3 & ADB Special Funds & 19 \\
\hline 4 & New Zealand & 14 \\
\hline 5 & IDA (International Development Agency) & 14 \\
\hline 6 & EU Institutions & 10 \\
\hline 7 & IMF (Concessional Trust Funds) & 4 \\
\hline 8 & GEF & 2 \\
\hline 9 & United States & 1 \\
\hline 10 & UNDP & 1 \\
\hline
\end{tabular}

Source: (OECD, 2011)

There are a number of regional organisations based in Samoa: Food Agricultural Organisation (FAO); United Nations Educational, Scientific and Cultural Organisation (UNESCO); European Union (EU); Secretariat of the Pacific Regional Environment Programme (SPREP) and Japan International Cooperation Agency (JICA) (Government of Samoa, 2011b).

Figure 6 provides a snapshot of the development funding to Samoa based on 2005 and 2010 statistics. The figures highlight an increase in ODA between these periods.

Figure 6: Development Funding

\begin{tabular}{|l|l|l|l|l|l|l|}
\hline $\begin{array}{l}\text { Type of } \\
\text { Development }\end{array}$ & \multicolumn{2}{l|}{ Domestic Source (SAT) } & \multicolumn{3}{l|}{ External Source (SAT) } & \multicolumn{2}{l|}{ Key Sectors } \\
\hline & 2005 & 2010 & 2005 & 2010 & 2005 & 2010 \\
\hline Capital & $41.41 \mathrm{~m}$ & $60.55 \mathrm{~m}$ & $605.68 \mathrm{~m}$ & $855.05 \mathrm{~m}$ & Construction & Electricity \\
\hline $\begin{array}{l}\text { Technical } \\
\text { Assistance }\end{array}$ & $15.93 \mathrm{~m}$ & $22.48 \mathrm{~m}$ & 171.04 & $614.07 \mathrm{~m}$ & $\begin{array}{l}\text { Public } \\
\text { Administration }\end{array}$ & Education \\
\hline $\begin{array}{l}\text { Recurrent } \\
\text { Costs }\end{array}$ & $2.47 \mathrm{~m}$ & $7.19 \mathrm{~m}$ & $34.57 \mathrm{~m}$ & $116.22 \mathrm{~m}$ & & \\
\hline Totals & $59.81 \mathrm{~m}$ & $90.22 \mathrm{~m}$ & $811.29 \mathrm{~m}$ & $1585.34 \mathrm{~m}$ & & \\
\hline
\end{tabular}

Source: (Government of Samoa, 2010a, p. 30)

I worked in Samoa from $2002-2003$ for the New Zealand aid programme managing the scholarships scheme. It was at this time that the GoS recognised it was 
shouldering a large administrative burden due to the Pacific Regional Awards ${ }^{8}$ offered by New Zealand and Australia. The Pacific Regional Awards were similar but the GoS was expected to complete two different reporting systems and manage the awards using two different guidelines. This was an early example of development policy sovereignty. Work started in early 2003 to harmonise both procedures and limit the duplication of work by the GoS Scholarships Division of the Ministry of Foreign and Trade. Modalities of aid delivery have shifted significantly since 2003, "[a]II bilateral donors (apart from China and Japan), the EU and the UN agencies use Samoa's own country systems to varying degrees" (Government of Samoa, 2010a, p. 37).

High level talks to discuss the commitments of donors are undertaken annually with a mid-term review factored in to discuss progress and challenges. The GoS holds quarterly aid consultation meetings in-country with all donors. Some donors such as New Zealand and Australia have developed joint commitments with the GoS. This is a move away from longer documentation that is never read or understood to shorter (eight page) summaries of a shared vision for achieving long-term development outcomes.

The major factors supporting this shift to joint assistance strategies by New Zealand and Australia have been their historical involvement with aid programming in Samoa, the synergies in the areas they selected to be involved in, the similarity in their systems and processes, and their familiarity with the constraints in the government's systems and processes" (Government of Samoa, 2010a, p. 46).

In the early to mid-90s a public sector reform programme was undertaken to improve the GoS's systems.

In 2006 a review of the GoS's Public Financial Management (PFM) was undertaken over two weeks by external consultants using the internationally recognised Public Expenditure Financial Accounting (PEFA) methodology. Reviews of this nature are undertaken every three years to monitor the robustness of developing countries' PFMs. The outcome of the review was not accepted by the GoS based on the time

\footnotetext{
${ }^{8}$ In 2001 the Pacific Regional Awards refer to scholarships offered by the New Zealand and Australian Governments to students that have successfully completed their University Preparatory year at the National University of Samoa. The recipients of the awards are based on the students overall grade and their academic ranking against other students of the same year.
} 
spent by consultant's in-country and the lack of consultation with relevant stakeholders to provide contextual advice. In 2009 the GoS undertook a selfassessment with workshops and meetings with a large number of stakeholders. The findings showed that although there are a number of areas that could do with improvement, the GoS PFM is fairly comprehensive and transparent. Evidence of the successful impact of Institutional Strengthening Programmes (ISP) assists in the improvement of the GoS PFM.

As Samoa has a relatively robust financial system donors feel confident in the use of the GoS PFM. Several donors such as AusAID and the New Zealand aid programme are using more elements of government systems, but other major donors including China and the EU currently use only their own systems. Both the WB and the ADB require additional approval for purchases above a certain amount (Government of Samoa, 2011a, p. VI). Budget support continues to be the modality that some argue as the Mecca of all aid modalities (Lister \& Nyamugasira, 2003). The fairly robust GoS PFM is a contributing factor for the EU providing $85 \%$ of its assistance in the form of sector budget support for the 2009/10 financial year (Government of Samoa, 2011a). The GoS received five million dollars from Australia and one million from New Zealand in sector budget support (Simi, 2012).

\section{Conclusion}

This chapter lays a foundation for this research findings and has outlined the structure of the GoS and how aid is managed. There has been particular attention paid to the Samoan economy to build a picture of the huge contribution aid has on the GoS budget. It also highlights what was happening on an international scale economically at the time and how this has impacted the GoS. Samoa does not have any real mineral resources or land which has made them less of a target to foreign investors. As a result Samoa has been able to retain its culture and traditions of fa'aSamoa leading to a relatively positive relationship with donors. The GoS has proven to donors, through its systems and processes, it is a trustworthy aid recipient. It has learnt from past mistakes and now has a well educated and well informed public service which, this research will show, has development sovereignty when working with donors. 


\section{CHAPTER SIX: GoS sovereignty through development policy}

\section{Introduction}

From the research findings it was highlighted that the GoS has implemented development policy into its aid programme. This chapter will start by looking at Samoa's involvement with development policy on a global scale, the GoS's involvement in development policy on a regional scale and then finally look at how the GoS has implemented development policy on a national scale. The aim of this chapter is to provide examples of how the GoS asserts its development sovereignty through policy and how the GoS engages with the global level and translates this into its own policy.

\section{Development Policy Globally}

As mentioned in chapter two, the Paris Declaration on Aid Effectiveness (2005), the Accra Agenda for Action (2008) and the Busan Partnership for Effective Development Co-operation (2011) were key high level forums that aimed to strengthen the partnership between donors and recipient governments. The main objective of the forums was to make aid more effective leading to improved development work. The GoS did not formally endorse the Paris Declaration until 2008 (just before the Accra Agenda for Action summit) but the Paris Declaration legitimised its government reform agenda that had started in the early '90s (Government of Samoa, 2010a).

The GoS took part in an independent evaluation of the implementation of the Paris Declaration and Accra Agenda for Action in the Samoan context in 2010. The evaluation was undertaken by local and overseas consultants as a global appraisal of international aid since 2005. The evaluation helped to identify whether signatories of the Paris Declaration working in Samoa were meeting their commitments (OECD, 2011c). The evaluation included a wide representation of all sectors within Samoa and the results, although not perfect, indicated the GoS was on the right track to meet the five Paris Declaration principles (see chapter 2). The GoS is much further ahead in the first three principles of the Paris Declaration than the last two. Each of the five principles in Samoa can be summarised as follows. 


\section{GoS and the principles of the Paris Declaration}

Ownership: As reflected in the previous chapter the GoS accepts and places a huge importance on the ownership of its development. What the Paris Declaration has provided is a tool that has enabled the GoS to hold donors accountable, ensuring that their assistance is in line with the GoS priority development areas. As will be reflected by comments below, donors are becoming increasingly respectful of the GoS owning its development. This is reflected in the donors' use of the GoS's Medium-term Expenditure Framework (MTEF) as well as donors coordinating their assistance to support the Samoa Development Strategy and moving away from project based development (Government of Samoa, 2010a).

Alignment: Like many developing countries the GoS's long-term aim is for all development funds to be delivered as budget support. There is still a long way to go before donors align to one system and process for implementing the development programmes. Although some donors, such as the European Union and Australia, have shown great willingness to trust the GoS's systems, others, such as multilateral banks, are more reluctant displaying varying levels of confidence. While it can be risky for donors to use the GoS's systems for procurement, if the systems prove to be legitimate, transparent and accountable, it would be less time consuming and taxing on public servants if all donors aligned to a single system. As a result the GoS "sees the Paris Declaration's commitment to alignment as an opportunity to focus on its own development, acknowledging that its systems, while adequate, will continue to improve with on-going scrutiny and capacity building support" (Government of Samoa, 2010a, p. 68)

Harmonisation: When donors work together on a common development programme there is usually a 'lead donor' that deals with the partner government to avoid duplication of information by the recipient government. This is reflected in a World Health Organisation SWAp in Kenya, Malawi and Tanzania in 2001 where the Swiss Development Cooperation (SDC) was given a lead donor role (WHO, 2001). Interestingly the GoS has stated in its evaluation of the Paris Declaration that 'Samoa does not accept the term 'lead donor', its view is that the government is the leader of all development in Samoa" (Government of Samoa, 2010a, p. 68). The term 'coordinaing development partner' is used instead and the decision is made by 
the donors who are funding similar sectors on who becomes the coordinating development partner.

As mentioned there are some donor supported programmes where the GoS financial systems are deemed unacceptable by donors. In these cases donors use one system (usually a multilateral agency) for procurement. "In health this is the World Bank system; in power it is the Asian Development Bank system" (Government of Samoa, 2010a, p. 683)

The GoS also has a missions calendar. At the start of every calendar year donors are asked to provide annual mission plans to the ACEO of the Aid Coordination Debt Management Division. Donors coordinate mission trips to avoid dupication for the GoS. The mission's calendar helps the GoS avoid overwhelming and unnecessary visits from donor missions.

Managing for results: Donors rightly need to account for their funding and, as the European Union has led the way for budget support, this is based on a "demonstrated commitment to managing for results" (Government of Samoa, 2010a, p. 69). The GoS has a monitoring and evaluation framework as part of its Samoa Development Strategy.

Mutual accountability: This principle ensures that both the GoS and donors are accountable for development results (OECD, 2005). Understanding of the principles of the Paris Declaration is slowly reaching all sectors of Samoa. Certainly those who I met with for interviews from public, private and CSO were all familiar with the Paris Declaration which showed a change from the evaluation report of 2010 . The GoS is working on building "mechanisms for mutual accountability into partnership agreements and program plans" (Government of Samoa, 2010a, p. 70).

\section{GoS and the Millennium Development Goals}

The GoS signed up to the MDGs in 2000 recognising their importance in assisting the development of Samoa. In 2005 the MDGs were fully integrated into specific targets of the Strategy for the Development of Samoa 2005-2007 and 2008-2012; as well as all sector and corporate plans. The GoS has a National MDG Taskforce 
chaired by the MoF and includes key stakeholders from public and CSOs. The GoS charged the taskforce with completing two MDG reports; the first in 2004 that "assisted to generate and enhance awareness among all development stakeholders of the importance of reaching these goal" (Government of Samoa, 2010b, p. 13) and the second in 2010 that "contextualizes the MDGs to reflect Samoan realities and provides a more diagnostic approach to the country situation including the identification of major challenges in the pursuit of the MDGs" (Government of Samoa, 2010b, p. 13).

The main results of the 2004 report highlighted positive outcomes in health and education but raised concerns about women's empowerment and the environment. Since the SDS 2005 - 2007 the MDGs has been fully integrated into all sector and corporate plans. The 2010 report's findings show that Samoa is well on its way to achieving the MDGs by 2015 with good progress on extreme poverty (MDG1); child mortality (MDG4); maternal health (MDG5) and universal primary education (MDG2). Setbacks from the 2009 tsunami and the impacts of climate change pose a challenge to meet the environmental sustainability goal (MDG7). Samoa has strongly benefited from having regional organisations such as SPREP based in Apia to support the GoS's domestic policies and strategies (Government of Samoa, 2010b). Along with the support from CSOs through church groups, village matai and donors, stronger effort is needed on MDG3 to promote gender equality and empower women, "especially when it comes to promoting women's representation in Parliament and addressing the issue of violence against women definitely requires stronger efforts in order to be achieved" (Government of Samoa, 2010b, p. 62).

\section{South-South Cooperation and Capacity Development Programme}

Over the past decade the GoS has received capacity building opportunities for public, private and CSO mid-level managers to share and exchange experiences in order to improve their processes and procedures. The initiative is supported by UNDP. Samoa has received assistance in enhancing its aid effectiveness; aid coordination and outcomes performance-based budgeting from other similar development countries. The idea is to tailor experiences learned from other countries to a Samoan context and the results have seen an improvement in the human resources in Samoa. This, in turn, improves the provision of sound economic and 
social advice on Samoa's development status. Samoa is also a trainer under the South-South Cooperation and Capacity Development Programme for other countries in the Pacific region. The South-South cooperation complements the GoS interaction with donors learning from experiences and therefore not repeating mistakes made by other developing countries.

\section{Development Policy Regionally}

The GoS has been an active member of the Pacific Islands Forum Secretariat (PIFS) and, on a regional scale, has been very active in its involvement in development policy throughout the Pacific. Through PIFS leaders of regional governments agreed to work collaboratively through the Pacific Plan (2005). The main objective of the plan is to guide and strengthen regional cooperation to "[e]nhance and stimulate economic growth, sustainable development, good governance and security for Pacific countries through regionalism" (Pacific Islands Forum Secretariat, 2005). The Pacific Plan is a living document so that it can adapt to the changing nature of the region. At a regional level PIFS has encouraged principles of the Paris Declaration and has been able to enforce this through regional policy.

\section{Cairns Compact}

The Cairns Compact was agreed to by PIFS leaders at a meeting in Cairns in August 2009. In line with international aid effectiveness best practice, as reflected through the Paris Declaration; Accra Agenda for Action and the Busan Partnership, the Compact sets out collective actions to strengthen coordination with donors and recipients of all development resources (Pacific Island Forum Secretariat, 2009). The Compact aims to assist in increasing the economic and development performance of PIFS members by working collaboratively and learning from respective country experiences. Although the Pacific is in a better position to meet the targets of the MDGs (Government of Samoa, 2010b) there is still much work needed to support the more vulnerable states within the region.

The Compact is guided by a set of agreed principles to encourage aid effectiveness:

- a recognition that broad-based, private sector-led growth was essential to achieving faster development progress and that donors should encourage the 
private sector, including through micro-finance and support for larger-scale private sector projects;

- a recognition that improved governance and service delivery are essential to achieving faster development progress;

- a recognition that greater investment in infrastructure would underpin greater economic development;

- an acknowledgement that country leadership, mutual accountability and mutual responsibility between Forum Island countries and their development partners are fundamental to successful development outcomes;

- the need to draw on international best-practice as expressed in the Paris Declaration on Aid Effectiveness and the Accra Agenda for Action; and

- a revitalised commitment to the achievement of the MDGs in the Pacific.

A key feature of the Cairns compact is peer reviews, similar to the South-South Cooperation and Capacity Development Programme. Peer reviews assist in mutual learning not only between regional governments but also donors. The peer review is not seen as a threatening feature but aims to enhance the capacity of regional countries and the management of their development resources. The reviews are carried out by four PIFS country representatives, donors and other stakeholders. There have been a number of reviews that have taken place since 2009 (Pacific Island Forum Secretariat, 2009). The GoS have been a part of the peer review of the Government of Niue in July 2011 and the Government of Vanuatu in August 2011 (Pacific Islands Forum Secretariat, 2011a; 2011b). All peer reviews are done in consultation with the respective governments.

The GoS is committed to the Compact in its efforts to improve not only its national development outcomes but that of the region. It will take time to develop further but is a step in the right direction in realising the principles of the Paris Declaration are achieved.

\section{Development Policy Locally}

The GoS has used development policy globally and regionally to implement development policy locally ensuring the principles of aid effectiveness are reflected 
in all its development work. These policies have evolved over time and are supported by all sectors of Samoa.

\section{Strategy for the Development of Samoa (SDS)}

Perhaps the most crucial GoS development policy is the Strategy for the Development of Samoa (SDS). The SDS has a four year cycle and the current SDS 2012 - 2016 is the sixth SDS document that has changed from the calendar year to aligning with the fiscal year. The SDS is the national strategic plan and sets out Samoa's development needs and goals as well as the strategies to achieve them. The SDS 2012 - 2016 is managed by the Economic Policy and Planning Division of the Ministry of Finance. There is wide consultation with public, private and CSOs including church and community groups. The SDS is designed and delivered by Samoans for Samoans (Government of Samoa, 2012b).

The vision of the SDS 2012 - 2016 is 'improved quality of life for all' with an underlying theme 'boosting productivity for sustainable development', and relies on the effective implementation of development work within Samoa.

Each priority area covers key sectors which is a shift in the government approach from past experiences. Each sector has a sector plan to guide donors in development programmes. The SDS $2012-2016$ is linked to the MDGs, the Paris Declaration, the Accra Agenda for Action and the Busan Partnership as well as the regional plans on aid effectiveness. All government departments, private sector, CSOs, and donors link their development work back to the SDS and it has become the key guiding document for the GoS.

The economic sector is a priority area for Samoa. In the SDS 2008 - 2012 the Samoan economy did not achieve its macroeconomic targets with a decline in GDP by an average of $0.7 \%$ per annum. Factors that led to this decline were the economic recession and a resulting decline in remittances that traditionally made up $24 \%$ of GNI, due to rising unemployment amongst the Samoa diaspora abroad. The SDS 2012 - 2016 focuses on the strengths of Samoa through agriculture using organisations such as the Scientific Research Organisation of Samoa (SROS) whose key role is to boost value added processes within the sector to further 
facilitate import substitution. SROS has already developed avocado oil for Samoa and more recently started to develop gluten free breadfruit flour, initiatives SROS hopes to sell to the private sector to assist in the further development of Samoa (Government of Samoa, 2012b).

Sustainable tourism is an area that brings in over $20 \%$ of the GDP. The GoS recognises the large number of visitors (both Samoan and expatriate) that visit Samoa every year. Encouragement of tourism ventures such as the popular beach fale (unique to Samoa) is an initiative supported by the Samoa Tourism Authority. Tourism training provided by outfits such as the Small Business Enterprise Centre give entrepreneurs the opportunity to improve their services. The 2009 tsunami destroyed $13 \%$ of the sector and the GoS as well as donors recognise the huge financial contribution tourism has made to the economy. Donors such as New Zealand have committed up to NZ\$20 million to the tourism sector over the next five years from 2011/2012 (New Zealand \& Samoa, 2011). This is an indication that donors align their assistance to the development needs of Samoa.

The SDS is prepared by Samoa and it has taken into account all donor assistance when developing the document. The GoS is strategic in that it knows who amongst donors can support what areas. Obviously not all donors can cover every sector, for example the New Zealand aid programme seldom commits to infrastructure projects but this is a focus for the Chinese government. Priority area 3: Infrastructure sector is therefore a part of the SDS 2012 - 2016 that the Chinese will focus on. Each donor is able to slot into areas of the SDS 2012 - 2016 that is specific to its respective donor priorities. By doing so the GoS has provided a buffet menu that suits all tastes and budgets, while still being in control of its own development.

\section{The Development Cooperation Policy}

Samoa's first aid policy was developed and passed by Cabinet in 2010 based on mutual agreement between donors and the GoS. The Development Cooperation Policy places the GoS as the leaders and owners of all development work for the country and for donors to respect the GoS's decisions in setting national priorities. Furthermore the policy asks donors to use the GoS's procedures and systems to limit the time spent on the varying accounting and reporting systems of the different 
donors. The process was not only time consuming but left public servants feeling overwhelmed and unproductive resulting in poorly completed reports. All donors in Samoa know and understand the policy and it is well written with links to the MDGs; Paris Declaration, Accra Agenda for Action and Busan Partnership.

\section{Structural Adjustment Programmes}

SAPs were a feature of the late 1990's and early 2000's. The GoS, through multilateral institutions, was encouraged to introduce the reform programmes to service foreign debts. Kerslake (2007) as part of her thesis on SAPs in Samoa highlights the privatisation of the former Department of Works due to mismanagement of funds, poor performance from staff and high level corruption. The GoS was embarrassed by the Chief Auditor's report of the former department and were left with very little option but to start the privatisation process. Reviews were undertaken by external and internal consultants and the results favoured the disestablishment of positions and the department becoming the current Ministry of Works, Transport and Infrastructure with a lot of its non core functions tendered to private enterprises. The free market reforms had hoped to combat practices of corruption and nepotism as outlined in the Chief Auditor's report. Although the restructuring was successful, partly due to the fact the consultants worked within a culturally appropriate way when redundancies were made, Kerslake (2007) found strong evidence former employees of the Department of Works felt victimised by the privatisation programme.

\section{Sector Wide Approaches}

SWAps became the preferred aid modality for the GoS when the SDS focussed on sectors. As a result of SWAps there has been a shift from $100 \%$ of donor funding delivered through project-based modalities prior to 2005 to $74 \%$ in 2010 channelled through sector programmes (Government of Samoa, 2010a). Under SWAps, "there has been a significant increase in the volume of aid pooled by donors. It is anticipated that there will be significant savings from reduced transaction costs as a result of the new framework for delivering aid, especially through budget support (as used by the EU for the water sector) and the use of country systems" (Government of Samoa, 2010a, p. 42). Donors are working more collaboratively with the GoS and other donors as is reflected in Figure 7 below taken from the GoS's 2010 statistics. 
AusAID, NZ, WHO, WB, ADB, JICA and EU use the same reporting format to monitor and evaluate the SWAps for each key sector they work in.

Table 1. Co-operative/ Joint Work between Agencies

\begin{tabular}{|l|l|l|l|}
\hline Sectors & $\begin{array}{l}\text { Coordinating } \\
\text { donor }\end{array}$ & $\begin{array}{l}\text { Other } \\
\text { donors }\end{array}$ & Division of Labour \\
\hline Health & NZ & $\begin{array}{l}\text { WHO; Aus; } \\
\text { WB; UN }\end{array}$ & $\begin{array}{l}\text { Three donors contribute to pooled resources for sector } \\
\text { program. UN contributes to specific areas of the sector } \\
\text { program relevant to its respective mandates. For } \\
\text { donors in pooled arrangements, ADB, manages } \\
\text { finances in collaboration with GoS and applies use of } \\
\text { Bank systems for contracts. Operates under Joint } \\
\text { Partnership agreement. Delegated responsibility } \\
\text { between Australia and New Zealand. }\end{array}$ \\
\hline Education & Australia & NZ, ADB, & $\begin{array}{l}\text { Again a pooled financing arrangement with ADB tasked } \\
\text { with overall financial management in collaboration with } \\
\text { GoS. Use of bank systems for procurement as well } \\
\text { those of GoS. Operates under joint partnership } \\
\text { agreement. Delegated responsibility between Australia } \\
\text { and New Zealand. }\end{array}$ \\
\hline $\begin{array}{l}\text { Community } \\
\text { Development }\end{array}$ & Australia & EU, NZ & $\begin{array}{l}\text { Again a pooled arrangement to set up a Community } \\
\text { Support Facility. Australia is supporting the } \\
\text { administrative set up with NZ looking at capacity } \\
\text { development and the EU to provide financing for } \\
\text { community initiatives. }\end{array}$ \\
\hline $\begin{array}{l}\text { Private Sector } \\
- \text { Tourism }\end{array}$ & NZ & UN, ADB & $\begin{array}{l}\text { Donors provide support to common fund under the } \\
\text { Private Sector Support Facility which includes support } \\
\text { for tourism. }\end{array}$ \\
\hline
\end{tabular}

(Government of Samoa, 2010a)

\section{Conclusion}

At the international level the GoS has embraced the new global aid agenda as reflected in the evaluation of the Paris Declaration and Accra Agenda for Action in 2010. Although the GoS did not endorse the Paris Declaration until 2008 it was already well underway on a government reform that reflected the principles of the Paris Declaration. The implementation of SAPs, SWAps and MDGs are examples of how international best practice is implemented in Samoa. The SDS $2012-2016$ is a good example of how the GoS has taken the global agenda but shaped this to local needs. The SDS 2012 - 2016 also takes into account donor assistance and the focus for their respective governments. Through the GoS development policy it is

\footnotetext{
9 "The use of common pooled financing arrangements is a way to ensure that there is harmonisation of the financing resources that will eventually be aligned to country systems. In the case of the sector programs where the multilateral financial institutions are involved (namely education and health) the donors have deferred to using the procurement systems of the banks rather than the GoS. Challenges remain in terms of harmonisation, alignment; results based management and mutual accountability in varying degrees with alignment the most challenging for the partners, especially in moving to using government systems and processes fully. Results based management and mutual accountability is work in progress" (Government of Samoa, 2010a, p. 47).
} 
evident that they have a good understanding of High Level Aid Effectiveness changes and adapted these to suit their cultural context. This is a key finding as to why the GoS is sovereign in its aid programme. 


\section{CHAPTER SEVEN: Markers of development sovereignty}

\section{Introduction}

This chapter is the core of this thesis and sets out the findings from the research. The foundation of the thesis is the interviews with a range of different people from public service, private enterprise, CSOs, donors and independent representatives in both Samoa and beyond. At the completion of the reaserch I left Samoa feeling confident that the GoS really does have development sovereignty when dealing with donors. I found the local Samoans that I interviewed were of a high calibre; educated, well informed, confident individuals who were not afraid to speak their minds. This chapter looks at the 'markers of development sovereignty' highlighting many examples of how the GoS asserts its development sovereignty when dealing with donors. I provide examples from both the recipeients' and donors' experiences.

\section{Markers of Development Sovereignty}

Whilst the motivations and intentions from the Paris Declaration, were to make aid more effective for its recipents, there are always ulterior motives as donors are guided by their constituencies. The GoS's donors have varying levels of implementation of the Paris Declaration. Some are more accepting of the declaration than others as shown in the GoS evaluation of the Paris Declaration and the Accra Agenda for Action (Government of Samoa, 2010a). One thing that stood out from my research is that Samoans (public, private and CSOs) were unified in their approach when dealing with donors. They subscribe to similar views and approaches and have developed strong relationships with donors that allows the GoS to be sovereign in the delivery of aid to Samoa.

\section{Educated Samoans}

While I was growing up as a first generation New Zealand-born Samoan, most of the adults I knew from my extended family, church and community worked in factories with only a handful holding positions as teachers, nurses and office jobs. The ultimate intention for early Samoan immigrants was for my generation to excel at school and gain university qualifications and therefore better jobs that my parent's palagi counterparts held. 
Moving to Samoa in 2002 to work was an eye opener for me. I recall my first symposium I was asked to attend on behalf of my then manager was held at the National University of Samoa on the Samoa curriculum of which New Zealand was a major donor. The proceedings opened with devotion. Although I was accustomed to this in a typical church setting, this was a professional setting. We sung a common hymn from the Congregational Christian Church of Samoa hymn book 'Fa'afetai i le Atua' in beautiful four part harmonies with no rehearsal. It reminded me of my childhood in so many ways. The symposium then moved on to the formalities with different speakers from the then Ministry of Education talking to the new curriculum in articulate Samoan and English. It was the first time that I had really seen my parent's generation outside of a church setting speaking with confidence on strands and objectives of the Samoa curriculum. I came away feeling proud to be Samoan and continued witnessing a high calibre of well educated people throughout my year and a half working in Samoa.

I was therefore not surprised when undertaking my research in Samoa to encounter a strong workforce of confident and articulate government staff. All of the local staff I interviewed at least held undergraduate degrees with some holding post graduate qualifications to $\mathrm{PhD}$ level. University qualifications were gained from institutions within the Pacific region or internationally.

The GoS places a major emphasis on educating local people. When I worked for the New Zealand High Commission in 2002, at least half of the New Zealand aid budget was spent on scholarships alone. The GoS had instituted a bond scheme that meant graduates had to serve the GoS (for the length of the time they studied) once they had successfully completed their studies. This stopped the GoS losing their graduates to competitive salaries internationally. GoS5 said "Scholarships are based on the priority needs of the country. There are four types of scholarships, undergraduate, post graduate, vocational and mature age. There are scholarships set aside for the University Preparatory Year and another for everyone else, civil servants, private, people with limited education etc.". 
The GoS recognises the importance for maintaining a scholarship programme, "You can have all the development programmes but if you don't have a qualified, experienced workforce, it's a waste of time" (GoS4). GoS4 also went on to say "there is a large investment by donors on scholarships and training. As a result Government of Samoa has a very qualified and capable workforce, and human resources has developed with relevant skills and know-how. Donors can see a qualified workforce to carry out the development needs of Samoa".

Locally engaged staff working for donors in Samoa hold very competitive positions. When I was working at the New Zealand High Commission, other than the scholarship programme, a lot of the project work was contracted to both local and international consultants. Now donor funded programmes are managed by locally engaged staff which is a change in the last 10 years as reflected by D3: "Even local staff at the High Comm. are having more responsibilities devolved to them because they have the goods to do the job".

GoS has placed a huge emphasis on educating public servants, and as reflected the calibre of individuals that were interviewed were of a high standard. This places Samoa in a better position when dealing with donors.

\section{Long service/ Continuity}

One of the reasons the GoS can confidently converse on the international stage when it comes to High Level Aid Effectiveness talks and also hold donors accountable is due to the long service and continuity of local staff. GoS3 has been working for the GoS for many years, holding senior positions with good exposure to aid. GoS5 has worked for both the GoS as well as being a locally engaged staff for a major donor therefore having good exposure to processes for both parties in the aid relationship. GoS6 has worked for the GoS for 16 years holding senior positions and represents the GoS at international forums. GoS1 has served the public sector for 10 years moving very fast up the ranks. PS3 worked for the GoS for many years before moving to the private sector in an area which received core funding from a major donor. D3 worked for the GoS after completing a degree qualification from a prestigious international university and is now working as a locally engaged staff for a major donor. 
What has helped to retain local staff working for the GoS is a $42 \%$ increase in public service salaries as part of the public sector reform programme. The increase was staggered over 2005/6 to 2007/8 (Government of Samoa, 2010a). GoS4 comments that "...the salary bracket for public servants pays more than the private sector. Back in 2003 an ACEO started on SAT\$40k, now ACEOs start on SAT\$81k. The government are providing competitive salaries to keep experienced qualified staff in the public sector instead of losing them to private sector". PS3 laughed and said "the private sector often lose valuable staff to the government as we can't compete with government salaries. Once upon a time it used to be the other way around".

Most diplomatic postings to Samoa are a maximum of three years so Samoa is in a stronger position with a long serving public service that has good institutional knowledge. The GoS has been clever to retain public servants by adjusting their salaries.

\section{Well prepared, well informed}

The level of experience and expertise held by local staff in different sectors is very strong in Samoa. The people that I interviewed were hard working and knowledgeable individuals who placed emphasis on being well prepared and well informed on their specific areas of work as reflected by GoS3 "I read extensively as part of my job and am forever creating, adapting and adjusting what I read to the context of Samoa. That is why Samoa is comfortable where we sit with donors and the international donor forum...we are always reading and trying to keep abreast of up to date discussions, always learning" (GoS6).

Public servants also travel extensively to represent the GoS on different topics of interest. GoS1 has travelled widely and never takes this for granted: "work ethics are very important and we don't want to look incompetent, we want to keep it together even though the job can put you under a lot of pressure". GoS1 represented the GoS at United Nations conferences where it was imperative to know how to follow due procedures for a number of different donor agencies, "There is a culture of taking pride in your work so we make sure we know the 'ins' and 'outs' of everything we 
work on. As a result Samoa knows and understands how to prioritise their development needs, they know how to promote the interests of Samoa".

A typical trait for Pacific people when attending international conferences is to remain silent, yet anecdotally GoS representatives have a reputation of being very vocal. "I attend these conferences and Pacific people say nothing, yet they are there to give feedback on national positions. When I go I make sure I am well read and ready to contribute to discussion., It's not just about picking up your per diems or travelling for a vacation, it is hard work" (GoS1). GoS6 reinforced these comments by saying "Work travel is not a vacation, it is work and I expect people to go prepared. You need to speak up, if not you will be missed out and we don't want to look stupid". As it is most likely that the same people represent their countries at international meetings GoS6 would the opportunity to build relationships and networks with small island states, developing an alliance to help promote the interests of both countries.

Young staff members are not exempt from this strong work ethic. GoS3 comments "I also throw my young staff in the deep end to work hard, read thoroughly and don't be intimidated. My staff receive opportunities to learn new experiences". This helps with junior staff gaining confidence and authority in their line of work and therefore being able to articulate what they want (GoS4).

It is also important to bear in mind that the GoS has a relatively small public service in comparison to major donors. The people that are representing the GoS on the international stage are the same people that entertain mission trips that come through Samoa "Australian and New Zealand missions are always impressed by our work ethics and what we can get done with limited resources. Any Pacific mission visits, it's the same people that are tasked with entertaining; protocol; and policy. It takes lots of multi-tasking but the work gets done and staff take pride in their work" (GoS1).

Because GoS officials are well prepared and well informed they are confident in their dealings with donors. GoS officials are not shy to state the position of Samoa on particular topics both in Samoa and when they travel abroad. 


\section{Fa'aSamoa}

A strong educated, long-serving, well prepared public service should be linked to fa'aSamoa. As mentioned in a previous chapter, fa'aSamoa remains a core value for many Samoans scattered around the globe.

I interviewed a palagi in Samoa who works in the private sector. PS2 has been resident in Samoa for two years and recently had the opportunity to visit a neighbouring Polynesian country. PS2 found that in comparison to Samoa this other island had lost a lot of its culture. Housing looked very similar to Western homes, the place was overrun by tourists and it seemed everything on the island was designed for outsiders rather than the locals. Although PS2 appreciates that proud Samoans vary like in any culture, there are some that are subservient and some that are proud, one thing that remains is "Samoa is very Samoa, pride runs through the place and the culture is very strong. What impressed me about Samoa was that I felt like I was in a foreign country, the culture has not been bulldozed aside. I watched a movie made in 1926 called 'Moana' set in Safune that was about life in Samoa. I was impressed to see that everything in the movie from 1926 I had seen since living in Samoa since March 2010, pig capture, harvesting taro, umu preparation, fishing, collecting coconuts. Sure there were a lot more Western influences but the culture is still evident in the place" (PS2).

GoS2 works for a State Owned Enterprise, is not Samoan but from another Pacific country. GoS2 found that knowing the Samoan language is very important working for the GoS. In order to be a policy analyst in Samoa you must be fluent in both Samoan and English. GoS2 found that 'if you don't know the language you will get lost. The language and culture in official government settings is very important".

I found that GoS officials use gagana (language) Samoa to their advantage. GoS8 gave an example of negotiating with a donor what the donor could financially contribute towards rebuilding hotels. The hotels were closed down due to a cyclone and as a result local Samoans were without work. The donor was accompanied by a locally engaged staff and kept talking around in circles but was not able to commit to an amount. GoS8 became increasingly frustrated with the donor so the donor eventually committed to a figure. At the end of the meeting as the donor and locally 
engaged staff were leaving GoS8 said in Samoan to the locally engaged staff "don't come back with your donor if you haven't got any money". The donor laughed and responded "I think I know what you're saying" GoS8 replied "good that was my intention" and closed the door. All donors in Samoa speak English and follow the international aid policy which is also in English so normally donors would be in the position of power. However in the example above GoS8 controlled the process by introducing gagana.

Understanding fa'aSamoa is difficult to comprehend if you have not lived it in person. D3 found this working as a locally engaged staff for a donor. "Sometimes fa'aSamoa doesn't make sense, and as a local staff I see this played out between donors and Samoa all the time. One time our donor unintentionally offended a government of Samoa representative. When we returned to the office the donor asked me I don't understand why they reacted that way, what did I say wrong to offend them? It was difficult to articulate but I knew why Samoa was offended".

Even in the eyes of the donors Samoans are seen to be strong. "Samoans have no inferior complex, even with a colonial history it has not affected them at all. Even if a Samoan is not wealthy they are not second best to anyone ... very resistant to outsiders this sometimes even extends to New Zealand Samoans at times. There is definitely nationalism and pride in being Samoan" (DS1).

A candid conversation with GoS2 unfolded a very amusing story. GoS2 studied at the University of the South Pacific (Suva) and often found that other Pacific Island students would come together to gossip about the Samoan students. "Samoans think they're it, they're such an arrogant bunch, they think they rule USP Suva campus. Most students would support any rugby team that played against Samoa because they were so arrogant on the field, and now l'm married to one".

When working alongside donors this arrogance referred to by GoS2, which others might interpret as 'pride', go hand in hand with fa'aSamoa. In the context of working alongside donors this pride is very strong. Because public servants are experts in their respective fields they are confident in their dialogue with donors. "Samoans are very vocal and not shy to speak their mind and ask for money. They don't beat 
around the bush and sometimes do it in a joking manner but there is a level of truth to the request" (GoS2). Samoans do not feel that they are second class citizens in their own country nor do they hide the way they feel if they disagree with donors. "Samoans are very proud people, 'who are these palagi coming here and telling us what to do on our own soil?' " (GoS2)

The locally engaged D3 staff member often jumped between donor and the GoS camp throughout our interview. "Samoans can be so stubborn they are willing to be poor to prove a point. Even to the point of losing donor funding. Samoans are 'fierce warriors', we know what we want. We are egalitarian despite our hierarchical structure. No matter what our role is we are very proud of our culture. Pride can be both a strength and weakness. It's good that we don't let people put us down" (D3).

Fa'aSamoa influences the way GoS officials work with donors. GoS Officials are not intimidated and use language and culture to assert their development sovereignty.

\section{Long serving Prime Minister}

As identified in an earlier chapter the Samoan Prime Minister has been in power since 1998. A lot of the people I interviewed attributed the strength of the public service to Tuilaepa's strong leadership. "People put their faith in leadership. Samoans are strong minded they therefore need someone with thick skin, the PM is bright, intelligent and has had a lot of international exposure. He has a finance background, Minister of Finance, and has strong leadership skills" (GoS1). GoS3 said “Tuilaepa isn't fussed on protocol, but he has a good understanding of finance that puts him in a good position to run the country"

Following the 2009 tsunami D3 was fortunate to accompany the GoS on an inspection of the devastated areas. Following the inspection a meeting was called at the NUS lecture theatre and all government ministers, public, private; CSOs, church leaders and the donor community were invited along. It was first time D3 had seen Tuilaepa in action. It was obviously a stressful time for Samoa, but Tuilaepa was assertive and confident in his address. As the area that was affected was only on the South Coast of the island of the main island of Upolu, Tuilaepa assured his people they could work together to fix the situation. Tuilaepa turned and asked each 
government department CEO to provide an update on the status of their work. After each update he gave them instructions on what to do from there, creating sub committees to support their work. Tuilaepa also actioned the disaster advisory committee. D3 comments: "It was so impressive to watch him take control of the situation and nothing fazed him, he was confident and didn't allow emotions to get in the way. He was remarkable and I felt so proud to be Samoan that day".

During natural disasters donors will appear to provide assistance with varying motivations for their support. D3 talked about a particular donor who had only recently arrived into Samoa and was not aware of the strength of the Samoan people. The donor tried to stand up to announce their contribution to the disaster but Tuilaepa closed down the announcement by directing the donor to a relevant committee. "This wasn't about donors shining and wanting their assistance heard by the media, the focus was on Samoa and its people. We were so happy Tuilaepa did this. The donors would be acknowledged at another time"(D3).

In 2009 TV3 presenter John Campbell aired a story accusing Tuilaepa of misappropriating donor funds for disaster relief efforts. GoS3 was keen to defend Tuilaepa which reflected loyalty and trust to his leadership. I was told by GoS3 that all the funds for the tsunami were received and disseminated through the GoS financial systems. "Tuilaepa didn't touch it. He was never involved in the distribution of any money. Roads were operational the day after the tsunami with power line poles going up. Even relocation roads to the hills were starting to be cut out, it's an ongoing programme that is where the money was spent".

GoS3 was asked by Tuilaepa to prepare two reports one shortly after the tsunami and another post report. Both reports outline how SAT48 million was spent. The GoS cannot account for every cent it received. "You must remember that there are funds that were only pledged and we still haven't received that money. Also there was a lot of funding that went straight to Non-Government Organisations that we cannot account for as we have not been informed about this"(GoS3).

GoS3 spoke with great respect for Tuilaepa and also felt he was unfairly accused by John Campbell. Following Campbell's story, donors that contributed money to the 
disaster relief effort returned to survey how their money was spent and they left feeling pleased with what they saw and did not question Tuilaepa or the GoS on Campbell's accusations (GoS3).

With a strong Prime Minister who is not intimidated by anyone, the GoS officials that were interviewed held similar characteristics when working with donors. There is a level of patriotism attributed to Tuilaepa by those interviewed and public servants were very protective of the Prime Minister and looked to him as a role model.

\section{GoS officials know how to use donor resources to their benefit}

As the GoS officials are so well versed and keep abreast of high level aid effectiveness decisions they are able to hold donors accountable and therefore use donor resources to their benefit. Similarly most donors have built strong trusting relationships with the GoS over time which has given donors the freedom to release aid knowing the GoS has a proven track record.

This was proven when the 2009 tsunami hit Samoa. GoS3 was away and upon GoS3's return a meeting was called between donors. When GoS3 arrived at the meeting there was a new donor representative that had only recently landed in Samoa for a posting. Whilst GoS3 was aware of the new donor representative they had never met face to face and a briefing was not scheduled until GoS3 had returned from overseas. With the tsunami recovery efforts underway the new donor representative decided to chair the meeting, not being aware of the personalities and procedures for the GoS when dealing with donors. Australia joined the meeting on a telecon. from Canberra and asked who was chairing the meeting and also asked whether GoS3 was present in the meeting as they were not going to participate if GoS3 was not there. The recently arrived donor representative soon understood that the GoS was in charge of their aid programme and GoS3 took control of the meeting. "I advised donors what to do as we have been in a state of emergency before so I was calm and I could direct people. The emergency advisory committee was activated and we knew what to do" (GoS3).

When interviewing a representative from the private sector who held a senior position in the GoS for many years PS4 said "donors don't bully Samoa, they are in a 
position of maturity. Samoa also has officials that have worked for donors so they know what their demands are and they can deliver on this."

Donors have conditions that they put in place but the GoS are very clever in finding ways to work around these conditions. PS4 gave an example using a European Union (EU) water project. Typically for EU projects all material must be purchased from Europe. However the GoS wanted to save funding to spend on other areas within the project and found they could get material much cheaper from Australia and New Zealand. The GoS therefore set up a national standards framework for water projects that adopted Australia and New Zealand standards. EU therefore had to comply with the GoS national standards that included New Zealand and therefore materials were approved to be purchased from New Zealand. "Samoa are motivated to get around stringent rules if it means they can save on funding to spend in other areas" (PS4). GoS4 reiterates these sentiments. "We draw on what is beneficial for us".

With a strong educated population the GoS also utilises internal sources to gain a better understanding of different sectors. GoS6 was working on a programme that involved the environment sector. GoS6's team had little experience in this area so an environment expert within the GoS was included in the team so that the most recent information on the environment sector was embedded in the programme acknowledging local expertise.

Human resources are always a problem when donors work alongside recipient countries. GoS4 was approached by a donor who was interested in offering more scholarships to the GoS which are always appreciated. However with a limited public service who are already stretched GoS4 had to make sure that the offer was not going to increase the workload for staff. GoS4 directed the donor to follow the SDS 2012 - 2016 to find out the GoS priority areas and then suggest suitable tertiary institutions where scholarship recipients could be posted. "I don't have time to research this information but the donor knows their training institutes and what suits us from the SDS" (GoS4). One could argue that GoS4 may come across as ungrateful in this situation, unfortunately the reality for recipient countries is they 
need to be savvy in the way they manage offers from donors so that they are not stretching an already overworked public service.

The GoS understands the strategic plans for each of its donors so it knows who to ask to fund particular aid projects and programmes (DS2). For example China is more likely to fund infrastructure projects than New Zealand.

The GoS also takes a vested interest in the design of its aid programmes. D1 said that "...ten years back donors would lead the development of aid programmes, usually with a development consultant tasked with the duty of preparing a first draft of the design document. Now Samoa does the first draft of the design document and they are not interested in external consultants".

The GoS has taken on more responsibility of its programme, "...There is a desire for education to move to 'budget support' bringing together donors and Samoa's needs. Samoa want to analyse the situation against their Education Sector Plan Donors offer funding to support this work but the Government of Samoa decline the support replying that they want to take responsibility for their own plans" (D1).

Donors have the potential to change their strategic plans based on the directions set by newly elected governments. Funding for projects and programmes can therefore be affected. No one felt that more than the civil society sector in Samoa who for eight years received funding from New Zealand for its umbrella organisation for NGOs. Since the National Party were elected as the government in New Zealand in 2008, replacing the left wing Labour party, the focus for New Zealand has changed and funding has been stopped for the CSO sector. To mitigate this problem the GoS set up a Civil Society Support Programme (CSSP) and asked donors to pool their resources together to support this sector. Both EU and AusAID provide funding. The GoS acted on feedback received from CSO members who "wanted a one stop shop to ask for funds, rather than not having an understanding on where to go to when they wanted to access donor funding" (CSO1). CSSP is governed by a steering committee made up of representatives from the Ministry of Women, Ministry of Finance, donors, and two CSO reps (CSO1). Through the CSSP Samoa is able to 
negotiate with AusAID and the EU to use one reporting system as the CSO sector do not have the capacity to produce different reports for different donors.

PS3 gave an example of how the private sector use donor funding to their advantage. The organisation that PS3 manages has received donor funding since 1994 with partial funding from the GoS. PS3 kept abreast of what was happening politically for their donor as they were aware that a change in government could affect ongoing funding. PS3 learnt that the then opposition leader was visiting Samoa prior to the elections. PS3 made sure that a meeting was arranged to showcase the work of their organisation and essentially to secure ongoing funding which was necessary for the continuity of their work. The leader of the opposition was impressed with the work of PS3 and the staff. PS3 was keen to make a lasting impression which paid off when the opposition party for this donor won the elections that year.

The company PS3 works for involves their donor as it sees fit. PS3 feels that they have nothing to hide and if targets are met then the donors are happy. PS3 has also received a message from the GoS to find ways to remain sustainable so that they do not become dependent on donor funding. The company PS3 works for has developed training programmes that are currently being accredited under the Samoa Qualifications Authority and they hope to offer trainings to the region to ensure extra funding is received. PS3's company generates up to SAT100k per year on their own through contract work carried out by their staff. PS3 has a good understanding of reporting requirements, and staff study these carefully and produce reports accordingly. As a result the organisation that PS3 manages has secured funding for the next five years from their donor. "You've got to perform, everything is analysed thoroughly so I make sure systems are in place to cover the work. Building relationships with donors is key to meet the needs of Samoa" (PS3). PS3 has also received interest from other major donors who were impressed with their work. PS3 has worked for the GoS and therefore has a good understanding and appreciation of what it is like to work with donors. PS3 values the importance of monitoring and evaluation and can see why donors need to account for money as they are accountable to tax payers so PS3 has no problems in reporting back to donors. PS3 often gives messages to people that they offer training to. "If you've been given 
money and you didn't sweat for it, you don't appreciate the value of the money. If you get a loan you know you have to work hard to pay it back so you don't have a relaxed attitude." PS3 encourages members not to have a dependency attitude towards donor funding.

Taking a holistic view of Samoa, the country has a good reputation within the Pacific region amongst its peers. I recently travelled with a colleague to Samoa on a work trip. My colleague made the comment that Samoa is so similar to New Zealand the transition is easy to make between both places because the infrastructure is well set up. One thing that is prominent in Samoa compared to other Pacific countries is the amount of local businesses run by Samoans. The GoS market these locally-owned businesses to donors by using local establishments to host lunches and delegations therefore showcasing what can be achieved by Samoans. I am not entirely sure this is a strategic move by the GoS to influence the decisions of donors to provide funding to the GoS but donors are impressed and feel more confident that money can be utilised to improve Samoa's development. Talking to a prominent business owner, PS1 said that the GoS often hosts lunches for visiting missions at PS1's establishment, "The government like to use us an example of a successful business owned and operated by a Samoan. We try as much as we can to use local produce that is grown by local providers in the area. At our last lunch hosted by a major donor, my wine and beverage manager gave a five minute presentation about where the local food was grown, who the local growers were and how the food was prepared by the local chef of the establishment" (PS1). The head of the delegation was really impressed with the presentation and appreciated that the establishment was supporting local growers and the produce was of such a high quality. PS1 continued to say, "we aim to use local produce but still meet international cuisine standards". PS2 reinforced the message of the donors by saying that PS1's establishment is "the flagship for Samoa" (PS2). From this example donors can see further opportunities to encourage more local people to grow local produce and therefore make opportunities for themselves.

\section{Development policy}

Development policy is only a partially effective way to indicate whether a recipient of aid country has development sovereignty when dealing with donors. However if the 
theory reflects the practice it really does strengthen the position of a recipient country. As shown earlier (chapter six) the GoS has changed its development policy to reflect what is happening internationally with aid and what works best for the Samoan context. As well as the CSSP fund being set up there is also a Public Sector Fund (PSIF) managed from the Prime Minister's Department that any GoS departments can apply to for improving services. Both AusAID and New Zealand are donors for PSIF (GoS5). There is a steering committee made up of a representative of the Prime Minister's Office, Ministry of Finance, Public Service Commission, Ministry of Women, Audit Office, and just recently a donor representative who is an observer with no voting rights. The PSIF Steering Committee is guided by the Public Admin Sector Plan (PASP) 2007 - 2012 PASP has activities outlined from objectives in the SDS. The PSIF Steering Committee decides eligibility of funds based on the PASP (GoS5). The distribution of PSIF is through the GoS's financial systems based on the Public Financial Act 2001. "Even though money is from donors all departments apply using GoS procedures" (GoS5).

When GoS3 first started working with donors over 20 years ago anyone in Samoa could go directly to a donor for assistance and there was no coordination. A Coordination Committee was set up but was inactive. As a result problems started to surface as recipients were not reporting back to donors to account for funds. Donors then came to the GoS to chase up recipients of aid on behalf of the donors. Distrust started to occur and donors started to apply strict conditions (GoS3). The Coordination Committee was revitalised and tasked with providing a balanced perspective for both the donors and the GoS.

The GoS is forever creating, adapting and adjusting its aid programme to the context of Samoa. "That is why Samoa is comfortable where we sit with donors and the international donor forum" (GoS3). Around eight years after, following global trends, the GoS could see the benefits of adapting a sector approach for Samoa (GoS3). Changes were made, Cabinet backed this move and Government departments followed suit. GoS officials are always reminded, "they are not donor programmes they are your programmes. You're not beholden to the donor demands" (GoS3). 
In a SWAp there is always a lead donor. The GoS did not like the term 'lead donor' as it expected to lead its own development. "They prefer the term 'coordinating donor" (D1). The coordinating donor liaises with other donors before sharing feedback with the GoS, "we're busy people, if you want to support us on similar work, do it as a joint team" (GoS3).

As mentioned the Samoa Development Strategy is another initiative completely owned and delivered by the GoS. "Donors are not part of the draft of design process at all" (D1). D1 was not offended at all by not being included in the design process. "Fair enough, Samoa need to consult with internal politics first before complicating things with donors. There have been consultations in Savai'i for the development of the new SDS 2012 - 2016. Donors will be consulted once Samoa is ready" (D1). If in a SWAp the development policies clash with donor policies both parties try to find common ground. "Samoa [GoS] is not shy to state their position" (D1).

Being overrun by mission trips is always a problem for recipient countries (Wrighton, 2010). The GoS noticed around five years ago that a large majority of their time was taken up hosting mission trips. Most missions were travelling to Samoa when it suited them and when donors were not busy. The GoS therefore decided to create a calendar for mission visits. At the start of every year calendar year donors are asked to give a schedule for their proposed mission visits then a calendar is developed and sent to all donors so that mission visits are coordinated and planned. The GoS also has a 'mission free zone' from mid March to the end of April and November December so that the GoS can work on budgets and prepare for the Christmas season (D1). The GoS reserves the right to allow missions through that are deemed important to them. "At first the donors did not take it seriously until they saw that no one was available when their missions arrived in country and it was embarrassing. As a result donors started to take it seriously and they now comply" (GoS3). The mission schedule allows the GoS to prepare accordingly as they know what donors are coming for and when.

A meeting is held every three months and donors can ask or discuss whatever they wish. An agenda is sent around prior to the meetings and the outcomes assist in donor planning (GoS3). With the development of the SDS 2012 - 2016 the donor 
meeting in April 2012 was dedicated to discussing the SDS. Donors are then able to align their strategic plans to the SDS. "It is also at these meetings that we hold donors accountable and keep all parties on a common table" (GoS3).

\section{GoS officials are assertive in their dealings with donors}

This research would suggest or confirm that the GoS is not afraid to challenge donors even to the extent of losing donor funding. The GoS decides on its own aid programme and its own processes (D3). GoS7 works as an assets manager for a government department and a donor had signed an agreement with the GoS to build a major infrastructure project. GoS7 was part of a panel that welcomed the donor at the very first meeting. The donor came to the meeting with two building plans and asked the panel to choose one and the donor would build it. The panel looked at the donor in surprise and reviewed both plans before replying that neither of the options suited the GoS. The donor responded that the agreement was already signed with the GoS so one of the two options should be chosen. The panel disagreed and the donor left the meeting. GoS7 said they waited for three months almost thinking that the donor had retracted their offer. Four months later the donor returned having changed their approach this time asking the GoS representatives, "ok tell us what you want. That's when we gave them plans on what we wanted so that a purposebuilt structure could be provided" (GoS7). The building is now underway and there are milestones that are set at each stage of the project between the donors the GoS. "Eight times out of 10 the donor delivers on what we ask for. If the two things they fail to deliver on are not worth fighting for then we show flexibility and let it go. We trade off some things if it's not important. However if there are things that are essential to our work then we don't compromise and we fight to rectify it" (GoS7).

D3 was part of a donor dialogue with a GoS ministry that has very strong personalities at its helm. The GoS were adamant on where they wanted to spend donor funding but the donor disagreed. The GoS representative replied: "are you telling us that we don't know what we want? Donors go in with their agenda, especially new diplomats, but after one meeting with the Government of Samoa they soon realise that as a donor you need to be flexible with Samoa" (D3). 
D3 was part of a donor/ GoS meeting where a donor adviser provided some strong feedback to the GoS. The GoS representative was not impressed with the donor adviser's feedback and replied: "the days of colonisation in Samoa have long gone, the things that you are asking us to do have not worked, the things we are asking you to support us with will work because we know the context. If you bring your funds with conditions, there's the door" (D3). The GoS representative then stood up and walked out. D3 commented that the GoS would rather have no money than accept the money with the tight conditions and restrictions. "It really showed who's the boss!" (D3). "Donors assume they know what's best for us, but Samoa is mature enough to say no that is not going to be good for us and we're not interested in that assistance" (GoS3)

Interestingly as D3 is a locally engaged staff and speaks fluently in both Samoan and English this person is often used by the GoS to get messages across to donors if the GoS feels the donor is not listening or is asking too many questions. D3 was sitting in a meeting where a particular donor kept asking questions of the GoS. The GoS representative leaned over to their team and asked how much the donor who was asking all the questions was giving to the project? The reply was only $10 \%$ of the budget. The GoS representative then said in Samoan to all the locally engaged donor staff, "tell the donor who is asking all the questions that they are only contributing $10 \%$ of the budget to the programme so they really should only be asking $10 \%$ of the questions" (D3).

\section{Donors trust GoS development processes and procedures}

'You've got to be constantly reading to keep up. With donors if you can demonstrate you can account for money then you get a bigger cut of the pie" (GoS6). As reflected earlier in this chapter the GoS are very assertive when working alongside donors. "We can make these demands to donors because if you look at our age and experience we walk the talk" (GoS3). I found donors to be quite flexible in their dealings with the GoS. Donors were complimentary of the GoS. "What is common place in the Pacific isn't necessarily common place here in Samoa" (D1).

D1 was happy with the quarterly meetings hosted by the GoS that link traditional and non-traditional donors together and provide opportunities for all donors to ask 
questions regarding the delivery of aid to Samoa. The pooling of money together for a common goal places the GoS at the forefront of its development. The GoS does not feel threatened by donors and happily directs them (D1). "Samoa [GoS] don't mince their words and they won't hesitate to tell people both local and donors if they weren't doing what Samoa [GoS] asked for" (GoS2).

There are some donors who are able to make decisions on the spot for their respective governments. However others need to check back with their head offices before decisions can be made. The GoS, although preferring decisions to be made by posts in-country, show flexibility to the different donor processes (GoS3).

Donors show flexibility when dealing with the GoS because, "Samoa [GoS] has good systems in place to manage donor funds" (D3). These good systems assist the GoS to secure money from donors and therefore releases the GoS from having real local ownership (D3): "The more I work in this role the more I know it's about a common sense approach, listening carefully and making sure we do what Samoa want".

When GoS2 worked as a locally engaged donor staff, "it was the objective of the donor to always push for the good of Samoa". Another reason donors felt confident was due to the GoS staff. "The new CEO for Education worked in education for a long time and joined the Ministry knowing and understanding the sector as well as the donor requirements. Having the right people with the right skills and experience does put confidence in the donors that aid money is in good hands" (GoS2).

The GoS is the implementing agency and donors play an advisory role (GoS2). AusAID is perhaps the most trusting of donors and have already provided budget support to the GoS. GoS2 now works for a state owned enterprise which receives a substantial amount of donor funding. The donor is not interested in quarterly reports and is happy to receive one report at the end of the project on how the money was spent. This is not an easy decision for donors to make but I got the sense from the people that I interviewed, both donors and GoS, that donors are pleased with the way the GoS carry out its development work. 
If donors feel confident to use the financial systems of a recipient government it is a good indicator of the recipient country having good financial systems in place. "Samoa has a reasonably robust public finance system, reasonably accountable and they don't overspend. This means donors have reasonable confidence to hand over money" (D1). The GoS has been working hard on the development of their financial systems to meet international standards since 2006. Rather than having a raft of different donor financial systems to report on, the GoS would prefer for donors to use the GoS's financial systems. Ultimately the GoS would prefer and are actively encouraging donors to give aid as budget support. "The benefits of sector budget support is that it throws out the window all the complex procedures some donors have in place and we can use our own financial processes" (GoS3). It will take some time before this materialises but already donors are working towards budget support.

The EU is giving the GoS sector budget support based on the outcomes of the Public Expenditure and Financial Accountability (PEFA) review (see chapter four). The donors were happy with the results of PEFA and saw that the GoS were actively implementing feedback from the review and the processes in place worked for the GoS (GoS3). Other benefits for the GoS if they perform well in the use of donor funds from the EU and there is surplus money left over from countries within the African Caribbean Pacific programme - it will be allocated additional money for meeting development targets. "Samoa receives $\$ 5 \mathrm{~m}$ from AusAID and $\$ 1 \mathrm{ml}$ from New Zealand for general budget support and we can spend this on anything we want. This contribution is on top of what these donors give us in the bilateral programme" (GoS3).

The GoS is confident in its development processes and procedures. "We are good at accounting for how we spend donor funds. We spend money on what we say we are spending it on, donors are therefore happy with financial framework" (GoS6); "We perform well and donors see value for money, they see money is well spent" (GoS4); "We're set up with processes of what we want. We have a good reputation in managing funds, donors are willing to let us take lead roles. Donors will only release money if there are robust systems and ours meets International best practice." (GoS5) 


\section{Regionally GoS is strong in comparison to its peers}

The GoS is held up as an example for other Pacific Island aid recipients to follow. Some countries within the region take this well while others find the GoS to be arrogant. 11 has attended regional meetings on behalf of a Pacific country for some time. At regional meetings donors can take the lead in discussions, particularly because they have the resources to provide a team of advisers to support their representatives. 11 has always been impressed and at the same time amused by the GoS who is always vocal during discussions and behaves like the strong donors. "Like the rest of the Pacific Island countries the GoS do not have a raft of advisers supporting them but they have experience and really know their stuff" (I1). I1 also laughs and recalls other Pacific Island countries that often roll their eyes when Samoa is being held up as a shining light of the Pacific "I think people just get sick of hearing how good Samoa is when others want to get ahead too" (I1).

Because the GoS is strong when working alongside donors they are not shy to give hard-to-hear advice to their Pacific peers. GoS3 is often asked my counterparts in neighbouring Pacific countries "how do you stand up to donors? My reply is if we can do it, you can do it. It's your aid programme not the donors" (GoS3).

Pacific Island countries also receive support from regional organisations. GoS6 was one of a number of country officials in the region that received a foreign adviser to assist with a particular piece of work. The position for the GoS was filled by a young foreign graduate who lacked experience so GoS6 used the graduate as an extra pair of hands in the office. The adviser has a travel budget that allows for travel to relevant meetings. GoS6 decides when and where the adviser travels and a GoS will always lead the delegation. Other recipients within the region have used their adviser position to speak on their behalf and the adviser often leads the delegation. When GoS6 was asked by other representatives within the region "where is your adviser?" GoS6 replied "why would a foreigner speak on behalf of Samoa? We will speak for ourselves" (GoS6). GoS3 reinforces these sentiments by saying "don't place the Pacific under one size fits all". At regional meetings GoS officials are known for their upfront honesty and not hiding their feelings "I don't talk a lot but choose the time and my words very carefully to leave an impact on discussions. I tell Pacific countries 
if you're not good at securing money you'll be left behind, move with the times" (GoS3).

GoS5 formally worked for a major donor in Samoa and attended training for all locally engaged staff members within the Pacific. One individual from a Pacific country shared how a consultant was tasked with writing a development plan for their government. The consultant spent two weeks in country, wrote the development plan and then sent the plan back for approval. As the government were approving the plan there was reference to Kenya throughout the whole document. As this representative was sharing his story GoS5 asked "were you not keeping the consultant accountable every step of the way, and were you involved in the design process of the document?". The individual replied, "no". GoS5 was so irate with the response that they said: "well the problem doesn't lie with the consultant, the problem lies with your people. If some outsider comes in and does high level work for your country's future direction and you aren't proactive in getting involved well quite frankly you deserve the development plan for Kenya!" Whether the example of this country getting a copy and paste of the development plan for Kenya is true or not I have shared this anecdote to show just how strong the GoS is regionally and how they are not afraid to speak whether people want to hear it or not.

\section{Conclusion}

It is easy to see from the ten markers of development sovereignty highlighted in this chapter that the GoS exercises development sovereignty when dealing with donors. All sectors in Samoa from public, private and CSOs provided good examples of how recipients of aid can be sovereign in its delivery. Donors also supported this view that are reflected in their responses.

The reason why the GoS can be sovereign in the delivery of its aid programme comes down to its experience as a nation when it is dealing with donors and aid. Public servants are well educated and prepared individuals who can confidently compete on the international stage alongside big and influential donors. Because of their strength and experience the GoS is not afraid to assert is authority and tell donors if they feel its development strategy is being compromised, despite possibly 
losing donor funding. The donors are given confidence that their aid funds are being well spent due to the fact that the GoS has relatively good financial systems in place to account for the use of donor funds. The GoS know the donor processes so well that it has stuck to financial accounting systems for respective donors and now donors like AusAID have done away with their own financial reporting systems and adopted that of the GoS. The GoS is a mature aid recipient and this chapter reflects a lot of markers of development sovereignty that the GoS can be proud of. 


\section{CHAPTER EIGHT: Conclusion}

\section{Summary}

The aim of this thesis is to examine how the Government of Samoa asserts its development policy sovereignty when working with donors. The aim suggests at the outset that the GoS already has development policy sovereignty when working alongside donors which was identified early on in this research after a review of the GoS development policy. However, policy and practice can reflect very different outcomes which set this thesis on its path to discover how development policy sovereignty is being asserted by the GoS.

Over the past 50 years donors have trialled a number of different aid modalities such as project funding, Structural Adjustment Programmes, Poverty Reduction Strategy Papers, Sector Wide Approaches and budget support to deliver aid to recipient countries. By and large aid has increased over time particularly in the last decade but there has been a shift in the delivery of aid that encourages donors to work more effectively under the principles signed in the Paris Declaration for Aid Effectiveness 2005. It is these principles in the Paris Declaration that has given Samoa the license to have sovereignty when working alongside donors. Sovereignty therefore, in the context of this research, not only refers to the conventional state sovereignty but more to how the theory on how aid is exercised by both the GoS and donors on a day-to-day basis.

The GoS's assertiveness with donors is also reflected in their colonial history. Samoa was fortunate not to have a very long colonial history. Prior to Tongan rule each village was governed by their district political system with no national political body which made it easy for foreign poweres to take control of Samoa. When the German and New Zealand governments controlled Samoa between 1900 - 1962 the four tama'aiga (paramount) titles (Tuia'ana, Tu'iatua, Gatoaitele, and Tamasoali'l referred to as Tafa'ifa) were established and was crutial in leading Samoa to Independence. The Tafa'ifa became the national political body that could stand up for the district levels and back the resistance group Mau a Pule. Although there was a strong push by foreign powers to establish colonial rule, Samoa pushed back through 
the Mau and proved to foreign powers that they were not going to stand for colonisation. In chapter three we can see how Samoa has taken Western concepts such as Christianity and blended this into fa'aSamoa creating a unique set of denominations.

Preparing for independence in 1962, Samoa worked closely with New Zealand to ensure that fa'aSamoa was an integral part of the new government. The Tafa'ifa all held key positions in the first government and Samoa's political system merged a Western model with the village polical system. In 1990 the Village Fono Act recognised the leadership of matai (chiefs) at the local level. Whilst there are traces of colonisation in Samoa today, their Fa'aSamoa is still strong reflecting a country that were vocal in the development of their independence. Equally the signing of the Treaty of Friendship in 1962 between Samoa and New Zealand has provided financial benefits for Samoa as well as opportunities for Samoans to live in New Zealand as citizens.

As this study is about development policy sovereignty for the GoS, finding a suitable methodology was crucial. Ensuring that Samoa were at the centre of this research aligned with the owneship principle of the Paris Declaration. The voice of Samoa needed to be heard throughout this study and being Samoan, understanding the culture and being fluent in both Samoan and English (the two official languages of Samoa) I was influenced by worldviews and ontology which is outlined in chapter four. The methodology for this research is qualitative and the methods used were interviews/ talanoa as well as a review of the GoS documentation and my own personal observations from working in Samoa over the past 10 years.

To appreciate the findings of my interviews it is important to provide a backdrop of the current aid programme for the GoS. The governing party HRPP has had an uninteruppted reign since 1982. There have been government officials who have been working in the aid sector for the same length of time so there is good understanding of donor practices and relevant experience to be assertive. Chapter five also looks at donors and how aid impacts on the economy of Samoa. 
Reviewing the development policy of Samoa is essential to identify whether the new global aid agenda is evident in the GoS development policy. Chapter six examines development policy on a global, regional and local level. There is strong evidence to show that development policy at a global level is reflected in the GoS development policy at a local level as shown by the Strategy for the Development of Samoa 2012 - 2016 and the Development Coorperation Policy. The GoS also engaged in different aid modalities such as Structural Adjustment Programmes and Sector Wide Approaches. The more recent Paris Declaration is commonly referred to by all sectors in Samoa and the GoS are keen to ensure that they are up to date with the global aid agenda. However at a regional level it is clear that the GoS does not really gain a lot in terms of development policy. Samoa is seen as a type of 'big brother' within the region and GoS officials are often used to review their peers under the Cairns Compact.

How then does the GoS assert their development sovereignty? There were a number of examples how the GoS assert their development policy sovereignty when working alongside donors. The GoS officials are an experienced, educated group who are well prepared and informed and have not only aligned their development policy to the global aid agenda as already identified but they also put the theory into practice. The GoS officials have gained credibility with donors and subsequently donors are able to be more flexible with conditions due to long lasting relationships with donors and the GoS's proven ability to account for donor funding.

In order for donors to release funds to the GoS there needs to have confidence in the GoS financial systems. For example Australia now only uses GoS financial reporting systems which makes it easier for the GoS rather than using a myriad of different financial systems. Donors are coordinated with their approaches being careful not to double up on administrative tasks.

The GoS also has a good understanding of what each donor can provide funding for and they use this knowledge to their advantage. This is reflected in the SDS 2012 2016 that provides option areas for donors to fund. As a result of these markers of development sovereignty the GoS are therefore able to talk candidly to donors if it disagrees with donor comments as is reflected in the examples in chapter seven. 


\section{Learnings}

The GoS has recognised that it is the leader of its development, it is sovereign. Aid does make a huge contribution to the GoS but just how that contribution is delivered is within a Samoa context that works for the people of Samoa. I have identified seven major learnings from this research to provide a summary of my findings:

\section{1) The GoS is sovereign in the delivery of its aid programme?}

As mentioned throughout this study, identified at the outset of this research is the fact that the GoS is sovereign in the delivery of its aid progamme. I arrived at this conclusion after doing a review of the GoS development policy as well as from my own experience of working in Samoa since 2002. This was further reinforced following my interviews with comments such as, "the days of colonisation in Samoa have long gone. The things that you are asking us to do have not worked, the things we are asking you to support us with will work because we know the context. If you bring your funds with conditions, there's the door" (D3). This comment reflects a mature aid recipient who is willing to jeopardise funding if the GoS feels donors are compromising on what the GoS is asking for. This was further reinforced by GoS3 who said, "donors assume they know what's best for us, but Samoa is mature enough to say no that is not going to be good for us and we're not interested in that assistance".

\section{2) Sovereignty is not new to Samoa.}

From chapter three we can see that the concept of 'sovereignty' is not new to Samoa. Foreign rulers tried to control Samoa and implement Western influences that did not work for the local people. Subsequently the resistance Mau movement emerged and, despite strong efforts from the German and New Zealand administration to disempower the movement by exiling their leaders, the Mau movement did not give up. Samoa therefore came out of a period of colonisation relatively unscathed and with their culture still in tact. Fa'aSamoa was included in the formation of a new government at Independence and the matai system was also recognised at the domestic level as a governance structure. 


\section{3) Samoa places major emphasis on the global aid agenda and lesser focus on the regional aid agenda.}

The development policy in Samoa reflects the outcomes of the high level aid effectiveness forums. The GoS is up to date with the global aid agenda and have conducted reviews of the MDGs as well as an evaluation of the Paris Declaration 2005 and Accra Agenda for Action 2008 in the context of Samoa. The GoS officials are proactive in staying abreast of what is happening on an international level with aid and adjusting their aid programme locally accordingly. All sectors that I interviewed have a good understanding and appreciation of the principles of the Paris Declaration which gives them confidence when working alongside donors.

On a regional level however, the GoS seems to engage for the benefit of its peers rather than the GoS actually gaining any real benefits. Some of the comments made by the GoS representatives that I interviewed reflect that the GoS seems more advanced than their regional peers. Additionally the GoS is often part of peer review teams under the Cairns Compact indicating that the GoS has an idea of what is required to improve aid programmes for their peers.

\section{4) Samoa has made aid work for them.}

Looking at the the GoS development policy the Samoa Development Strategy (SDS) 2012 - 2016 shows that the GoS has taken into consideration the different types of assistance each donor working in Samoa has to offer. The SDS was written by Samoa for Samoa with wide consultation with all sectors within Samoa. The beauty of the SDS is that it caters for all donor budgets and their respective focus areas. The SDS is a clever tool to utilise donor funding while placing Samoa at the centre of its own development.

\section{5) GoS officials are a clear strength.}

The GoS offcials that I interviewed are an educated group of people. I was impressed with their strong work ethic and the way that they placed a huge importance of staying in tune with development policy internationally as reflected in their development policy nationally. There is a pride and patriotism in Samoa that runs across all sectors and this pride is carried even further when working alongside donors. Through my line of work at VSA in there have been times recipient countries 
who have had a negative dealings with volunteers are reluctant to voice their feeligns because they fear by telling the truth it may affect receiving ongoing assistance. In the case of the Samoans I interviewed there is no fear in telling donors how they really feel even to the point of losing the funding. This is articulated beautifully by GoS3. "...We can make these demands to donors because if you look at our age and experience, we walk the talk'.

The GoS have identified that to ensure the institutional knowledge remains in the public sector there has been an increase in pay that exceeds what the private sector are offering. GoS officials can therefore remain in roles that are challenging but also recognises where they are remunerated for their skills. By GoS officials staying in their roles longer they are able to lead relationships with donors who are only on a maximum of three year postings, lead the donor - recipient dialogue and the donor aligns accordingly.

\section{6) GoS processes are relatively robust and usable by donors.}

The outcomes of the Public Expenditure Review recognises a relatively robust financial system that donors can trust and adds to the development sovereignty of the GoS. The Australian Government use only the GoS financial systems and saves the Ministy of Finance having to account for the use of donor funds using a myriad of different systems. This is less of strain on human resources. If all donors recognised the GoS financial systems as robust it would make accounting for funding easier for GoS public servants.

\section{Final comments}

Using these learnings I have been able to show how the GoS assert their development policy sovereignty when working alongside donors. Using Hauofa's (1993) view, although Samoa is small comparitively to its large donors, I argue that Samoa 'punches above its weight'. The view of a helpless, defenceless, dependent country soon diminishes after speaking to all sectors of Samoan society when is is clear the local officials controlling aid in Samoa are educated, strong and confident individuals who have cleverly used aid to their country's advantage. 
Samoa is a good example for other recipient countries to follow. I would like to end with a comment made by GoS3 who made this statement to recipient countries within the region as I believe this best describes the outcome of this study: "they are not donor programmes they are your programmes. You're not beholden to the donor demands" (GoS3). 


\section{Reference list}

Addison, T., Mavrotas, G., \& McGilivray, M. (2005). Development assistance and development finance: Evidence and global policy agendas. Journal of International Development 17, 819-836.

Agnew, J., \& Entrikin, J. N. (2004). The Marshall Plan Today Model and Metaphore. Great Britain: Routledge.

Ana, G. R., \& Shendell, D. G. (2010). School environmental health programs and the challenges of achieving the millennium development goals. Journal of School Health , 55-56.

Anae, M. (1998). Fofoa i Vao Ese The Identity Journals of New Zealand Born Samoans unpublished thesis. Auckland: University of Auckland.

Anae, M., Mila-Schaaf, K., Coxon, E., Mara, D., \& Sanga, K. (2010). Teu Le Va. Auckland: Ministry of Education New Zealand.

Batibasaga, K., Overton, J., \& Horseley, P. (1999). Vanua: Land, people and culture in Fiji. In J. Overton, \& R. Scheyvens, Strategies for Sustainable Development: Experiences from the Pacific (pp. 100-108). Sydney: University of New South Wales Press.

Beneria, L. (1999). Structural adjustment policies. In J. Peterson, \& M. Lewis, The Elgar Companion to Feminist Economics (pp. 1-9). Northhampton: Edward Elgar Publishing Limited.

Bermeo, S. B. (2009). The Curse of Aid? Re-Examining the Impact of Aid on Regime Change. PLAID Data Vetting Workshop (pp. 1-22). Washington DC: Sanford School of Public Policy Duke University.

Bertram, G. (1999). Sustainable development in Pacific micro-economies. World Development, 14 (7), 105-138.

Bertram, I. G., \& Watters, R. F. (1984). New Zealand and its Small Island Neighbours: A Review of New Zealand Policy Toward the Cook Islands, Niue, Tokelau, Kiribati and Tuvalu. Wellington: Institute of Policy Studies, Victoria University.

Bertram, I. G., \& Watters, R. F. (1985). The MIRAB Economy in South Pacific Microstates. Pacific Viewpoint 26 (3) , 497-519.

Bird, N., \& Glennie, J. (2011). Going Beyond Aid Effectiveness To Guide The Delivery Of Climate Finance. London: ODI.

Bodley, J. (1999). Victims of Progress 4th ed. London: Mayfield Publishing Company.

Boone, P. (1996). Politics and the effectiveness of foreign aid. European Economic Review, $40,289-329$.

Booth, D. (2011). Aid Effectiveness: Bringing Country Ownership (and politics) Back In. London: ODI. 
Brownlie, A. (2008). Aid and Development. China: Bojang Evans Brothers.

Buiter, H. (2007). Country ownership: a term whose time has gone. Development in Practice, vol 17, No 4-5, 647-652.

Buss, T. F. (2007). Foreign Aid and Foreign Policy: Lessons for the Next Half-Century. New York: M.E Sharpe.

Busse, M., Hoekstra, R., \& Koniger, J. (2010, September). The Impact of Aid for Trade Facilitation on the Costs of Trading. Retrieved December 3, 2011, from Social Science Research Network: SSRN: http://ssrn.com/abstract=1635884

Cassen, R. (1994). Does Aid Work? . USA: Oxford University Press.

Chambers, R. (1983). Rural Development: Putting the Last First. London: Longman.

Claessen, H. M., \& van de Velde, P. (1991). Early State Economics Political and Legal Anthrology Series, Volume 8. New Brunswisk, New Jersey: Transaction Publishers.

Clemens, M. A., Kenny, C. J., \& Moss, T. J. (2007). The Trouble with the MDGs: Confronting Expectations of Aid and Development Success. World Development Vol 35, 735-751.

Community. Scoop. (2012). Retrieved October 27, 2012, from Community Scoop: http://community.scoop.co.nz/2012/08/honorary-doctorate-for-samoan-prime-minister/

Coxen, E., \& Tolley, H. (2005). Aid to Pacific Education: An Overview. In K. Sanga, C. Chu, \& L. Crowl, Re-Thinking Aid Relationships in Pacific Education (pp. 28-82). Suva: University of the South Pacific.

Crew, E., \& Harrison, E. (1998). Whose Development: an Ethnography of aid. London: Zed Books.

Davidson, J. (1967). Samoa mo Samoa; The Emergence of the Independent State of Western Samoa. Melbourne: Oxford University Press.

Deruyttere, A. (1997). Indigenous Peoples and Sustainable Development: The Role of the Inter-American Development Bank. http://www.iadb.org/sds/doc/IND-97101E.PDF. Retrieved from http://www.iadb.org/sds/doc/IND-97101E.PDF

Easterly, W. (2001). The Elusive Quest for Growth. Cambridge: The MIT Press.

Escobar, A. (2000). Beyond the Search for a Paradigm? Post Development and Beyond. Development, 43 (4) , 11-14.

Esteva, G., \& Prakash, M. S. (1998). Beyond development what? The Development Dictionary , 280-296.

Eyben, R. (2007). Harmonisation: How is the orchestra conducted? Development in Practice $17,4-5,640-646$.

Field, M. J. (1984). Samoa's Struggle Against New Zealand Oppression. Wellington, New Zealand: A.H \& A.W Reed. 
Field, M. (1984). Mau: Samoa's Struggle Against New Zealand Oppression. Wellington: Reed.

Fisher, H. (2011, April 6). Organisation for Economic Co-operation and Development (OECD). Retrieved December 7, 2011, from Organisation for Economic Co-operation and Development (OECD): http://www.oecd.org/document/29/0,3746,en_21571361_44315115_47519517_1_1_1_1,00. $\mathrm{html}$

Folke, S. (2004). Review [untitled]. Development in Practice Vol.14 No4.

Gajida, A., LLiyasu, Z., \& Kemevou-Asima, D. (2010). Knowledge and attitude of health care professionals towards the health related Millennuim Development Goals (MDGs) in a Tertiary Health Institution in Kano State, Nigeria. Nigerian Journal of Clinical Medicine, Vol 4, No 2 .

Gegeo, D. (1998). Indigenous knowledge and empowerment: Rural development examined from within. The Contemporary Pacific, Volume 10, Number 2 , 287-316.

Gegeo, D., \& Watson-Gegeo, K. (2002). 'Whose knowledge? Epistomological colllisions in Solomon Islands community development". The Contemporary Pacific, Volume 14, Number $2,377-409$.

Gibson, J., \& Graham, K. (2005). Surplus possibilities: Postdevelopment and community economics. Singapore Journal of Tropical Geography, 26 (1) , 4-26.

Gilson, R. (1970). Samoa 1830 to 1900: The Politics of Multi-Cultural Community. Melbourne: Oxford University Press.

Gimbel, J. (1976). The Origins of the Marshall Plan. Stanford, California: Stanford University Press.

Glennie, J. (2011). Who should lead the aid effectiveness debate in the future? Speech at the first ODI Busan Debate House of Commons, London, UK. London: ODI.

Global Education. (2011, December 01). Retrieved December 01, 2011, from http://www.globaleducation.edna.edu.au/globaled/page1.html:

http://www.globaleducation.com

Goldthorpe, J. E. (1975). The Sociology of the Third World Disparity and Involvement. Cambridge: Cambridge University Press.

Gould, J. (2005). The New Conditionality: The Politics of Poverty Reduction Strategies. New York: Zed Books Ltd.

Government of Samoa. (2010a). Development Cooperation Policy Partners in Development: Promoting Aid Effectiveness. Apia, Samoa.

Government of Samoa. (2010b). Evaluation of the Paris Declaration on Aid Effectiveness and the Accra Agenda for Action. Apia: Government of Samoa. 
Government of Samoa. (2010c). Millennium Development Goals: Second Progress Report. Prepared by the National Task Force with support of the UN System. Apia: Government of Samoa.

Government of Samoa. (2010d). Tsunami. Apia: Government of Samoa.

Government of Samoa. (2011a). Public Finance Management Reform Plan: Phase II Project Report December 2010 - November 2011. Apia: Government of Samoa

Government of Samoa. (2011b). Ministry of Foreign Affairs and Trade. Retrieved October 23, 2012, from http://www.mfat.gov.ws/EMBASSIES.html

Government of Samoa. (2012a). http://www.govt.ws/. Retrieved October 2, 2012, from Government of Samoa official website: http://www.govt.ws/

Government of Samoa. (2012b). Strategy for the development of Samoa (SDS)2012 - 2016. Apia: Government of Samoa.

Guillaumont, P. (2009). Aid effectiveness for poverty reduction: macroeconomic overview and emerging issues A report for the Department of Social Affairs (DESA), Division of Social Development, United Nations. New York: United Nations.

Gulrajani, N. (2011). Transcending the Great Foreign Aid Debate: managerialism, radicalism and the search for aid effectiveness. Third World Quarterly, Vol. 32, No. 2 , 199 - 216.

Hansen, H., \& Tarp, F. (2000). Policy Arena Aid Effectiveness Disputed. Journal of International Development, 12 , 375-398.

Hau'ofa, E. (1993). Our Sea of Islands. In E. Waddle, V. Naidu, \& E. Hau'ofa, A New Oceania, Rediscovering Our Sea of Islands (pp. 2-17). Suva, Fiji: School of Social and Economic Development The University of the South Pacific.

Haverkort, B., van't Hooft, K., \& Hiemstra, W. (2003). Ancient roots, new shoots: Endogenous Development Practice. London: Zed Books.

Hayter, T. (1971). Aid as Imperialism. Middlesex: Penguin Books Ltd.

Hempenstall, P. J. (1978). Pacific Islanders under German Rule: a study in the meaning of colonial resistance. Canberra, Australia: Australia National University Press.

Hjertholm, P., \& White, H. (2000). Foreign aid in historical perspective Backgrounds and trends. In F. Tarp, Foreign Aid and Development lessons learnt and directions for the future (pp. 80-102). London: Routledge.

Hogan, M. (2002). The Marshall Plan. New York: Cambridge University Press.

Huffer, E., \& So'o, A. (2003). Consensus versus dissent: Democracy, pluralism and governance in Samoa. Asia Pacific Viewpoint, Vol 44, No , 281 - 304.

Hunter, S. (1984). OPEC and the Third World the politics of aid. Sydney: Croom Helm Ltd.

Hutchings, J. (2010, March 23). Lecture. Wellington, New Zealand: Victoria University. 
Hyden, G. (2008). After the Paris Declaration: Taking on the Issues of Power. Development Policy Review, vol 26, no 3 , 259-274.

lati, I. (2005). Civil Society and political accountability in Samoa. In J. Henderson, Securing a Peaceful Pacific. Christchurch: University of Canterbury.

lati, I. (2000). The good governance agenda for civil society: implications for the fa'a Samoa. In E. Huffer, \& A. So'o, Governance in Samoa: Pulega i Samoa (pp. 67-77). Canberra: Asia Pacific Press.

loane, L. (1992). Review of Mau: Samoa's Struggle for Freedom, by Michael J. Field. Special Issue, Th Contemporary Pacific 4 (2): , 449-452.

Ishkanian, A. (2006). From Inclusion to Exclusion: Armenian NGOs Participation in the PRSP. Journal of International Development, vol 18 , 729-740.

Kailahi, S. (2007). Pasifika Women: Our Stories in New Zealand. Auckland: Raupo Publishing (NZ) Ltd.

Keesing , F. M. (1934). Modern Samoa: Its Government and Changing Life. London: Allen and unwin.

Keesing, F., \& Keesing, M. (1956). Communication in Samoa. Great Britain: Geoffrey Cumberlege Oxform University Press.

Kerslake, M. T. (n.d.).

Kerslake, M. T. (2007). Maloafua Structural Adjustment Programmes: The case of Samoa. Unpublished thesis submitted to Massey University in the fulfillment of the requirements for the degree of Doctor of Philosophy. Auckland: Massey University.

Kharas, H. (2008, August 27). Brookings. Retrieved September 29, 2012, from Brookings Web site: http://www.brookings.edu/research/opinions/2008/08/27-aid-accra-kharas

Killick, T. (2005). THe Politics of Ghana's budgetary system. CDD/ODI Policy Brief No 2 , 2 5.

Komives, K., \& Dijkstra, G. (2011). The Legacy of the Poverty Reduction Strategy Processes in Latin America: . European Journal of Development Research Vol. 23, 2 , 181 - 190.

Kramer, A. (1994a). The Samoa Islands Volume I. Translated by T.Verhaaren. Auckland: Polynesia Press.

Kramer, A. (1994b). The Samoa Islands Volume II. Translated by T.Verhaaren. Auckland: Polynesia Press.

Lancaster, C. (2007). Foreign Aid Diplomacy, Developemnt, Domestic Politics. Chicago: The University of Chicago Press.

Lesage, D., Van de Graaf, T., \& Westphal, K. (2009). The G8's Role in Global Energy Governance Since the 2005 Gleneagles Summit. Global Governance. A Review of Multilateralism and International Organizations: April - June 2009, Vol 15, No 2 , 259-277. 
Levine, H. (2003). Some reflections on Samoan cultural practice and group identity in contemporary Wellington, New Zealand. Journal of Intercultural Studies, Vol.24, No. 2 , 175186.

Lichtman, M. (2006). Qualitative Research In Education: A User's Guide. Thousand Oaks, CA: Sage.

Lilomaiava-Doktor, S. (2004). Fa'aSamoa and population movement from the inside out: the case of Salelologa, Savai'i (unpublished doctoral theses). University of Hawai'i.

Lincoln, Y. S., \& Guba, E. G. (1985). Naturalistic Inquiry. Beverly Hills, CA: Sage Publications.

Lister, S., \& Nyamugasira, W. (2003). Design contradictions in the "new architecture of aid"? Reflections from Uganda on the roles of Civil Society Organisations. Development Policy Review, Vol 23, no 1, 93-106.

Liuvaie, S. (2009). Investing Impediments to Aid Effectiveness: New Zealand's Development Assistance to Niue. In R. Gounder, Pacific Development Perspectives: Meeting Our Diverse Goals (pp. 142-190). Palmerston North: Massey University.

Lockwood, B. (1971). Samoan Village Economy. Melbourne: Oxford University Press.

Macpherson, C. (1997). The persistence of chiefly authority in Western samoa. In G. White, \& L. Lindstrom, Chiefs Today: Traditional Pacific Leadership and the Postcolonial State (pp. 19 - 48). Stanford: Stanford University Press.

Macpherson, C. (2008). Will the 'Real' Samoans Please Stand Up? Issues in Diasporic Samoan Identity. New Zealand Geographer, Volume 55, Issue 2 , 55-59.

Macpherson, C., \& Macpherson, L. (2000). Where theory meets practice: the limits of the good governance program. In E. Huffer, \& A. So'o, Governance in Samoa: Pulega i Samoa (pp. 17-39). Canberra: Asia Pacific Press.

Mageo, J. M. (1991). Samoan Moral Discourse and the Loto. American Anthropologist, Volume 93, Issue 2 , 405-420.

Maiava, S. (2002). Devnet Conference 2002. Retrieved February 27, 2010, from Devnet Conference 2002: www.devnet.org.nz/conf2002/papers/Maiava_Susan.pdf.Auckland

Marcus, R., Wilkinson, J., \& Marshall, J. (2002). Poverty Reduction Strategy Papers (PRSPs) - Fulfilling their potential for children in poverty? Journal of International Development 14, 1117 - 1128.

Mathez-Stiefel, S.-L., Sebastien, B., \& Stephan, R. (2006). Promoting the diversity of worldviews: An ontological approach to bio-cultural diversity. Switzerland: Centre for Development and Environment, Institue of Geography, University of Berne.

McCann, G., \& McCloskey, S. (2003). From The Local To The Global. London: Pluto Press. 
McGillivray, M., Feeny, S., Hermes, N., \& Lensink, R. (2006). Policy arena controversies over the impact of development aid: It works; it doesn't; it can, but that depends. Journal of International Development, 18, 1031-1050.

McMichael, P. (2004). Development and Social Change a global perspective. California: Pine Forge Press.

Meleisea, L. D. (2012). Introduction. In L. M. Meleisea, \& P. S. Meleisea, Samoa's journey 1962-2012 (pp. 13-17). Wellington: Printshop.

Meleisea, M. (2005). Governance, development and leadership in Polynesia: a microstudy from Samoa. In A. Hooper, Culture and Sustainable Development in the Pacific (pp. 76-87). Canberra: The Australian National University.

Meleisea, M. (2000). Governance, development and leadership in Plolynesia a micro-study from Samoa. In E. Huffer, \& A. So'o, Governance in Samoa (pp. 189-200). Australia: Southwood Press Pty Limited.

Meleisea, M. (1995). "To whom gods and men crowded"'" chieftainship an hierarchy in ancient Samoa. In J. Huntsman, Tonga and Samoa Images of Gender and Polity (pp. 1936). Chirstchurch: University of Canterbury.

Meleisea, M. (1987a). Lagaga: A Short History of Western Samoa. Suva: University of the South Pacific.

Meleisea, M. (1987b). The making of modern Samoa. Suva: University of the South Pacific.

Meleisea, M. (1980). O Tama Uli: Melanesians in Samoa. Suva: Institute of Pacific Studies, University of the South Pacific.

Mertens, B. (2004). Why Do Aid Agencies Exist? Paris: OECD.

Meti, L. (2002). The Making of the Constitution. Samoa: National University of Samoa, Lepapaigalagala.

Mitlan, D. (2001). Poverty Alleviation or Poverty Reduction: The Contribution of Civil Society. Journal of International Development, Vol 13, 1003-1008.

Moon, P. (2000). Maori sovereignty and concepts of state. He Tuhinga Aronui 4 , 46-59.

Mulitalo-Lauta, P. (2000). Fa'aSamoa and social work: Within the New Zealand context. Palmerston North, NZ: Dunmore Press.

Murithi, T. (2009). Aid colonisation and the promise of African continental integration. In $\mathrm{H}$. Abbas, \& Y. Niyiragira, Aid to Africa: redeemer or coloniser? (pp. 2-3). Cape Town: Pambazuka.

New Zealand, \& Samoa. (2011). Joint Commitment for Development. Apia: New Zealand Aid Programme.

NORAD. (2004b). SWAps and Civil Society: The Roles and Responsibiilties of Civil Society Organisations in Zambia's Basic Education Sub-Sector Investment Programme. Norway: NORAD. 
NORAD. (2003a). SWAps and Civil Society: The Roles of Civil Society Organisations in Sector Programmes Synthesis Report. Norway: NORAD.

ODI. (2005). Scaling up versus absorptive capacity: challenges and opportunities for reaching the MDGs in Africa. London: ODI.

OECD. (2011c, Dec 1). 4th High Level Forum on Aid Effectiveness 19 Nov-1 Dec 2011, Busan, Korea. Retrieved October 28, 2012, from 4th High Level Forum on Aid Effectiveness 19 Nov-1 Dec 2011, Busan, Korea website: http://www.aideffectiveness.org/busanhlf4/

OECD. (2011a). Busan Partnership for Effective Development Co-operation. Busan: OECD.

OECD. (2011b). OECD better policies for better lives. Retrieved October 23, 2012, from http://www.oecd.org/countries/samoa/aidstatisticsrecipientaidataglance.htm

OECD. (2011, December 01). Organisation for Economic Co-operation and Development (OECD). Retrieved December 01, 2011, from http://www.oecd.org/: http://www.oecd.org/html

OECD. (2008). The Accra Agenda for Action. Accra: OCED.

OECD. (2005). The Paris Declaration on Aid Effectiveness. Paris: OECD.

OECD. (2010). The Working Party on Aid Effectiveness - Transforming Global Partnerships for Development. Paris: OECD.

O'Leary, Z. (2004). The Essential Guide to Doing Research. London: Cromwell Press Limited.

Orange, C. (2004). An Illustrated History of the Treaty of Waitangi. Wellington: Bridget Williams Books Ltd.

Otsuka, S. (2005). Talanoa Research: Culturally Appropriate Research Design in Fiji. International Education Conference. Melbourne: Proceedings of the Australian Association for Research in Education.

Overton, J., \& Murray, W. E. (2011). Neoliberalsm is dead, long live neoliberalism? Neostructuralism and the international aid regime of the 2000s. Progress in Development Studies 2011 11:307, 307 - 319.

Overton, J., \& Murray, W. E. (2011). The inverse sovereignty effect: Aid, scale and neostructuralism in Oceania. Asia Pacific Viewpoint, Vol 52, No 3 , 3-12.

Overton, J., Prinsen, G., Murray, W. E., \& Wrighton, N. (2012). Reversing the Tide of Aid: Investigating Development Policy Sovereignty in the Pacific. Journal de la Societre des Oceanistes, $135,26-38$.

Pacific Island Forum Secretariat. (2012). Pacific Island Forum Secretariat. Retrieved October 28, 2012, from http://www.forumsec.org/

Pacific Island Forum Secretariat. (2009). Pacific Islands Forum Secretariat. Retrieved October 28, 2012, from http://www.forumsec.org/pages.cfm/strategic-partnershipscoordination/pacific-principles-on-aid-effectiveness/cairns-compact-1.html 
Pacific Islands Forum Secretariat. (2007a). Pacific Islands Forum Secretariat. Retrieved October 28, 2012, from http://forumsec.org/pages.cfm/about-us/the-pacific-plan/

Pacific Islands Forum Secretariat. (2007b). Pacific Principles for Aid Effectiveness and the Pacific Plan. Retrieved October 28, 2012, from http://www.forumsec.org/pages.cfm/strategicpartnerships-coordination/pacific-principles-on-aid-effectiveness/

Pacific Islands Forum Secretariat. (2011a). Pacific Islands Forum Secretariat. Retrieved October 28, 2012, from http://www.forumsec.org/pages.cfm/strategic-partnershipscoordination/pacific-principles-on-aid-effectiveness/peer-reviews.html

Pacific Islands Forum Secretariat. (2011b). Pacific Islands Forum Secretariat. Retrieved October 28, 2012, from http://www.forumsec.org/pages.cfm/strategic-partnershipscoordination/pacific-principles-on-aid-effectiveness/peer-reviews.html

Pacific Islands Trade and Invest. (2009). Pacific Islands Trade and Invest. Retrieved October 27, 2012, from Pacific Islands Trade and Invest: http://www.pitic.org.au/index.php?option=com_content\&task=view\&id=496\&1temid=185

Peabody, J. W. (1996). Economic Reform and Health Sector Policy: Lessions from Structural Adjustment Programs. Soc. Sci, Med. Vol 43. No. 5 , 823-835.

Pedersen, S. (2012). Samoa on the World Stage: Petitions and Peoples before the Mandates Commission of the League of Nations. The Journal of Imperial and Commonwealth History, Vol 40, No. 2 June , 231-261.

Peet, R. (1991). Post Structuralism, Post Colonialism and Post Developmentalism. In Theories of Development (pp. 123-162). New York and London: Guilford Press.

Pieterse, J. N. (1998). My Paradigm or Yours? Alternative Development, Post Development, Reflexive Development. Development and Change, 29 , 343-373.

Poirine, B. (1995). A Theory of Aid as Trade, with Special Reference to Small Islands. Sydney: Centre for South Pacific Studies, University of New South Wales.

Poirine, B. (1998). Should we hate or love MIRAB? . The Contemporary Pacific 10 (1) , 65105.

Poku, N., \& Whitman, J. (2011). The millennium development goals: Challenges, prospects and opportunities. Third World Quarterly 32(1) , 3-8.

Puna, H. (2012, March 21). The Cook Islands Herald Online Edition . Retrieved October 17, 2012, from http://www.ciherald.co.ck/articles/h631a.htm

Rahmena, M. (1996). The Post Development Reader. New Jersey: Zed Books.

Richards, R. (1994). The Decision to LOTU: New perspectives from whaling records on the sources and spread of Christianity in Samoa. Pacific Studies, Vol 17, No $1,29-43$.

Riddell, R. (2007). Does Foreign aid really work? USA: Oxford University Press. 
Robinson, D., \& Robinson, K. (2005). Pacific Ways o Talk - Hui and Talanoa. Social and Civic Policy Institute Wellington and Council on Public Policy Education. Wellington, Dayton, Ohio.

Rostow, W. W. (1956). TheTake-Off Into Self-Sustained Growth. Economic Journal, 66 , 2548.

Rothschild, E. (May, 1994). Adam Smith and the Invisible Hand. The American Economic Review, Vol. 84, No. 2, Papers and Proceedings of the Hundred and Sixth Annual Meeting of the American Economic Association , 319 - 322.

Rowe, N. A. (1930). Samoa under the Sailing Gods. London \& New York: Putnam.

Sachs, W. (1992). The Development Dictionary. Witwatersand: University Press.

Sanga, K., \& Niroa, J. (2004). First Steps and Small Beginnings in Vanuau Education Research. In K. Sanga, K. Matai, J. Niroa, \& L. Crowl, Re-thinking Vanuatu Education Together (pp. 14-21). Port Vila: University of the South Pacific.

Sapolu, P. F., Suaali'i-Sauni, T. M., Mulitalo, T. L., Fuata'i, F. D., \& Temese, S. V. (2012). Law and Custom. In L. M. Meleisea, \& P. S. Meleisea, Samoa's Journey 1962-2012 (pp. 1843). Wellington: Printshop.

Sauni, S. (2011). Samoan Research Methodology: The Ula - A New Paradigm. Pacific-Asian Education, Vol. 23, No. 2 , 53-64.

Simi, N. (2012, April). Interview with ACEO Aid Coordination and Debt Management Unit of the Government of Samoa. (J. Ulu, Interviewer)

Smith, L. T. (1999). Decolonizing Methodologies: Research and Indigenous Peoples. London: Zed Books.

Smith, S. J. (1924). The Samoa (NZ) Expeditionary Force 1914 - 1915. Wellington: Ferguson \& Osborn Limited.

So'o, A. (2009). Samoa. In S. Levine, Pacific Ways Government and Politics in the Pacific Islands (pp. 202-211). Wellington: Victoria University Press.

So'o, A. (2005). The Establishment and Operation of Samoa's political party system. In R. Roland, L. Hambly, \& M. G. Morgan, Political Parties in the Pacific Islands (p. 189). Canberra: Pandanus Books.

So'o, F. A. (2012). Political Developmen Samoa's Parliamentary Journey from 1962 - 2012. In L. M. Meleisea, \& P. S. Meleisea, Samoa's Journey 1962 - 2012 (pp. 44-76). Wellington: Printshop.

Ssewakiryanga, R. (2011, Novemeber 29 ). From Aid Effectiveness to Development Effectiveness. Devex, p. 1.

Stiglitz, J. E. (2003). Globalisation And Its Discontents. New York: Norton \& Company Inc.

Stiglitz, J. (1998). More Instruments and Broader Goals: Moving Toward the PostWashington Consensus. Helsinki: The World Bank. 
Storey, D., Bulloch, H., \& Overton, J. (2005). The poverty consensus: some limitations of the 'popular agenda'. Progress in Development Studies 5, 1, 30-44.

Stuebel, C., \& Brother, H. (2010). Tala o le Vavau Myths and legends of Samoa. New Zealand: Pasifika Press.

Swain, P. (1999). Civil Society and Development: Pacific Island Case Studies Unpublished doctoral thesis. Wellington: Massey University .

Tait, M. (2008, May 12). The New Zealand Herald. Retrieved December 2012, 19, from http://www.nzherald.co.nz/world/news/article.cfm?c_id=2\&objectid=10509553

Tamasese, K., Peteru, C., Waldegrave, C., \& Bush, A. (2005). Ole Taeao Afua, the new morning: a qualitative investigation into Samoan perspectives on mental health and culturally appropriate services. Australia New Zealand Journal of Psychiatry 39, 300 - 309.

Tariq, B. (1990). Modernization and its Discontents: A Cultural Perspective on the Theories of Development. In S. A. Marglin, \& F. A. Marglin, Dominating Knowledge (pp. 73-101). New York: Oxford University Press.

Tarp, F. (2000). Foreign Aid and Development lessons learnt and directions for the future. London: Routledge.

Taufeulungaki, A., Benson, C., \& F, P. (2002). Tree of Opportunity: Rethinking Pacific Education. Suva: Institute of Education, University of the South Pacific.

Tcherkezoff, S. (2000). The Samoan category matai: A singularity in Polynesia? Historical and etymological comparitive queries. The journal of the Polynesian Society, Volume 109 , 151-190.

Tchuigoua, B. F. (2009). The future of aid in North-South relations. In H. Abbas, \& Y. Niyiragira, Aid to Africa: redeemer or coloniser? Cape Town, Dakar, Nairobi, Oxford: Pambazuka.

Thaman, K. H. (Spring 2003). Decolonizing Pacific Studies: Indigenous perspectives, knowledge, and wisdom in higher education. The Contemporary Pacific, Volume 15, Number 1, , 1-17.

The NZ Ministry of Foreign Affairs and Trade . (2012). Ministry of Foreign Affairs and Trade. Retrieved October 17, 2012, from Ministry of Foreign Affairs and Trade: http://www.aid.govt.nz/where-we-work/pacific/samoa

Thomas, A., Humphreys, D., \& Carr, S. (2001). Influence thrust upon them? NGOs role in public action on the environment in Africa. In A. Thomas, S. Carr, \& D. Humphreys, Environment Policies and NGO Influence: Land degradation and sustainable reserve management in Sub-Saharan Africa (pp. 171 - 192). London: Routledge.

Tuafuti, P. (2011). Multiple challenges in research within the fa'asamoa context. Pacific Asian Education, a journal about education in Pacific circle countries , 33-42.

Turner, G. (1884). Samoa, A Hundred Years Ago and Long Before. Suva: University of the South Paciic (Reprinted 1984). 
Ulu Kini, M. A. (2000). O Lou Ala i malo. Auckland: Mano'o Ulu.

UNDP. (2010). What will it take to achieve the Millenium Development Goals? - An international assessment. New York: UNDP.

United, N. (2000, September 18). United Nations Millennium Declaration. General Assembly . New York, United States of America: United Nations.

Uphoff, N. (2005). Analytical Issues in Measuring Empowerment at the Community and Local Levels. In D. Narayan, Measuring Empowerment Cross-Disciplinary perspectives (pp. 219-246). Washington DC: The World Bank.

Va'a, F. P., Va'a, T. L., Fuata'i, F. L., Chan Mow, M. C., \& Amosa, D. (2012). Aspects of Economic Development. In L. Meleisea, \& P. S. Meleisea, Samoa's Journey 1962-2012 (pp. 97-140). Wellington: Victoria University Press.

Va'a, U. (2000). Local government in Samoa and the search for balance. In E. Huffer, \& A. So'o, Governance in Samoa, Pulega i Samoa (pp. 151-169). Canberra: Asia Pacific Press.

Vaai, L. K. (2012). Religion. In L. Meleisea, \& P. Meleisea, Samoa's Journey 1962-2012 (pp. 77-96). Wellington: Victoria University Press.

Vaioleti, T. (2006). Talanoa Research Methodology: A Developing Position on Pacific Research. Waikato Journal of Education, 12 , 21-35.

Veys, F. W. (2009). Materialising the king: The royal funeral of King Taufa'ahau Tupou IV of Tonga. TAJA The Australian Journal of Anthropology, Volume 20, Issue 1, April 2009 , 131149.

Warah, R. (2011, August 03). Famine in Somalia. NGOWatch / the NGOs \& conservation groups that are bargaining away our future. , p. 1.

Ward, M., Penny, A., \& Read, T. (2004). Education Reform in Uganda 1997 - 2004. London: DFID.

Watters, R. (2008). Journeys Towards Progress, Essays of a Geographer on Development and Change in Oceania. Wellington: Printlink.

WHO. (2001). Inter-Agency Group on Sector-wide Approaches for Health Development Orientation and Training Seminars for Agency Staff: SWAps for Health in a Changing Environment, Kenya, Malawi and Tanzania, Seminar Handboook. Nairobi: WHO.

Wiessner, S. (2007). Indigenous Sovereignty: A Reassessment in Light of the UN Declaration on the Rights of Indigenous Peoples. Vanderbilt Journal of Transnational Law, Vol 41: , $1141-1176$.

Wood, B., Betts, J., Etta, F., Gayfer, F., Kabell, D., Ngawira, N., et al. (2011). The Evaluation of the Paris Declaration, Final Report. Copenhagen: Danish Institute for International Studies.

Wood, R. E. (1986). From the Marshall Plan to debt crisis: foreign aid and development choices in the world economy. Los Angeles: University of California Press. 
World Bank. (1991). Pacific Island Economies: Building A Resilient Economic Base For The Twenty First Century. Washington DC: World Bank.

Wrighton, N. (2010). Participation, Power and Practice in Development: A Case Study of Theretical Doctrines and International Agency Practice in Tuvalu, Unpublished thesis submitted as partial fulfillment of a Master of Development Studies (MDS). Wellington: School of Geography, Environment and Earth Sciences, Victoria University of Wellington.

Yazaki. (2010). Yazaki Australia Arrow Pty. Ltd. Retrieved October 27, 2012, from Yazaki Australia Arrow Pty. Ltd: http://www.australianarrow.com.au/samoa.html

Ye, R. (2010). Torrens and Customary land tenure: a case study of the land titles registration act 2008 of Samoa. Victoria Univeristy of Wellington Law Review .

Younas, J. (2008). Motivation for bilateral aid allocation: Altruism or trade benefits. European Journal of Political Economy volume 24, issue 3, 661-674. 


\title{
APPENDIX 1: CONSENT TO PARTICIPATION IN RESEARCH
}

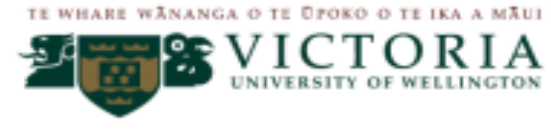

\author{
CONSENT TO PARTICIPATION IN RESEARCH \\ Title of project: Local sovereignty of development policy in Samoa \\ Researcher: $\quad$ Avataeao Junior Ulu, School of Geography, Environment and Earth Sciences, Victoria \\ University of Wellington
}

+1 have read the Participant Information Sheet and understand the purpose of this research project. +1 understand the interview will be manually recorded and any notes from interviews will be destroyed at the end of the research process.

+1 understand I have the right not to answer any question put to me.

+1 understand that all information I provide will be safely stored accessed only by the researcher and research supervisor.

+1 understand I will have an opportunity to see a summary of the research.

+ I understand I may withdraw myself, and amy information I have provided, from this research project without explanation during the interview or at any time before 1 June 2012.

+1 understand the results of this research will be included in a thesis and may be used for publication in academic or professional journals, and for dissemination at academic or professional conferences.

I agree to take part in this research.

Please tick as appropriate:

I would like to receive a summary of the results of this research when it is completed.

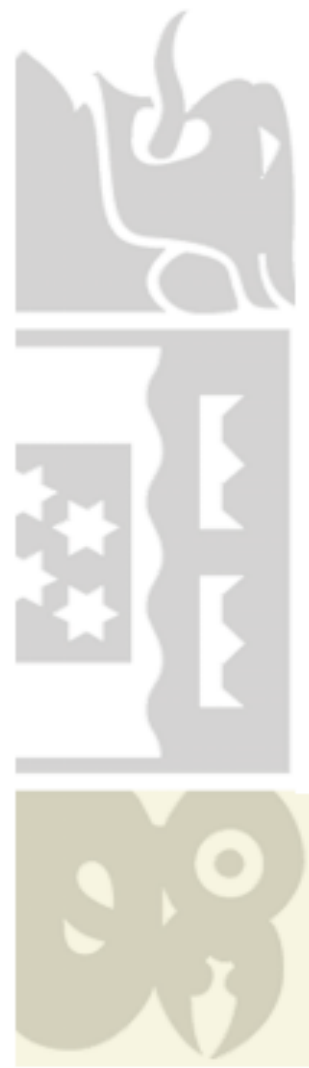

I consent to my name being used when my comments or opinions are used in this research. or

I request that my name be omitted and a pseudonym assigned by the researcher be used if my comments or opinions are included in this research.

I consent to the name of the organisation I work for being used in this research.

or

I request the name of the organisation I work for to be omitted from this research.

Name:

Date:

Organisation:

Email:

Signed: 


\section{APPENDIX 2: INFORMATION ON RESEARCH}

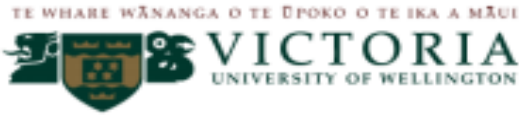

INFORMATION ON RESEARCH

Title of project:

Local sovereignty of development policy in Samoa

Researcher:

Avataeao Junior Ulu: School of Geography, Environment and Earth Sciences, Victoria University of Wellington

\section{Talofa}

I am Junior and I am completing my Masters in Development Studies at Victoria University of Wellington. As part of this degree I am undertaking a research project leading to a thesis. My thesis is to examine to what extent the Government of Samoa (GoS) has development sovereignty when working with donors (i.e. countries giving financial aid and development to other countries, in this research I have chosen to focus on Australia and New Zealand to major donors in Samoa).

As this research requires talking to people in Samoa, the University requires that ethics approval be obtained.

I will be talking to GoS and donor representatives who are senior officials in Samoa. Participants will be interviewed through semi structured interviews and talanoa that will be between one and two hours in length. I will have a basic line of questions to guide my interviews but mostly I would like the interviews to have a feel of a "conversation' between two trusted parties. To not interfere with the flow and atmosphere of the conversations I will not tape any interviews but I will take notes to capture information to assist in answering my research question. Participation is voluntary and participants do not have to answer all questions and can stop interviews at any stage.

Should any participants feel the need to withdraw from the research, they may do so without question at any time during the research.

Responses collected will form the basis of my research project and will be put into a written report by February 2013. As Samoa has a small population it would not be difficult to know who my participants are, therefore I do appreciate that people may want to remain anonymous due to the sensitivities around my research topic and the fear that any findings may impact on future donor funding. My intention is to keep the identity of my participants anonymous and confidential. I propose that all opinions and data will be reported in aggregated form in such a way that individual persons or organisations are not identifiable.

The thesis will be submitted for marking to the School of Geography, Environment and Earth Sciences, and deposited in the University Library. It is intended that one or more articles will be submitted for publication in scholarly journals. Research notes will be destroyed five years after the end of the project.

If you have any questions or would like to receive further information about the project, please contact me, Junior Ulu, at Office phone: 044725759 Mobile: 0273310876 email: uluavat@myvuw.ac.nz or my supervisor, Dr John Overton, at the School of Geography, Environment and Earth Sciences, Victoria University, P O Box 600, Wellington, ph: 044635281.

Yours sincerely.

Avataeao Junior Ulu 


\section{APPENDIX 3: LIST OF PARTICIPANTS}

\begin{tabular}{|l|l|l|l|l|l|}
\hline Government of Samoa & \multicolumn{1}{l}{ Private Sector } & Civil Society Organisation & Donor & Independent \\
\hline GoS1 & PS1 & CSO1 & D1 & I1 \\
\hline GoS2 & PS2 & & D2 & \\
\hline GoS3 & PS3 & & D3 & \\
\hline GoS4 & PS4 & & & \\
\hline GoS5 & & & & \\
\hline GoS6 & & & & \\
\hline GoS7 & & & & \\
\hline GoS8 & & & & \\
\hline
\end{tabular}




\section{APPENDIX 4: Semi structured Interview questions to frame my 'talanoa' interviews.}

1. What is your role and can you explain where your role fits within the donor/ recipient relationship. How long have you been in the position?

2. What does your work involve?

3. What are the key relationships you have in Samoa?

4. Who are the key donors/ GoS officials you work with and what are the key relationships you have with them and other development agencies?

5. Can you explain your level of engagement with these donors/ GoS officials?

6. Does the level of engagement raise any issues at a professional or government management level for you or others? Give me some examples of the issues you are referring to.

7. What are the sort of things that happen in the development relationship that make you feel that you have control over your own country's development agenda?

8. What are the sort of things that happen in the development relationship that make you feel you do not have control over your own country's development agenda? 
9. What opportunities exist for changing sovereignty practice to enhance the level of control you feel at a personal, departmental, structural or whole of government level?

10. What are some markers of development sovereignty, give examples. 


\section{APPENDIX 5: List of Government of Samoa Ministries (Government of Samoa, 2011)}

1) MAF - Ministry of Agriculture and Fisheries / Matagaluega o Faatoaga ma Faigafaiva

2) MCIL - Ministry of Commerce, Industry and Labour / Matagaluega o Pisinisi, Alamanuia ma Leipa

3) MCIT - Ministry of Communication and Information Technology / Matagaluega 0 Fesootaiga, Faamatalaga ma Feso'otaiga Vavave Fa'aneionapo

4) MESC - Ministry of Education, Sports and Culture / Matagaluega o Aoga, Taaloga ma Aganuu

5) MFAT - Ministry of Foreign Affairs and Trade / Matagaluega o le Va i Fafo ma Fefaatauaiga

6) MJCA - Ministry of Justice, and Courts Administration / Matagaluega o Faamasinoga ma le Faafoeina o Tulaga Tau Faamasinoga

7) MNRE - Ministry of Natural Resources and Environment /Matagaluega o Punaoa Faalenatura ma le Siosiomaga

8) MOF - Ministry of Finance / Matagaluega o Tupe

9) $\mathrm{MOH}$ - Ministry of Health / Matagaluega o le Soifua Maloloina

10) MOR - Ministry of Revenue / Matagaluega o Tupe Maua

11) MPMC - Ministry of Prime Minister and Cabinet / Matagaluega a le Palemia ma le Kapeneta

12) MWCSD - Ministry of Women, Community and Social Development / Matagaluega o Tina, ma Aga Fesootai

13) MWTI - Ministry of Works, Transport and Infrastructure /Matagulega o Galuega, Felauaiga ma Atinae Eseese 


\section{APPENDIX 6: 14 Key National Outcomes set out in the Samoa Development Strategy 2012 - 2016.}

\section{Priority Area 1: Economic Sectors}

- Key Outcome 1: Macroeconomic Stability

- Key Outcome 2: Re-invigorate Agriculture

- Key Outcome 3: Revitalized Exports

- Key Outcome 4: Sustainable Tourism

- Key Outcome 5: Enabling Environment for Business Development

Sectors covered are:

$>$ Finance

$>$ Agriculture

$>$ Tourism

$>$ Trade and

$>$ Public Administration

\section{Priority Area 2: Social Policies}

- Key Outcome 6: Healthy Samoa

- Key Outcome 7: Improve Focus on Access to Education, Training and Learning Outcome

- Key Outcome 8: Social Cohesion

Sectors covered are:

$>$ Health

$>$ Education

$>$ Community and

$>$ Law and Justice

\section{Priority Area 3: Infrastructure Sector}

- Key Outcome 9: Sustainable Access to Safe Drinking Water and Basic Sanitation

- Key Outcome 10: Efficient, Safe and Sustainable Transport System and Networks

- Key Outcome 11: Universal Access to Reliable and Affordable ICT Services

- Key Outcome 12: Sustainable Energy Supply

Sectors covered are:

$>$ Water 
Transport

$>$ Communication and

Energy

Priority Area 4: The Environment

- Key Outcome 13: Environment Sustainability

- Key Outcome 14: Climate and Disaster Resilience

Sectors covered are:

$>$ Environmental Sustainability

$>$ Climate and Disaster Resilience

(Government of Samoa, 2012b) 